Florida International University FIU Digital Commons

7-14-2009

\title{
A Study of the Relationship between Employee Virtuality and Technology Deviance as Mediated by Leadership and Employee Perceptions
}

Silvia Salas

Florida International University, silvia.salas@fiu.edu

DOI: $10.25148 /$ etd.FI09082402

Follow this and additional works at: https://digitalcommons.fiu.edu/etd

\section{Recommended Citation}

Salas, Silvia, "A Study of the Relationship between Employee Virtuality and Technology Deviance as Mediated by Leadership and Employee Perceptions" (2009). FIU Electronic Theses and Dissertations. 104.

https://digitalcommons.fiu.edu/etd/104 


\section{FLORIDA INTERNATIONAL UNIVERSITY \\ Miami, Florida}

\section{A STUDY OF THE RELATIONSHIP BETWEEN \\ EMPLOYEE VIRTUALITY AND TECHNOLOGY DEVIANCE AS \\ MEDIATED BY LEADERSHIP AND EMPLOYEE PERCEPTIONS}

A dissertation submitted in partial fulfillment of the

requirements for the degree of

DOCTOR OF PHILOSOPHY

in

BUSINESS ADMINISTRATION

by

Silvia Salas

2009 
To: Dean Joyce J. Elam

College of Business Administration

This dissertation, written by Silvia Salas, and entitled A Study of the Relationship between Employee Virtuality and Technology Deviance as Mediated by Leadership and Employee Perceptions, having been approved in respect to style and intellectual content, is referred to you for judgment.

We have read this dissertation and recommend that it be approved.
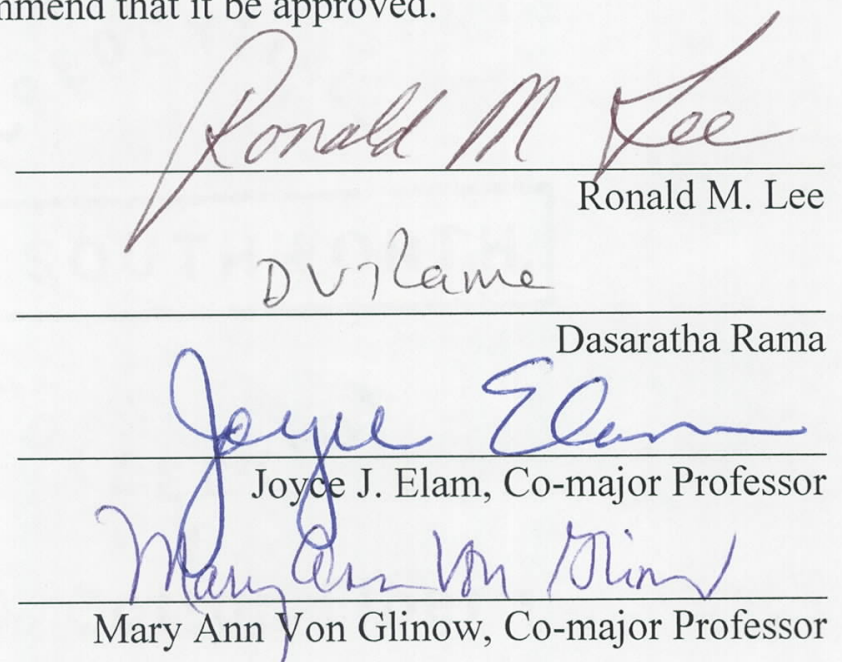

Date of Defense: July 14, 2009

The dissertation of Silvia Salas is approved.

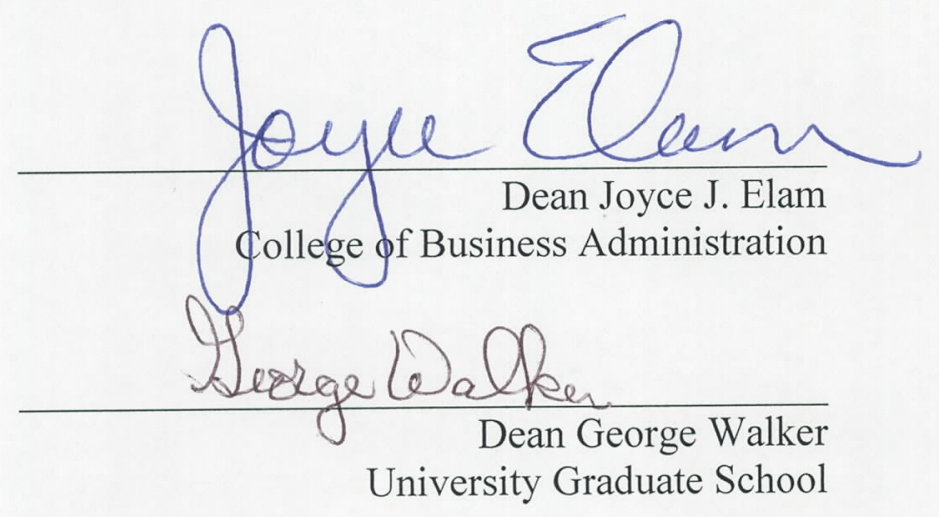

Florida International University, 2009 
(C) Copyright 2009 by Silvia Salas

All rights reserved. 


\author{
ABSTRACT OF THE DISSERTATION \\ A STUDY OF THE RELATIONSHIP BETWEEN \\ EMPLOYEE VIRTUALITY AND TECHNOLOGY DEVIANCE AS \\ MEDIATED BY LEADERSHIP AND EMPLOYEE PERCEPTIONS \\ by
}

Silvia Salas

Florida International University, 2009

Miami, Florida

Professor Joyce J. Elam, Co-Major Professor

Professor Mary Ann Von Glinow, Co-Major Professor

Recent studies found that organizations have been investing significant capital in developing teams and employees in geographic areas where labor and resources are considerably cheaper. Furthermore, organizations are moving core operational activities such as research and development and back-office processes to globally distributed teams.

However, several factors that are inherent to these virtual teams can have a negative impact on employee perceptions and engagement; specifically, the physical and temporal differences between employees and their supervisors, the lack of meaningful social interaction intrinsic to working relationships, and cultural biases that can be fostered when close, daily interactions is not there to help bridge the dissimilarity.

When strategies are not in place to mitigate these deficiencies, it can cause virtual employees to disengage emotionally and intellectually from the organization, or lead them to feel justified in working against the best interest of the company. 
Past research indicates that although deviant behavior in the workplace is not new, transgressions committed by employees have been increasing significantly every year. Beyond the focus of why employees are motivated to act against the organization, to what extent do the recent changes to the organization's structure influence this type of behavior through their actions at the macro (organizational) and micro level (leadership).

In addition, there is a related phenomenon that has aided the transformation of the workplace - namely, the ubiquity of technology. In the context of workplace deviance, established research has documented an increasing trend of employees utilizing company technology as a medium and amplifier when harming the organization. It is important to understand whether technology has facilitated or hindered workplace deviance by virtue of the technology itself (as a means), and as part of the new employee roles created by the evolving technology (i.e, virtual employees). Therefore, it is important to identify how individual attitudes and behaviors can be affected by an employee's degree of virtuality.

This study will add to the understanding of how social interaction and physical proximity, leadership and other perception factors contribute to the changes organizations are experiencing as their structure evolves and adapts to compete in the new global environment. 


\section{TABLE OF CONTENTS}

CHAPTER

PAGE

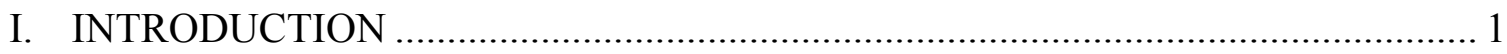

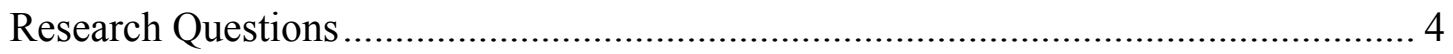

II. LITERATURE REVIEW AND THEORETICAL MODEL ..................................... 5

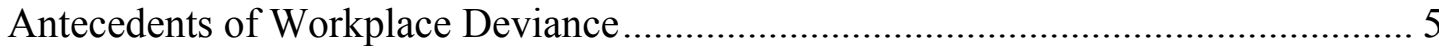

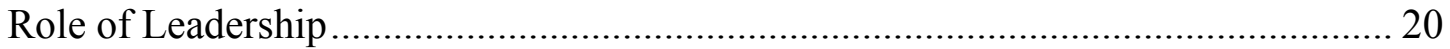

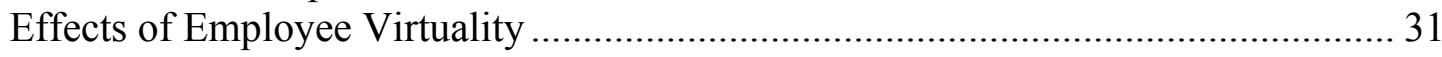

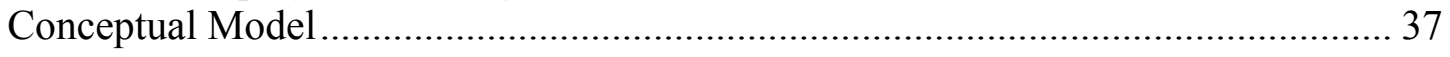

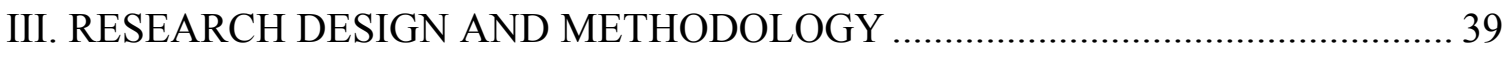

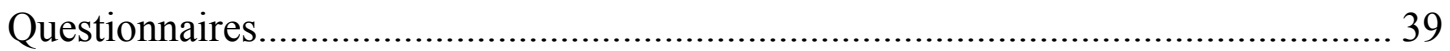

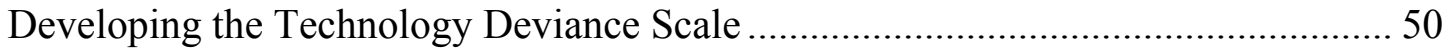

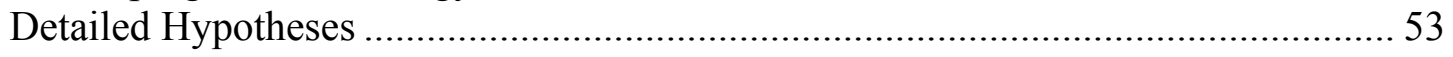

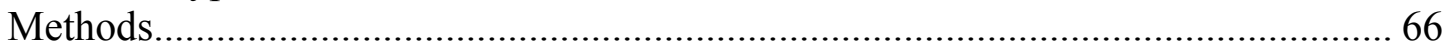

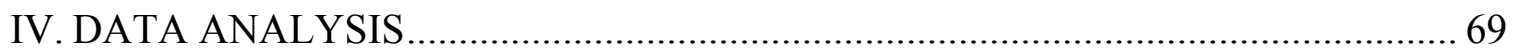

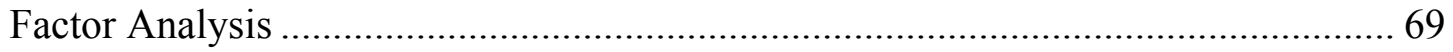

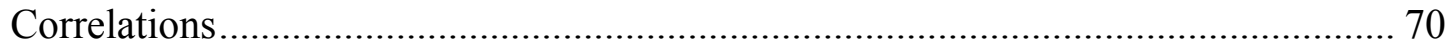

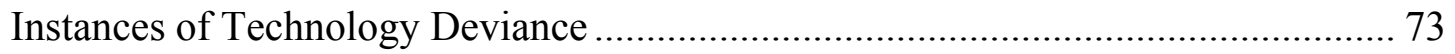

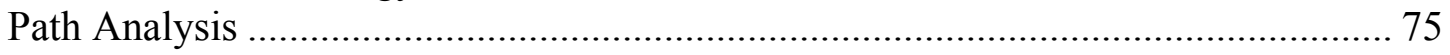

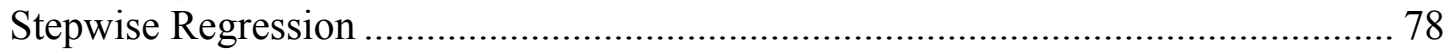

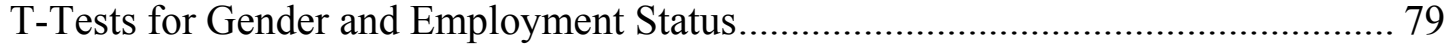

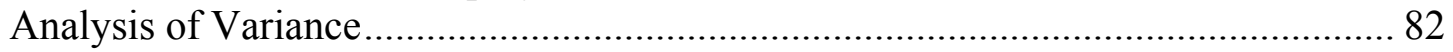

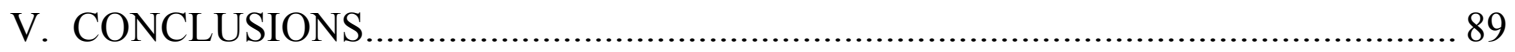

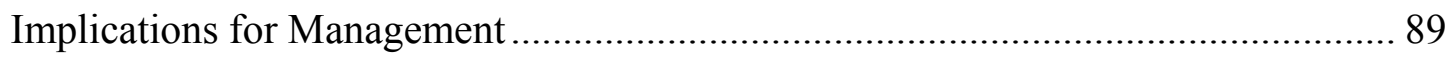

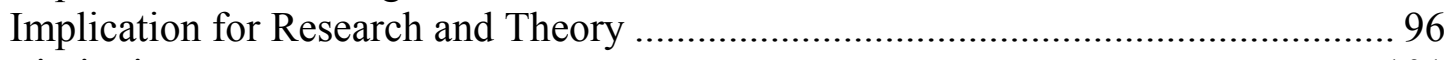

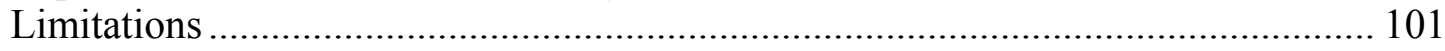

Significance of Study and Future Research .................................................... 102

LIST OF REFERENCES ............................................... 105

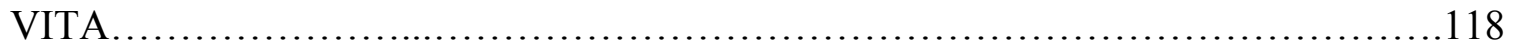




\section{LIST OF TABLES}

TABLE

PAGE

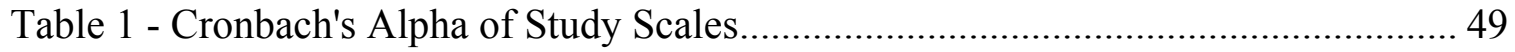

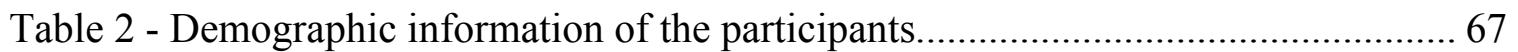

Table 3 - Component Loadings for Technology Deviance scale................................. 70

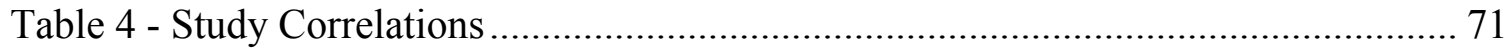

Table 5 - Respondent Admission to Technology Deviance.......................................... 74

Table 6 - $t$ test summary for Gender and Technology Deviance ................................... 79

Table 7 - $t$ test summary for Employment Status and Technology Deviance ................. 81

Table 8 - Analysis of variance for Technology Deviance - Intentional Harm................. 83

Table 9 - Analysis of variance for Technology Deviance - Misuse of Property............. 85

Table 10 - Analysis of variance for Technology Deviance - Loafing............................ 87 


\section{LIST OF FIGURES}

FIGURE

PAGE

Figure 1 - Model of Workplace Deviance. .................................................................. 7

Figure 2 - Model of Traditional versus Technology Deviance..................................... 17

Figure 3 - Model of Leadership influence on Technology Deviance............................. 21

Figure 4 - Model of Employee Virtuality on Technology Deviance.............................. 34

Figure 5 - Model of Motivation and Perceptions on Technology Deviance.................... 37

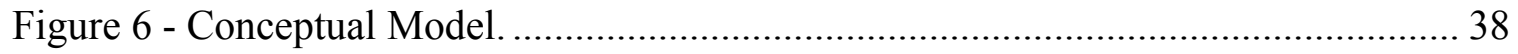

Figure 7 - Path Analysis of Research Model ........................................................ 76 


\section{Introduction}

Although global and international expansion of business operations is not new, studies indicate that organizations are quickly investing significant capital in developing teams and human capital in geographic areas where labor costs and resources are considerably cheaper. In addition, organizations are moving core operational activities such as research and development (R\&D) (Kumar, Van Fenema, \& Von Glinow, 2009; Pirola-Merlo, Hartel, Mann, \& Hirst, 2002) and back-office processes to virtual or globally distributed teams (GDT).

This increasing dependency on employees and / or employees that are not colocated can provide an organization with additional flexibility and market access, but can also pose a higher level of risk (Lurey \& Raisinghani, 2001). Since most organizational performance relies heavily on how well employees zare committed and fully engaged with the organization's mission and goals (Golden \& Veiga, 2008; Lu, Watson-Manheim, Chudoba, \& Wynn, 2006).

However, several factors that are inherent to virtual or globally distributed teams can have a negative impact on said commitment and engagement (Caballer et al., 2005; Golden \& Veiga, 2008; Pillis \& Furumo, 2007). Specifically, the geographic and spatial distance (Watt, 2007) between employees and their supervisors, the lack of social interaction (Koh, Kim, Butler, \& Bock, 2007) intrinsic to these distant relationships and certain cultural biases (Anawati \& Craig, 2006) that can be fostered when close, daily interactions are not there to help bridge the differences. 
When strategies are not in place to mitigate these deficiencies, it can cause virtual or distant employees to emotionally and intellectually disengage (Colbert, Mount, Harter, Witt, \& Barrick, 2004) from the organization, and even lead them to feel justified in sabotaging the company's efforts (Judge, Scott, \& Illies, 2006).

Recent studies indicate although deviant behavior in the workplace is an ongoing problem, studies indicate that crimes committed by organizational employees are increasing significantly every year (Lindenmayer, 2005; Magklaras \& Furnell, 2002). Beyond the narrow focus of why employees are motivated to act against the organization, is the question of how employees are accomplishing it - and to what extent do the recent changes to the organization's structure influence this type of negative behavior through their actions at the macro (organizational) (Trevino \& Brown, 2005) and micro level (leadership) (Appelbaum \& Roy-Girard, 2007).

In addition, there is a related phenomenon that has aided the transformation of the workplace - namely, the ubiquity of technology. In the context of workplace deviance, academic and practioner research has documented an increasing trend of employees utilizing company technology as a medium and amplifier when harming the organization (Lim, 2002). For example, in recent past, employees of Bank of America, Commerce Bancorp, PNC Financial Services Group, and Wachovia were arrested for 'remotely' stealing account data on 700,000 customers (Lindenmayer, 2005; Schneider, 2005). To have stolen the same amount of information ten years ago, employees would have required additional planning and risks, since it would have necessitated that they physically steal a large network server or a room full of filing cabinets. Therefore, 
technology is having an impact on the frequency and severity of workplace deviance as well as in higher risks to organizations (Lim, 2002; Swartz, 2007).

For this study, virtual employees are defined as individuals "who are allowed to work virtually but are otherwise considered regular employees of the organization" (Merriman, Schmidt, \& Dunlap-Hinkler, 2007).

In the context of workplace deviance, the proper definition is a "voluntary behavior that violates significant organizational norms and, in so doing, threatens the well-being of the organization or its members, or both” (Robinson \& Bennett, 1995:555). Specifically, an attempt is made to advance Robinson and Bennett's research by delving into the area of technology deviance, which is defined as workplace deviance that uses technology as the means to threaten the well-being of the organization or its members, or both.

With the advent of technology saturation in the workplace, it is important to examine whether technology is facilitating or hindering instances of workplace deviance by virtue of the technology itself (as a means), and as part of the new employee role allowed by the evolving technology platform (i.e, virtual employees).

Furthermore, it is important to identify how individual behaviors and attitudes can be affected by an employee's degree of virtuality (Shekhar, 2006). This will add to the academic and practioner understanding of how social interaction and / or physical proximity, leadership and other perception factors contribute to the changes organizations are experiencing as their structure evolves and adapts to compete in the new global environment. 
In the following sections, the relevant literature that forms the foundation of workplace deviance, technology deviance and employee virtuality is reviewed in an effort to clarify the research questions that will be tested empirically in this study.

\section{Research Questions}

The primary research questions explored in this study deal with the nature of technology workplace deviance in virtual or distant employees, and the impact that direct and indirect (organizational) leadership has on encouraging or deterring these negative workplace behaviors.

- Does an employee's degree of virtuality influence or predict negative workplace behaviors such as technology deviance?

- What role does leadership have in encouraging or deterring workplace deviance in virtual or distant employees?

- With the ubiquity of technology in the workplace, is there a shifting trend in how employees utilize technology as a medium for deviance or unethical behavior? 


\section{Literature Review and Theoretical Model}

A critical analysis of the literature suggests that there are many factors which can induce an employee to act out against the organization, and in an age of shifting loyalties and changing employment circumstance, employee commitment and affiliation is becoming harder to inspire and secure.

In this section, the different literature streams are reviewed, including those that relate and compliment our understanding of the interdependence between an employee's degree of virtuality (i.e., social interaction and physical proximity) and their propensity for positive or negative workplace behaviors.

Following that, traditional workplace deviance (non-technology specific) is established through the abundance of literature and research. In addition, because of the saturation of technology in the workplace, the shift in deviance from traditional to technological is explicated. Finally, how leaders and the organization can influence these individual perceptions, attitudes and behaviors is considered.

\section{Antecedents of Workplace Deviance}

Within the deviance and ethics literature, there is a debate as to whether an individual's behavior is caused by dispositional, situational or systemic factors. The dispositional approach considers that human traits such as "genetic makeup, personality traits, character, free will and other dispositions" are to blame for a person's actions (Zimbardo, 2007:7). Therefore, if a person causes harm, the assumption is that there is a basic flaw in their character or personality. 
The situational approach assumes that setting and social climate play a significant role in whether an individual will misbehave (Colbert et al., 2004). For example, sociologist Edwin H. Sutherland's differential association theory suggests that learning and culture (i.e., socialization) affects crime because this behavior is essentially learned or culturally assimilated (Akers, 1996; Miller, Schreck, \& Tewksbury, 2006). Sutherland went on to note that criminal behavior was learned through interaction with others, typically occured within intimate groups, included 'lessons' on techniques and methods (Miller et al., 2006), and affected the individual's perception of legal and ethical concepts (Beu and Buckley, 2004).

Recently, psychologist Philip Zimbardo (2007) (of the Stanford Prison Experiments) introduced a third factor, systemic influences on individual behaviors. According to Zimbardo, a "full understanding of the dynamics of human behavior requires that we recognize the extent and limits of personal power, situational power and systemic power. Changing or preventing undesirable behavior of individuals or groups requires an understanding of what strengths, virtues, and vulnerabilities they bring into a given situation" (Zimbardo, 2007:x).

In this study, all three levels of influence were considered. The dispositional influence was examined by the respondent's commission of technology deviance and the individual's motivation behind the behavior. The situational influence was measured by their relationship with their direct supervisor using leader-member exchange, job satisfaction and their perceived person-organization fit. Finally, systemic influence was examined by the perceived indirect organizational leadership and climate fostered by the senior leaders and executives. 


\section{Traditional Workplace Deviance}

In the following model (Fig. 1), the path towards deviance begins by taking into consideration how an employee experiences a trigger event (stressor) that causes his or her perception of the organization, and their own place in it, to shift from positive or neutral to negative (Fox, Spector, \& Miles, 2001).

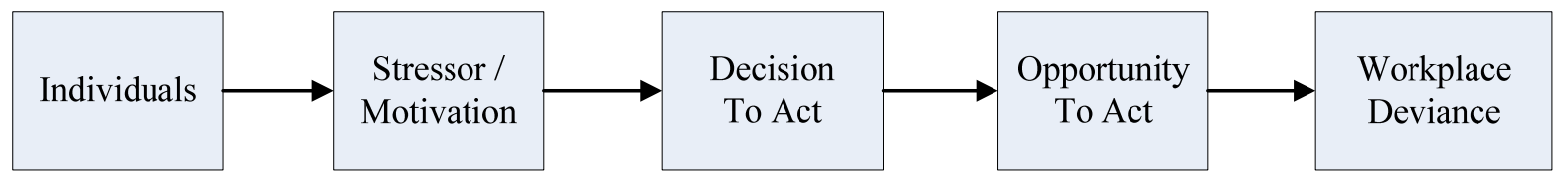

Figure 1 - Model of Workplace Deviance.

Stressors and motivations. There are many negative activities in the workplace that can affect employees such as layoffs (Folger \& Skarlicki, 1998), being disrespected or underestimated by supervisors or co-workers (Judge et al., 2006), or a sense of not receiving the same benefits as other employees (equity theory) (Liao, Joshi, \& Chuang, 2004). Similarly, employees have been known to retaliate or harm the organization due to social alienation (Akkirman \& Harris, 2005), termination (justified or not), real or perceived insults or slights, and the perception of inequity (i.e., being paid less than a coworker) (Cole \& Ring, 2006; Greenberg, 2006). Another possible trigger - financial need - is a little more complex because there could be multiple stressors involved such as greed or retaliation.

Once the stressor exists, employees have a greater propensity for acting against the organization (Ambrose, Seabright, \& Schminke, 2002; Skarlicki \& Folger, 1997). For example, one of the primary methods of workplace deviance cited in the literature is 
revenge or sabotage caused by an individual's need to restore a sense of equity to the relationship or the desire to get even for an injustice (Ambrose et al., 2002; Brockner, Chen, Mannix, Leung, \& Skarlicki, 2000; Skarlicki \& Folger, 1997).

Organizational injustice or inequity speaks to an individual's perception that they have not been treated fairly by the organization, management or co-workers (Greenberg, 2004). The current literature categorizes organizational justice (or injustice) into distributive, procedural and interactional (Ambrose et al., 2002).

Distributive justice refers to whether the individual feels that the gains and rewards handed out by the organization are being fairly 'distributed' (i.e., inequity) (Aquino, Lewis, \& Bradfield, 1999). If the individual feels that he or she is not being compensated properly, this will lead to feelings of perceived, distributive injustice or inequity. Research into the Adams' (1964) equity theory has demonstrated that when individuals perceive an inequity in their relationships with their supervisor, peers or the organization, they will take what they feel is corrective action to restore balance. As Skarlicki and Folger (1997:435) noted, "violations of distributive justice might increase the desire to punish and impose harmful consequences on a putative wrongdoer".

Procedural justice refers to how an individual is treated during a process or event (Brockner et al., 2000; Cropanzano, Prehar, \& Chen, 2002), such as during termination or reorganization or day-to-day. Several studies have found that individuals who were treated fairly and with dignity during a process, even if the outcome was negative (i.e., lay-off), did not perceive an injustice that needed correcting (i.e., were not angry with the organization). 
Interactional justice refers to the daily contact and socialization between an employee and his or her superiors and co-workers (Henle, 2005; Skarlicki \& Folger, 1997). If employees are excluded from group or department activities or their supervisor mistreats them, the employees will perceive interactional injustice (Bolin \& Heatherly, 2001; Mitchell \& Ambrose, 2007; Tepper, Henle, Lambert, Giacalone, \& Duffy, 2008). Because this study already looks at the interaction between a virtual employee and his or her supervisor, this factor is further explicated in the direct leadership section.

Research has found that when individuals feel an injustice has been committed against them, he or she will take action to restore their sense of being abused or victimized by sabotaging the organization in revenge (Bordia, 2008; Seabright \& Schminke, 2002). For example, an individual will collect customer information from the company's computer systems (such as names, addresses, identification numbers, financial account numbers, etc.) and then make the information public (i.e., posts proprietary information on the internet) with the intent to publicly embarrass the organization or even sell the information to an interested outsider. This is similar to individuals who behave unethically for personal gain (i.e., greed); however, in this case, the primary motivation is to seek revenge or restore equity.

A second motivation for acting against the organization deals with an individual wanting to profit illicitly from legitimate information or access he or she has obtained as an employee. For example, an individual creates false invoices in the system in order to collect funds from the organization (i.e., embezzling) (Wells, 2002). Unlike revenge, the individual does not need to be angry with the organization, just a desire for excessive personal gain. 
In an insider threat study conducted by the U. S. Secret Service and Carnegie Mellon University's Computer Emergency Response Team (CERT) on the Banking and Finance Sector (referred to as the 'banking finance study' from here on), financial gain was the primary motivator for $81 \%$ of the employees who perpetrated an offense against their organization. Other motives listed included revenge (23\%), dissatisfaction with the organization (15\%) and desire for respect (15\%) (Randazzo, Cappelli, Keeney, Moore, \& Kowalski, 2004).

One of the least addressed issues regarding employees who violate company rules is that of challenging authority. Whether it is the manifestation of a thrill-seeking personality or the desire to rebel against authority, these individuals are circumventing security policies and endangering the company's assets (Conway \& Schaller, 2005). For example, a company institutes a policy that prohibits employees from accessing their personal email accounts from company computers. One way companies do this is by blocking the word 'mail' when it appears in a browser http address (i.e., http://mail.yahoo.com). Employees that are risk-takers or seeking a challenge will spend hours and resources finding a way around the block (commonly referred to as a 'workaround'). These activities are harmful since employees are violating security policies that are in place for a reason, and they are also 'stealing' from their employers by not working the hours they were paid (Lim, 2002).

Deciding to Act. So far, the stressors and motivations that lead an employee to act out against the organization have been discussed. Now, deliberation is given to the decision-making process an individual considers when deciding to act (or not to act). 
Evaluating the process that individuals pursue can be difficult since the majority of the decision-making (ethical / unethical) literature and research focuses on organized, business-related decision-making (Fang, 2006; Trevino, 1986), and typically, for decisions made by managers or senior executives (Giacalone \& Payne, 1987; Trevino, Weaver, Gibson, \& Toffler, 1999). However, the types of decisions evaluated in this study are those taken by individuals, on matters that are considerably more personal and under strenuous circumstances (Rael, 2006; Robertson \& Ross, 1995).

As of yet, there is no clear agreement in the literature on whether individuals in stressful situations go through a 'rational', conscious decision-making process when determining whether to harm the organization or not. In many cases, the individual is angry or hurt by a stressor event, and looking to lash out or seeking a way to restore balance to the relationship.

Therefore, we consider the theory of reasoned action (Ajzen \& Fishbein, 1980; Fishbein \& Ajzen, 1975), which has been used extensively to understand and predict intention and behavior. This theory finds that attitude towards a behavior and the subjective norms (how others around them will view this behavior) influences intention to act, and subsequently, the manifestation of the behavior (Ajzen \& Fishbein, 1980; Fishbein \& Ajzen, 1975). Based on this theory, it can be determined how an employee's decision to act (i.e., theft of proprietary information) can be predicted by their viewpoint on workplace deviance (attitude) and how others (i.e., peers or supervisor) will view those actions (subjective norms).

Building upon theory of reasoned action, Ajzen developed the theory of planned behavior by introducing the notion of perceived behavioral control, which refers to 
"people's perception of the ease or difficulty of performing the behavior of interest" (Ajzen, 1991:183). Perceived behavioral control plays a very important role in technology deviance because unless the individual thinks that he or she will have the opportunity and resources (skills, access, etc.) to commit the offense, an employee is less likely to act against the organization (Ajzen, 1991; Felson \& Clarke, 1998).

Another factor to contemplate is the effectiveness of potentially 'negative consequences' as a deterrence of crime. Several researchers in different academic areas have predicted that the prospect of negative consequences suffered as a result of violating the rules would have an impact on an individual's decision to act (or not) (Furuya, 2002; Leitsch, 2004; Morris \& McDonald, 1995).

Opportunity to Act. Sociologists Cohen and Felson were the first to incorporate 'opportunity' into the criminal process. They believed that without a clear opportunity to get to - and away from - the crime scene, criminals were more likely to move on to another, easier target (Felson \& Clarke, 1998).

This notion of opportunity inspired Cohen and Felson (1979) to create the routine activity theory, where criminals deduced what routines the targets (and their guardians) followed, thereby working around those routines in order to commit their crime and get away successfully (Miller et al., 2006). Similarly, Ajzen found (as part of the theory of planned behavior) that the intention to act "depend[ed] at least to some degree on such nonmotivational factors as availability of requisite opportunities and resources" (1991:182), and called these factors actual control.

The theory of planned behavior is characterized as the prediction of a particular behavior based on (1) the individual's attitude towards a behavior, (2) the way others 
(i.e., peers or supervisor) will interpret or judge the action or behavior, and (3) the individual's perceived behavioral control. This last factor is a combination of actual control and the individual's perception of control.

In a report to the British Home Office, Felson and Clarke (1998) found that criminal opportunities depended on location, target, time and space, and that every 'opportunity' was highly specific to the crime committed. This is an import distinction because organizations tend to apply the same prevention strategies to both internal and external activities, when in fact the locations, targets, accesses and - opportunities - vary significantly in both types of incidents.

Another important point made by the Felson and Clarke report is that "one crime produces opportunities for others" (1998:17). According to their research, they discovered that once a criminal commits an offense successfully, there is a greater likelihood that the individual will go on to commit other crimes since they are now familiar with the process, the existing security apparatus and the target (victim).

In many ways, it is a positive reinforcement of deviant behavior; the employee has figured out how to act against the organization and escape repercussions. Therefore, the next time they plan to harm the organization, the majority of the hard work (i.e., preplanning, moral disengagement / neutralization, observation of the routines, the pretesting of boundaries and security), has already been done, and the level of anxiety is reduced. Attempting to put the problem into perspective, the authors went on to comment that opportunity played a role in all crimes, and therefore, could be targets of opportunity reduction strategies (Felson \& Clarke, 1998). 
An additional related factor is the message which co-workers and others acquire when one employee behaves inappropriately and is not punished. As a form of counternorm socialization, it is possible for an employee to set the tone for a group or department by demonstrating the ability to steal from the organization with impunity (Robinson \& O'Leary-Kelly, 1998; Vardi \& Weitz, 2004).

\section{Shifting from Traditional to Technology Deviance}

The past decade has seen great advances in technology in the workplace. With physical networks, databases and the internet, employees are becoming more dependent on technology to complete their tasks and duties. However, this dependence on familiarity with technology can be a double-edge sword.

Physical networks are the foundation of computer systems at most organization, since they provide the platform for business applications and interfaces, and they facilitate the connectivity that allows employees to work from multiple locations. Databases are software applications that permit organization to gather an unending supply of data and group them into usable information. Most of the applications that aid businesses in decision making (i.e., decision support systems) owe their flexibility and accuracy to the advances made with relational databases. Finally, the internet has experienced exponential growth since the early days of passive bulletin boards and Compuserve. In the last decade, an increase in broadband bandwidth (the technology that permits the lightening speed transmission of vast quantities of data through wires, fiber optics or wireless capabilities) has paved the way for the information superhighway. Prior to that, data were transmitted in painfully slow, phone communications utilizing highly- 
specialized equipment that was not fully diffused throughout the global business world. The evolution of these technologies has become the vehicle upon which globalization and globally-distributed work groups have been created and encouraged to flourish.

And yet, even these artifacts have a potential dark side. The past decade has revealed that technology used to advance business goals can also be used to advance criminal behavior in the form of data and property theft, which can be accomplished faster, anonymously and with far more catastrophic results.

The same technology that allows businesses to gather millions of data points and analyze them for trends and new business ideas (databases) also gathers enough data on the citizenry that, if stolen, could present a threat to individual identities, and become a potentially liability for the organization that was violated. The same connectivity and platform that provide companies with the flexibility to conduct business around the world (networks) can be used against an organization if the security is breached. As one analyst noted, "the number of companies suffering security breaches has dropped over the last two years, but the severity of the breaches has doubled, according to a new study" (Gaudin, 2007, September 21).

In both of the examples cited above, the threat comes from a breach in security. Companies are learning to protect their technological assets from external attacks through the use of erecting security defenses around the entry/exit points of their networks as well as through the monitoring of unusual system activity. These strategies all work fairly well (to some degree) at hindering an outsider from breaking into a company's system (hacking) and getting away undetected. However, the same strategies are less effective with insiders, since employees are already within the established security perimeter, and 
it is very difficult for a network administrator in one department to determine what 'activities' are unusual for any given employee in a different department. As Vijayan (2005, May 30) noted, “[s]ecurity managers and analysts say insiders often pose a bigger threat to corporate security than external hackers do".

Recently, several regulating bodies have become concerned with the increasing threat from insiders or employees. For example, the European Union's Eighth Directive, Basel II and Sarbanes-Oxley all include guidelines for preventing, monitoring and reporting when companies or other organizations suffer a loss of confidential or intellectual property, exposure of sensitive information, and damaged or destroyed assets.

Which brings us to the earlier stated research question, with the ubiquity of technology in the workplace, is there a shifting trend in how employees utilize technology as a possible outlet for deviance or unethical behavior?

In this study, an evaluation was made of the salient factors that take place during an incident of technology deviance, the mechanisms used to act against the organization and the opportunities that employees utilize to behave deviantly. The mechanisms of technology deviance are the ways in which individuals operationalize their strategy for justice or personal gain. Opportunity is the time and space an individual needs to carry out their plan, and what the organization can deny (or facilitate). In the context of this study, opportunity presents itself when an organization's assets (suitable target) are vulnerable to attack, and a preventive system (human or automated) is not in place (ineffective guardianship) to thwart it. 


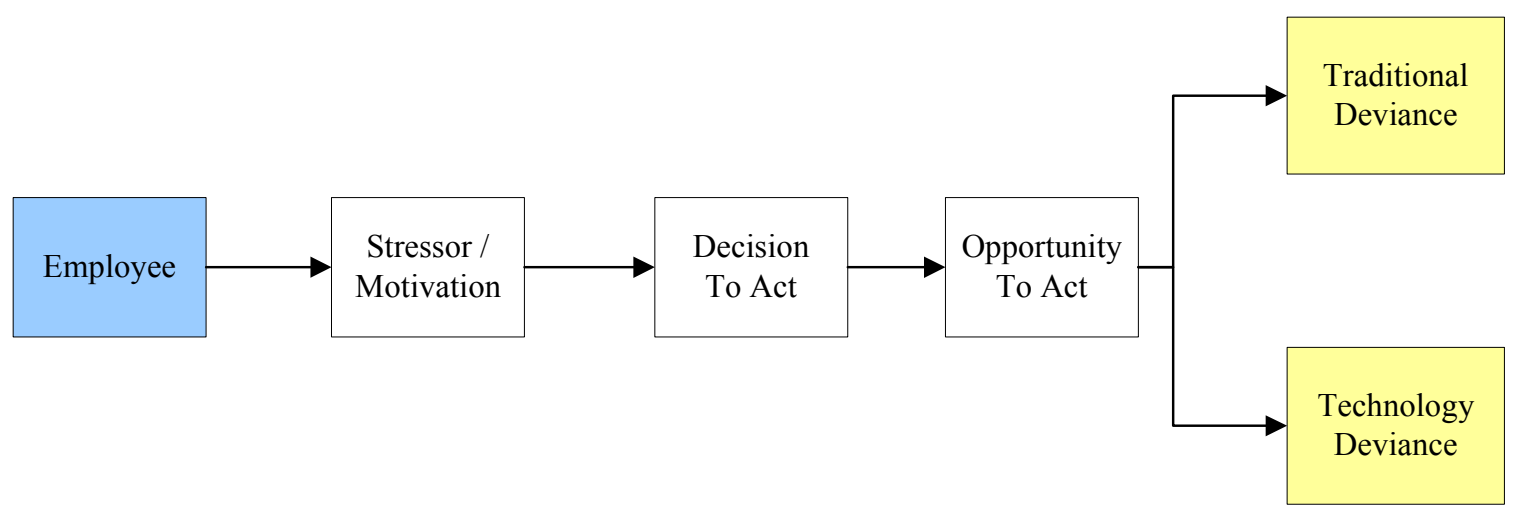

Figure 2 - Model of Traditional versus Technology Deviance.

Mechanism. Although the methods that employees use to commit a transgression can vary substantially, there are four types of incidents in particular that represent the majority of an insider, technical threat to an organization. In the 2006 CSI / FBI Computer Crime and Security Survey (Gordon, Loeb, Lucyshyn, \& Richardson, 2006), the four top losses suffered by the responding organizations accounted for $74 \%$ of the total losses, and it included the disruption of the company's computers, unauthorized access to information, the theft of a laptop or mobile device, and the theft of proprietary information. Therefore, there is a focus on these four types of technology deviance.

Even though most people with access to the internet are familiar with how employees can cause a disruption to the company's networks, one common example is the introduction of a virus contamination, which can be introduced by an employee. For example, an email virus is code in a file that lies dormant within an email message, and is activated when the user opens the attached file (Branigan, 2005). The most dangerous version of a computer virus is a logic bomb, the technical version of a time bomb. A logic 
bomb consists of code and commands that are embedded into the system and lie dormant until a predetermined date and time (Randazzo et al., 2004).

One infamous example is that of a director who had been responsible for the network systems at an organization (Randazzo et al., 2004). When passed up for a promotion he felt was deserved, he introduced a logic bomb into the network (mechanism) and erased the backup tapes (opportunity) prior to quitting. Within three weeks of his departure, the entire system had shut down and there was no backup data to use during recovery (ineffective guardianship). It is estimated that the organization suffered losses in the millions.

Unauthorized access is a difficult type of offense to classify. In some cases, employees 'accidentally' access files or information they did not have the permission or authority to view. In these cases, it is actually the organization's fault since they have not restricted or secured the information properly (Whitman \& Mattord, 2006). In the cases were the unauthorized access is committed with the expressed purpose of stealing, deleting or altering the information for nefarious purposes, then the individual is clearly committing 'malicious trespass' (Whitman \& Mattord, 2006).

As technology becomes increasingly portable, the theft of mobile devices has become an added risk. With the example of laptops and other mobile devices (i.e., PDAs and Blackberrys) assigned to employees, organizations are seeing an increase in the theft of these items (Felson \& Clarke, 1998; Gordon et al., 2006). For example, an employee can walk by another individual's workstation and slip their colleague's laptop into a large handbag or back pack. It is possible for the person to leave the premises without undue scrutiny. 
Even though the theft of a laptop can be costly to an organization, a serious danger becomes critical when you consider the content that resides in the laptop's hard drive. In May 2006, a person employed at the US Department of Veterans Affairs took home a laptop that was subsequently stolen from him. The laptop "contained the names, birth dates and Social Security numbers of millions of current and former service members" (Lee \& Goldfarb, 2005, A1). This incident demonstrated the lack of cohesive security policy in place at the government agency. Similarly, laptops belonging to US Navy recruiters were stolen in Trenton and Jersey City from recruiting offices with sensitive data on "about 31,000 recruiters and prospective recruits" (Weiss, October 17, 2006).

The theft or modification of proprietary information has become one of the most costly crimes perpetrated against organizations, and this action can be done in many ways. For example, data theft occurs when employees take information from the organization's system for their own purposes, including selling it or posting it online.

This type of theft can lead to identity theft and additional problems for the organization. If we consider the bank example in the introduction, the employees stole sensitive customer data and were seeking to sell it for personal gain (Lindenmayer, 2005). In addition, the theft of proprietary information can place an organization in the tenuous position of dealing with (1) the actual loss of the information, (2) the risk and uncertainty associated with a violation by a trusted individual, (3) the added cost of recovering the data and securing the networks and systems after an incident, (4) the bad publicity associated with these incidents, and (5) the liability of potential litigation by the individuals whose information was compromised. 
Another critical type of theft is that of trade secrets, which "are a form of organizational knowledge that can be a critical source of competitive advantage for contemporary organizations" (Hannah, 2006:71). Recently, a Coca Cola employee approached Pepsi Cola with the offer to sell them the 'recipe' for the Coca Cola soft drink. Pepsi Cola executives promptly contacted Coca Cola executives and the Federal Bureau of Investigations (McKay, 2006). In another case, the executive search firm Korn Ferry accused employees of stealing the company's client list - proprietary information intending to sell these data (Lublin, 2005).

\section{Role of Leadership}

The leadership and management literature suggests that leaders provide a spectrum of influencing behaviors which can be employed positively to persuade followers into behaving ethically - or in its absence, can provide the permissive, unethical organizational culture that results in workplace deviance. Specifically, leaders are in the unique position of having many roles in the organization, they act as representatives of the organization and set the tone for the rest of the employees as well as influencing employees that directly report to them.

In spite of the abundance of corrupt and unethical leaders, many researchers and practioners alike make the assumption that 'leaders' are de facto good - inspirational, caring, genuine, dependable and accountable (Brown, Trevino, \& Harrison, 2005). Likewise, when leaders behave criminally or unethically, there is a rush to isolate the blame (i.e., bad apple), and / or rationalize why the leader is not actually at fault (situational, downward influence) (Dunlop \& Lee, 2004). 
At the macro level, Zimbardo finds that the organization (systemic influence) can take the culture and environment one step further and foster an unethical environment; thus, being responsible for the construction of the 'bad barrel' in the first place, and ensuring that an unethical culture is the only possible outcome. To support this view, Zimbardo (2007:446) argues that the organization "consists of the agents and agencies whose ideology, values and power create situations and dictate the roles and expectations for approved behaviors of actors within its spheres of influence".

Similarly, Banerji and Krishnan argue that "it is the leader's beliefs, values, vision and action that set the tone and standard for organizations" (2000:405), and Trevino and Youngblood (1990:378) suggest that "ethical and unethical behavior in organizations is viewed as a consequence of both organizational and individual influences".

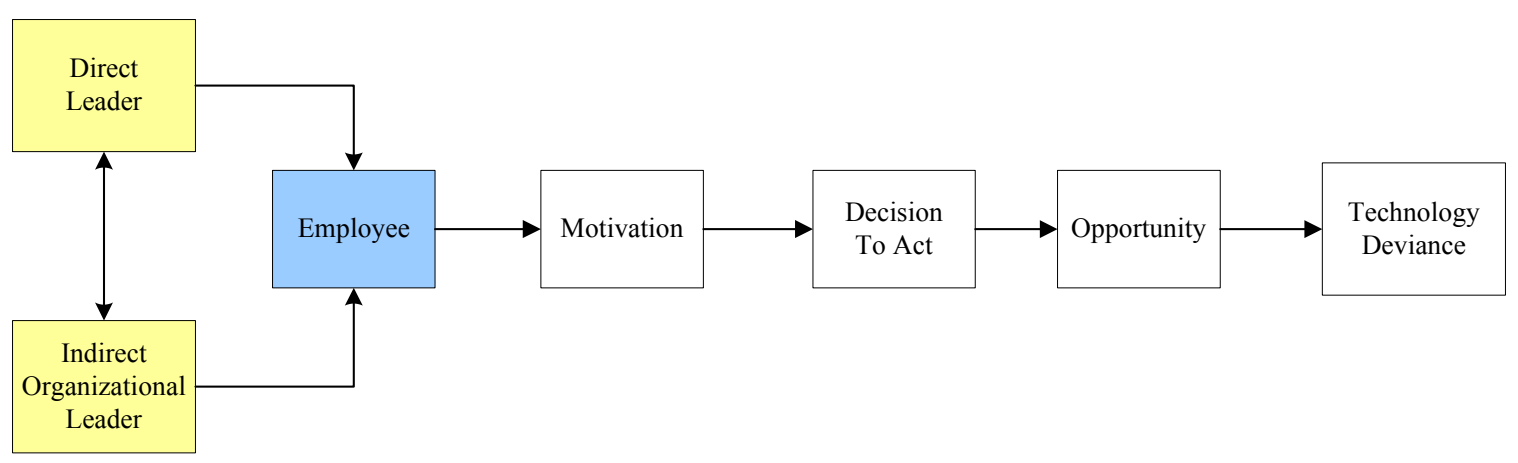

Figure 3 - Model of Leadership influence on Technology Deviance.

In the following two sections, a 'top to bottom' view of leadership is evaluated, and starts with how indirect organizational leaders (i.e., senior, executive managers) set the tone for the organization's culture, which in turn, influences, encourages and / or facilitates specific workplace behaviors. For example, an organization's culture can 
promote certain behaviors by (1) the objectives and goals that are pursued, (2) the business philosophy they foster, and (3) the ethical framework they use to guide all employee behaviors (from decision making to rewards and punishments). In addition, there is a reciprocal relationship between indirect organizational leaders and direct leadership (Yammarino, 1994).

Afterward, the context and factors that contribute to the relationship between a supervisor (direct leadership) and a subordinate, and subsequently, influence an employee's workplace behavior is described. Specifically, consideration is given to the (1) quality and nature of the relationship between supervisor and subordinate, (2) the ethical (or unethical) decision making pattern that supervisor's exhibit - and from which employees take their cue in the workplace, and finally, on (3) how a supervisor uses his or her power of reward or punishment to enforce and condition an employee's behavior and actions.

\section{Direct Leaders}

In a professional setting, the leadership relationship most employees are aware of is that of daily interactions with their direct supervisor. Defined by Yammarino (1994:26) as "the relationships and contact between a focal leader and his or her immediate followers", direct leadership is similar to executive (indirect) leadership in that a person (leader) has power and control over an individual employee - but in addition, you add the daily interface and socialization that employees do not necessarily share with indirect organizational leaders (i.e., CEO). Therefore, this study considers the nature and quality of the relationship between the direct supervisor and the employee and, how a leader 
inspires employee commitment based on the priorities they set and what behaviors he or she rewards or punishes.

\section{Relationship between leader and subordinate}

As in many social exchanges, leaders have been known to treat subordinates different, often due to some perceived display of characteristic or behavior by the employee. The leader-member exchange (LMX) theory describes how the supervisorsubordinate relationship evolves distinctively, to create vertical dyads even when the individuals all form part of the same hierarchical group within an organization (Graen \& Uhl-Bien, 1995; Scandura, 1999).

Previous theoretical and empirical research on LMX has discovered that the quality of the relationship between supervisor and subordinate can have significantly positive influence in employee outcomes such as reducing turnover, organizational commitment, job satisfaction, and job performance. Specifically, a high-quality relationship with a direct supervisor indicates that the employee is part of the "in-group", and allows the employee to enjoy the supervisor's trust and have the ability to influence the leader's decisions. In addition, employees have access to coveted resources and choice assignments. On the other end of the spectrum, a low-quality relationship determined that the employee was part of the 'out-group', and thus, found themselves with little influence and little access to the resources and people (i.e., leader) needed to succeed and grow with an organization.

Although extensive research had been conducted to determine the effects of a high-quality on employee outcomes very little has been done to determine whether low- 
quality relationship affects has the ability to create negative employee behaviors such as retaliation, sabotage, and workplace deviance. There are various leadership behaviors that continue to play a substantial role in explaining why a seeming normally and good employee can be driven to perform a harmful act against the organization or peers. As Trevino and Nelson (2004:152) explicate, a manager's role is crucial because they "can be the inspiration behind why someone stays with an organization or the impetus behind why someone leaves".

The power to reward or punish. There are several factors tied to rewards and punishments that have been found to affect and influence an employee's behavior, especially when supervisors inadvertently send employees mix signals. In particular, consideration is given to how the goals set by leaders and how resources are allocated can implicitly signal that employee should behave unethically, and how rewards and punishments can be used wisely to enforce good behavior.

Goals and resources. Past research in to unethical behavior by employees, researchers and practioners have discovered that setting unrealistic goals, regardless of the desirability of the end state, tends to have a detrimental affect on employee behavior and performance - especially goals that are tied to compensation or professional evaluations. As Trevino and Nelson theorize, "[r]eward systems are probably the single most important formal influence on people's behavior at work" (2004:165).

For example, in the early 1990s, Sears, Roebuck \& Co. changed the compensation structure for the employees working in their automotive repair shops, going from a set salary to commission-based selling (Streitfeld, 1992). Therefore, in order for an employee to take home the same amount of pay he or she had before (on a salary), they had to sell a 
specific number of parts, repair and labor hours. However, the new commission structure was so unrealistic, that employees ended up billing customers for unneeded repairs and returning cars to customers with additional damage - to ensure repeat business. Once the practice was discovered in California, and then New Jersey, Sears suffered enormous losses through customer lawsuits, damage to their corporate image and - ultimately, a lawsuit from the employees - for being forced to defraud customers on the company's behalf (Bernstein, 1993).

Ultimately, the leader can foster an environment of unrealistic performance objectives, where employees feel that they have to do "anything" in order to meet the goals (Levine, 2005). Although, the leader has not explicitly indicated that he or she wants the employees to act unethically or illegally, the employees are getting the implicit message anyway (Ashkanasy, Windsor, \& Trevino, 2006). The lessons learned from the Sears experience was that goals set by leaders for employees should be achievable, and that leaders should embed the motivation for ethical behavior into the goal as well as bottom-line performance.

Rewards and punishments. Because leaders have the ability to make decisions about how the company's financial and non-financial resources are allocated, this gives them the ability to grant or withhold rewards (and punishments) in an effort to achieve their ends. Research on motivation and behavior reinforcement, points to employees doing whatever is rewarded and avoiding that which is punished (Trevino \& Nelson, 2004).

In addition to the actual reward or punishment, leaders need to consider other factors such as that the outcome fits the behavior exhibited by the employee. For 
example, when an employee is rewarded or punished, other employees will judge whether the leader's actions were fair and just - according to the situation. Social learning theory has shown that employees will adjust their behavior based on how they see peers rewarded or punished.

In situations where an employee needs to be punished for a wrongdoing, leaders are advised to confer with the employee, and request his or her input in ways to fix the situation and possibly on the punishment that is deserved. An individual's input - similar to buy-in from the empowerment literature, ensures that the employee will find the punishment more palatable and reduce the feelings of a perceived interactional injustice.

\section{Indirect Organizational Leadership}

The organizational behavior literature has a plethora of studies that point to the power and influence that an organization's culture has on individual performance and overall satisfaction at work (Minkes, Small, \& Chatterjee, 1999). Organizational culture is described as a set of shared beliefs (Ravasi \& Schultz, 2006) and tacit assumptions (Aguinis \& Henle, 2003) that establish individual and group perceptions, thoughts, feelings and behavior (Schein, 1996). Similarly, Moorehead and Griffin (2004:496) define organizational culture as a "set of shared values, often taken for granted, that help people in an organization understand which actions are considered acceptable and which are considered unacceptable". Consequently, it is important to consider what effect these factors have on the attitudes and behaviors of individuals looking to harm the organization (Furnham \& Taylor, 2004; Vardi \& Weitz, 2004). 
Recent research indicates that much can be done to foster and maintain a positive organizational culture when senior managers lead by example, hire or promote employees with integrity, practice transparency, and ensure that the organization's tacit, ethical knowledge is set in the favor of ethical behavior and stringent adherences to rules and regulations. For example, the transformational leadership literature emphasizes two areas of the organization's culture that the leader can influence greatly, individualized consideration for all employees, and providing a safe environment for creativity and intellectual stimulation.

Individualized consideration consists of a leader creating a culture where employees are mentored and coached in a supportive climate, there is a two-way avenue of communication between management and employees, and the top leaders interact with employees regularly (open door policy) instead of isolating themselves from the individuals carrying out the company's business. In addition, leaders treat all employees as individuals with needs different to his or her own, and gives them the room to grow because what the employee thinks matters. Finally, the leaders ensure transparency all levels of the organization (including management), and creates an atmosphere where there is a two-way avenue of communication between the organization and the employees.

With individualized consideration, it is important to understand how the organization manages an employee's emotional wellbeing at work. With intellectual stimulation, it is important to consider how an organization cares for and nurtures an employee's intellectual growth. For many years, companies have been more and more dependent on knowledge and creativity to secure a competitive advantage (Cohen \& 
Levinthal, 1994). As Nonaka (1991:96) contends, "successful companies are those that consistently create new knowledge, disseminate it widely throughout the organizations, and quickly embody it in new technologies and products".

However, for this knowledge to be created, shared and applied in a profitable manner, the organization needs to tap into the endless source of know-how and creativity at their fingertips - employees (Salas \& Von Glinow, 2008). Therefore, the organization needs to provide an outlet for employees to generate and submit new ideas through their own supervisor or as part of a corporate program that rewards ingenuity. In addition, the organization should promote an environment that rewards employees for trying different ideas rather than punish them for falling short (intelligent failure) (Denton, 1998).

Finally, the organization needs to involve employees in identifying and solving problems, since their input will also ensure that employee resistance will diminish through their 'buy-in'.

On the negative side, there are many things an organization can do to create an unhealthy culture (i.e. culture of corruption), and it includes displaying greed, a sense of irrational entitlement, and the inability to distinguish the difference between right and wrong (Levine, 2005). The importance of leaders setting an ethical tone, from the top and by example, can make the different between employees doing the right thing or the organization being mired in scandal and legal proceedings (Minkes et al., 1999). As Trevino et al. (2000:133) indicated, "leaders must make ethics and values a salient aspect of their leadership agenda so that the message reaches more distant employees".

Ethical Climate and Culture. Several researchers have argued about the place of ethics in business, and specifically, what responsibilities leaders have to place ethics over 
profit. When asked, many leaders and managers describe their responsibilities as producing strategic growth for the organization, and ensuring the highest profit possible for themselves and their shareholders (agency theory - cf. Eisenhardt, 1989). While this is an acknowledged objective for those operating in a market system, this sentiment makes no mention of ensuring ethical behavior and responsibility to all stakeholders (not just shareholders) in the interim (Cadbury, 1987). In theory and practice, the diametrically opposed goals of profit versus ethics create a paradox for leaders making decisions, allocating resources, and exercising influence. Defined as the acknowledgement "that seemingly contradictory terms are inextricably intertwined and interrelated" (Calton \& Payne, 2003), a paradox plays an important role in understanding the dichotomies affecting leaders in decision making.

Therefore, the ethical culture paradox reveals ethical or unethical behavior stemming from the organization's climate, where leaders perceive a relaxed moral standard in the organization and allow this perception to continue. In turn, this sends the signal to employees that they can continue to behave unethically, or even escalate their behavior. This negative cycle leads to a pervasive culture of corruption that promotes insidious behavior - until someone blows the whistle or a scandal ensues (DeCelles \& Pfarrer, 2004; Levine, 2005; Vinten, 1990). In a practical sense, the importance of leaders setting an ethical tone, from the top and by example, can make the different between employees doing the right thing or the organization being mired in scandal and legal proceedings (Minkes et al., 1999).

Taking a closer look at recent research into ethical leadership, there have been three varying philosophical approaches that have influenced managers and leaders in the 
last forty years (Vardi \& Weitz, 2004), (1) during the 1960s, business was about profit and growth (reminiscent of economist Milton Friedman) (Minkes et al., 1999), and ethics had a periphery role in business, (2) a decade later, it was believed that business should behave ethically in the pursuit of profit, and (3) in the 1980s / 1990s, the "consideration [of business ethics] is not only sufficient, but a necessary condition for business success" (Vardi \& Weitz, 2004:200). Current research still points to ethical behavior as intrinsic for business success, but the recent abundance of corporate scandals at every level of the organization questions whether business leaders are actually paying attention to the literature.

Nevertheless, since philosophies and theories on ethics have been around for thousands of year, there is a general consensus on what constitutes ethical actions or behavior. Referencing Thomas Aquinas, Kanungo (2001) defines three key components of ethics, motive (intent of the person), manifest behavior (the action itself) and social context (acceptance or condemnation of the community were the action or behavior takes place). If we apply these standards to leaders, we are expecting them to intentionally behave in accordance with what the community at large considers to be ethical (acceptable) behavior. As Bass and Steidlmeier (1999:182) maintain, the "ethics of leadership rests upon three pillars, (1) the moral character of the leader; (2) the ethical legitimacy of the values embedded in the leaders vision, articulation, and program which followers either embrace or reject; and (3) the morality of the processes of social ethical choice and action that leaders and followers engage in and collectively pursue". Similarly, Trevino et al. (2000:128) reason that "as a moral manager, the CEO is thought 
of as the Chief Ethics Officer of the organization, creating a strong ethics message that gets employees' attention and influences their thoughts and behaviors".

\section{Effects of Employee Virtuality}

Much of the research done on globally distributed and virtual teams focus on how co-located managers and employees learn to interact with virtual employees or employees (downstream) (Rosen, Furst, \& Blackburn, 2007). However, a virtual employee's perception of their relationship with peers or supervisors (upstream) has been woefully understudied (Merriman et al., 2007). Yet, this perception relates directly to how much effort the employee will devote to their work, and affects the underlying motivation that will determine whether they perform on behalf of the organization or against it (Kirkman, Rosen, Tesluk, \& Gibson, 2004).

While it is often accepted that individuals gauge the quality of their relationship to others based on verbal and non-verbal cues, this social identification process becomes more difficult when employees are not able to interact with others in a traditional environment (i.e., in-person) (Jessup \& Robey, 2002). Therefore, to better understand what factors most influence an employee's attitude and propensity towards workplace deviance, several factors are evaluated: the level of social interaction or physical distance between the employee and their direct supervisor (degree of virtuality), the quality of a virtual employee's relationship with their direct supervisor (leader-member exchange) and the organizational environment (indirect organizational leadership), and how those interactions contribute to an employee being committed or disengaged. 


\section{Social Interaction and Physical Distance}

The extant literature on virtual teams and overall employment status tend to focus on traditional (co-located) and virtual employees in a vacuum; both polar examples along a continuous spectrum. Co-located employees work purely at the organization's central location, subsidiary or facility managed by the organization. At the other extreme, virtual employees are "typically distinguished from conventional employees by their geographic dispersion - the amount of time members spend working away from central offices or production facilities" (Merriman et al., 2007:7).

However, a recent article by Cousins, Robey and Zigurs (2007) theorized that that many employees do not fall in one extreme or the other. In fact, a significant number of employees will work at an office or facility part of the time and work virtually or remotely the rest of the time. The authors labeled these employees 'hybrid'.

Because technology makes it easier to bridge temporal and physical distances, it is important to determine whether the quality and frequency of social interaction via technological means (i.e, video conferencing, instant message, email and phone) can take the place of traditional, face-to-face social interaction (Hambley, O'Neill, \& Kline, 2007; Lee-Kelley, Crossman, \& Cannings, 2004).

A relevant factor that affects employee perceptions in distant teams is that of cultural bias (Anawati \& Craig, 2006; Elron \& Vigoda-Gadot, 2006). The same technology that facilitates the concurrent performance of work in multiple locations around the globe also attracts and attempts to mesh individuals from different nationalities, backgrounds, and belief systems. Therefore, the role of cultural bias needs 
to be considered when employee satisfaction and job performance is evaluated (Chudoba, Wynn, Lu, \& Watson-Manheim, 2005; Latapie \& Tran, 2007).

While much research has been done on the effect of global relationships in groups and as part of outsourcing, Rao's (2004) research on the issues surrounding the global distribution of work at the individual and country level provides an excellent, high level view of the problems organizations face. From the country level, Rao (2004:17) explores how the difference in "telecommunications infrastructure, legal and security issues, time zone differences" affect the interaction between the co-located and virtual employees. At the individual level, he looks into characteristics that are intrinsic to individuals but are expressed at the group level such as national culture and language barriers (Rao, 2004).

At the country (or global) level, it is possible for integrated teams to work more effectively and efficiently because of the advances in telecommunication technology such as videoconferencing, electronic mail and networks. However, it is this dependence on technology that makes it harder for countries that do not have an established and reliable infrastructure. In addition, because security and legal concerns over the handling of data in the US and Europe are stringent, adhering to US and European standards of data security is essential in acquiring work from these economic regions. 


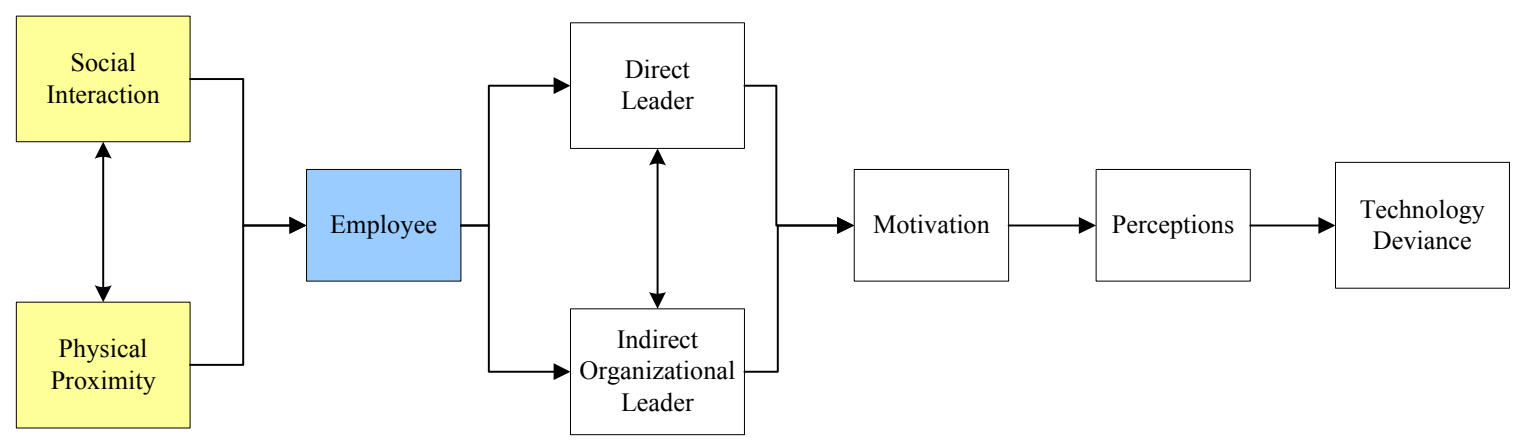

Figure 4 - Model of Employee Virtuality on Technology Deviance.

Time zones and the friction of distance are important country level factors that affect individuals directly (Lu et al., 2006; Rao, 2004). One of the key elements for team cohesiveness is the daily interaction and the face-to-face time with employees. With the differences in time zone (i.e., between the US and India), it is entirely possible for employees in both location to communicate only by electronic mail for extended periods of time. In the few occurrences when real-time meetings take place, one team has to make sacrifices. For example, a team or project staff meeting that is schedule for 10am (US time), requires that the Indian employees come in or stay in the office until 10pm (Indian time).

On the individual level, the factors that come into play include national culture (Chudoba et al., 2005) and language barriers (Pauleen \& Yoong, 2001). As defined by Rao, dimensions of national culture at the individual level include uncertainty avoidance, power distance, collectivism, gender egalitarianism, and assertiveness. A virtual employee's imbedded beliefs in their national culture can greatly affect their relationship with their leader and the organization as a whole. "[P]atterns of thought and behavior that 
seem so natural and ingrained in employees of offshore vendors may appear quite alien and incomprehensible to the companies that hire them" (Rao, 2004:18).

Language issues seem to be more straight-forward, but have the potential for causing significant problems. In fact, the ability to communicate in the same language is a key to successful partnerships. But speaking the same language is not enough; knowledge of idiomatic expressions, similarities in accent and cultural points-ofreference can determine how quickly team cohesiveness, and subsequently, team effectiveness can be achieved.

Therefore, the level of demographic homogeneity, or the similarity in ethnic and racial characteristics, shared by an organization's members can have an impact on the success of international relationships (Osborn, Hunt, \& Jauch, 2002). For example, if an organization has a high level of demographic homogeneity, this can cause additional stressors and pressure on the virtual employees to conform or make greater concessions than when dealing with a diverse group. At the other end of the spectrum, the greater the diversity, the less room there is for cultural bias.

\section{Mediating Factors}

Researchers have often focused on how employees can be made to improve their performance at work, thereby, improving the organization's operation. Past studies have found that getting an employee to commit and be loyal to a specific organization, while highly desirable, can also be difficult and complex (Becker, Billings, Eveleth, \& Gilbert, 1996). Different employee perceptions and beliefs can contribute to an individual's sense 
of commitment and loyalty to the organization, and include job satisfaction, perceived organizational support and person-organization fit.

Job satisfaction is the employee's belief that they are happy with their employment situation (Golden \& Veiga, 2008). Specifically, an employee will evaluate their satisfaction with their supervisor, their peers, the nature of the work they do, the compensation they receive for their pay and the opportunities that exist for potential growth within the organization. An employee's satisfaction with their job will not only determine how he or she feels about the organization, but can also influence their attitude towards negative workplace behaviors (Emery \& Barker, 2007; Griffin, O'Leary-Kelly, \& Collins, 1998). An employee's contentment can go a long way in forming the social bonds and attachment that generate loyalty and commitment to a specific organization (Golden, 2007).

Another factor that contributes to an employee's attachment is perceived organizational support (Vandenberghe, Bentein, Michon, Chebat, \& et al., 2007), a cognitive function where the employee feels that the company they work for will expend additional effort and resources to ensure they thrive in the workplace. A company can encourage trust and attachment by acknowledging the employee's contribution, by helping employees grow and improve, and by fostering a sense of community, where all employees are pulling together, focused on a common goal or purpose (Liao et al., 2004; Wayne, Shore, Bommer, \& Tetrick, 2002).

Finally, a third component of that contributes to commitment is personorganization fit (Valentine, Godkin, \& Lucero, 2002). Because social alienation and lack of trust is a relevant concern with virtual employees, integrating employees into the 
culture and the organization's mission becomes more difficult if the employee and the organization have different values and beliefs (Resick, Baltes, \& Shantz, 2007). Research has found that leaders at all levels of the organization have the ability to influence the beliefs and attitudes of its employees (Huang, Cheng, \& Chou, 2005). When those beliefs are similar to the employee's core beliefs, a synergy is formed and the individual is more likely to trust the organization and its leadership (Hurley, 2006; Tucker \& Russell, 2004).

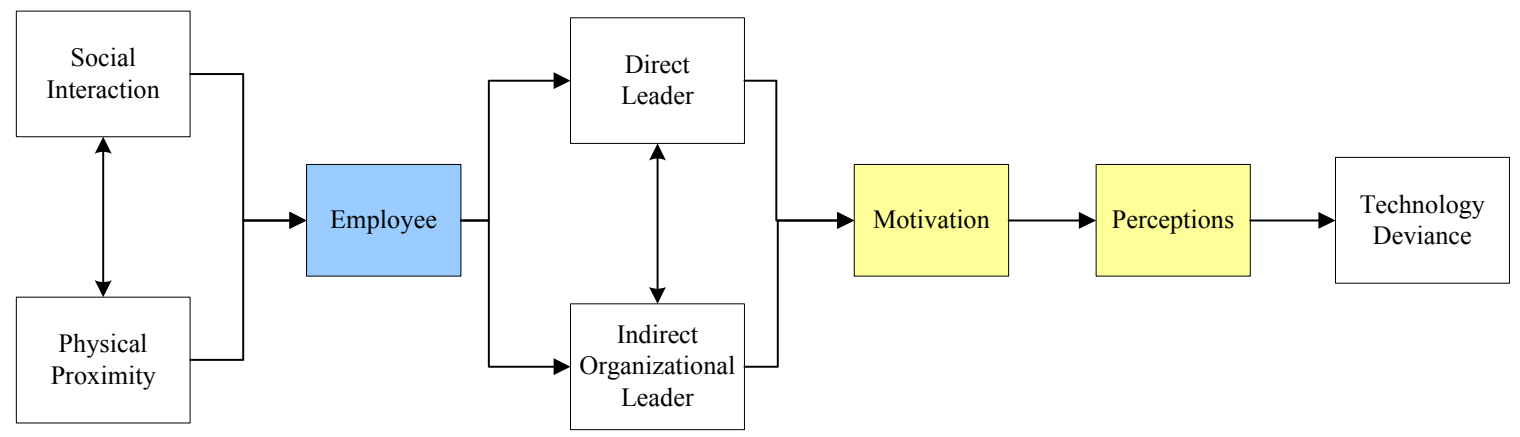

Figure 5 - Model of Motivation and Perceptions on Technology Deviance.

When the organization's goals and values are not inline with the employee's own beliefs, cognitive dissonance occurs and may cause further alienation and disengagement from the organization (Sarros, Tanewski, Winter, Santora, \& Densten, 2002). Therefore, it is highly important for an organization to hire employees that agree with the goals and mission set out by the leadership, and for leadership to continuously communicate those objectives to its employees.

\section{Conceptual Model}

The resulting research model for this study (Figure 6) consists of three principal components: employee virtuality, employee perceptions and employee behavior. Even 
though the literature has addressed these components separately, very little effort has been made to develop a comprehensive view of how interaction, leadership and perceptions of the organization impact employee behavior with positive or negative outcomes.

This conceptual model builds on previous research found in the management and technology literature, which was highlighted in the previous chapter

Employee Virtuality

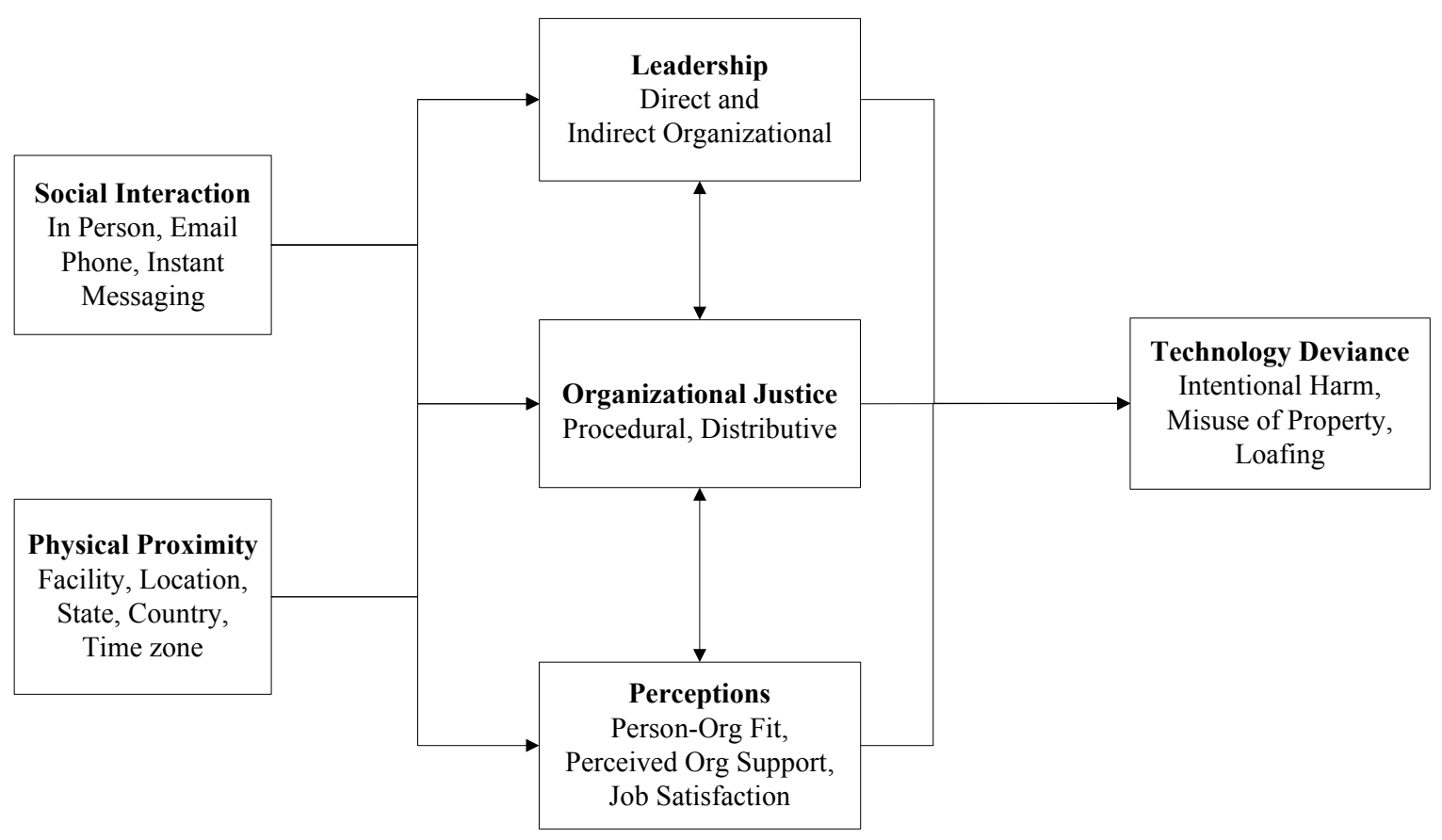

Figure 6 - Conceptual Model. 


\section{Research Design and Methodology}

Lacking true random assignment, a quasi-experimental approach was taken when designing the research study. Several independent and dependent variables were identified from the conceptual model (Figure 6) including items for social interaction, physical proximity between employee and supervisor, direct and indirect organizational leadership, procedural and distributive justice, person-organization fit, perceived organizational support, job satisfaction and technology deviance.

\section{Questionnaires}

Multiple scales were used in this study, including scales well-established in the management literature as well as those created specifically for this research. The established scales include leader-member exchange (LMX) for direct leadership, elements of the Multifactor Leadership Questionnaire (MLQ) for indirect organizational leadership, distributive justice, procedural justice, person-organization fit, perceived organizational support and job satisfaction. The new scales developed for this study include the items on social interaction between employee and direct leader (supervisor), physical proximity with direct leader and the technical deviance scale.

Social interaction. This construct measured the frequency and type of interaction the respondent has with their direct supervisor. The items used a six-point frequency scale: several times a day, at least once a day, several times a week, at least once a week, at least once a month, and never. The items were labeled $\mathrm{sd} 1, \mathrm{sd} 2, \mathrm{sd} 3$ and $\mathrm{sd} 4$ respectively. 
- How often do you speak with your supervisor in person?

- How often do you email your supervisor?

- How often do you speak with your supervisor on the phone?

- How often do you chat with you supervisor via 'instant message (IM)?

Physical proximity. This construct measured the physical or geographic distance between the employee's base of operations and their supervisor's base of operations. The items used a five-point frequency scale: $100 \%$ of the time, at least $75 \%$ of the time, half of the time, less than $25 \%$ of the time, and never. The items were labeled gd1, gd2, gd3, gd4 and gd5 respectively.

- How often do you work at a company facility (i.e., office building, store front, warehouse, etc.)?

- Are you and your supervisor based at the same company facility?

- Are you and your supervisor based in the same time zone?

- Are you and your supervisor based in the same state (or province)?

- Are you and your supervisor based in the same country?

Direct leadership. This construct was measured using Scandura and Graen's (1984) short version of the Leader-Member Exchange (LMX) scale. Their seven-item scale assessed the quality of exchange between supervisors and subordinates. Items were measured using a 5-point response format from 1 (strongly disagree) to 5 (strongly agree). Statistical analysis was conducted with an aggregate variable (LMX), derived by 
averaging the respondent scores across the seven items. The Cronbach's alpha for this subscale of items was .924 .

- Do you usually feel like you know where you stand with your immediate supervisor?

- How well do you feel that your immediate supervisor understands your problems and needs?

- How well do you feel that your immediate supervisor recognizes your potential?

- Regardless of how much formal authority your immediate supervisor has built into his or her position, what are the chances that he or she would be personally inclined to use power to help you solve problems in your work?

- Regardless of the amount of formal authority your immediate supervisor has, to what extent can you count on him or her to "bail you out" at his or her expense when you really need it?

- I have enough confidence in my immediate supervisor that I would defend and justify his or her decisions if he or she were not present to do so.

- How would you characterize your working relationship with your immediate supervisor?

Indirect organizational leadership. This construct was measured using a subset of Bass and Avolio's (1995) Multifactor Leadership Questionnaire (Form 5X); specifically, four items on inspirational motivation (IM), four items on intellectual stimulation (IS) and four items on individual consideration (IC) subscales. Items were 
measured using a 5-point response format from 1 (strongly disagree) to 5 (strongly agree). Statistical analysis was conducted with an aggregate variable (OC_all), derived by averaging the respondent scores across the twelve items. The Cronbach's alpha for this subscale of items was .918 .

The items were also analyzed as subsets of indirect organizational leadership, and they were derived as described in each subsection.

The inspirational motivation subscale measured to what extent an organization makes it possible for followers to be enthusiastic and visionary. Items were measured using a 5-point response format from 1 (strongly disagree) to 5 (strongly agree). Statistical analysis was conducted with an aggregate variable (OCIM), derived by averaging the respondent scores across the four items. The Cronbach's alpha for this subscale of items was .834.

- My organization wants employees to be optimistic about the future

- My organization wants employees to be enthusiastic about what needs to be accomplished

- My organization wants employees to articulates a compelling vision of the future

- My organization wants employees to express confidence that goals will be achieved

The individual consideration subscale measured to what extent an organization promotes coaching or mentoring of individual employees. Items were measured using a 5-point response format from 1 (strongly disagree) to 5 (strongly agree). Statistical 
analysis was conducted with an aggregate variable (OCIC), derived by averaging the respondent scores across the four items. The Cronbach's alpha for this subscale of items was .801 .

- My organization wants employees to spend time teaching and coaching

- My organization wants employees to treat others as individuals rather than just as another member of the company

- My organization wants employees to consider the needs of others

- My organization wants employees to help other employees develop their strengths

The intellectual stimulation subscale measured to what extent an organization allows and encourages employees to be innovative and creative. Items were measured using a 5-point response format from 1 (strongly disagree) to 5 (strongly agree). Statistical analysis was conducted with an aggregate variable (OCIS), derived by averaging the respondent scores across the four items. The Cronbach's alpha for this subscale of items was .912 .

- My organization wants employees to re-examine critical assumptions to question whether they are appropriate

- My organization wants employees to seek differing perspectives when solving problems

- My organization wants employees to look at problems from many different angles 
- My organization wants employees to suggest new ways of looking at how to complete assignments

Distributive justice. This construct was measured using Price and Mueller's (1986) six-item scale, which gauges how fairly the employee feels he or she is being rewarded for the effort and work they are put forth. Items were measured using a 5-point response format from 1 (strongly disagree) to 5 (strongly agree). Statistical analysis was conducted with an aggregate variable (DOJ), derived by averaging the respondent scores across the six items. The Cronbach's alpha for this subscale of items was .958.

- Considering my responsibilities, I am fairly rewarded.

- Taking into account the amount of education and training that I have, I am fairly rewarded

- Considering the amount of experience that I have, I am fairly rewarded

- Considering the amount of effort that I put forth at work, I am fairly rewarded.

- Considering the work I have done well, I am fairly rewarded.

- Considering the stresses and strains of my job, I am fairly rewarded.

Procedural justice. This construct was measured using Sweeney and McFarlin's (1993) four-item scale, which gauges how fairly the employee feels he or she treated by organizational procedures. Two additional items were adopted from Aquino et al. (1999) which deal with the fairness involved in termination and the handling of grievances. Items were measured using a 5-point response format from 1 (strongly disagree) to 5 (strongly agree). Statistical analysis was conducted with an aggregate variable (DOJ), 
derived by averaging the respondent scores across the six items. The Cronbach's alpha for this subscale of items was .890 .

- The procedures used to communicate performance feedback in my organization are fair.

- The procedures used to determine pay raises in my organization are fair.

- The procedures used to evaluate performance in my organization are fair.

- The procedures used to determine promotions in my organization are fair.

- The procedures used to terminate or discipline employees in my organization are fair.

- The procedures used to express grievances (complaints) in my organization are fair.

Person - organization fit. This construct was measured using Cable and Judge's (1996) three item scale. The three items asked respondents to agree or disagree with statements that indicated how in-synch their individual values are with the organization's values. Items were measured using a 5-point response format from 1 (strongly disagree) to 5 (strongly agree). Statistical analysis was conducted with an aggregate variable (POF), derived by averaging the respondent scores across the three items. The Cronbach's alpha for this subscale of items was .893 .

- My values match those of this organization.

- My values match those of the current employees in this organization.

- I think the values and "personality" of this organization reflect my own values and personality. 
Perceived organizational support. This construct was measured using items from Eisenberger, Huntington, Hutchinson and Sowa's (1986) scale. The scale items measured the employee's perception about their organization's interest in their individual well-being as well as how willing the organization is to help employees meet or exceed their contributions. Items were measured using a 5-point response format from 1 (strongly disagree) to 5 (strongly agree). Statistical analysis was conducted with an aggregate variable (POS), derived by averaging the respondent scores across the five items. The Cronbach's alpha for this subscale of items was .853 .

- The organization I work for values my contribution to its well-being.

- My organization strongly considers my goals and values.

- My organization disregards my best interests when it makes decisions that affect me (R)

- Help is available from my organization when I have a problem.

- Even if I did the best job possible, my organization would fail to notice (R)

Job satisfaction. This construct was measured using Schriesheim and Tsui's (1980; Tsui, Egan, \& O'Reilly Iii, 1992) Job Satisfaction Index. Their six item scale gauged overall satisfaction with work, supervisor, peers, pay, opportunities for advancement and an 'overall' satisfaction item. Items were measured using a 5-point response format from 1 (strongly disagree) to 5 (strongly agree). Statistical analysis was conducted with an aggregate variable (JS), derived by averaging the respondent scores across the six items. The Cronbach's alpha for this subscale of items was .810 . 
- How satisfied are you with the nature of the work you perform?

- How satisfied are you with the person who supervises you?

- How satisfied are you with your relations to others in your organization - your co-workers or peers?

- How satisfied are you with the pay you receive for your job?

- How satisfied are you with the opportunities which exist in the organization for advancement or promotion?

- Overall, how satisfied are you with your current job situation

Technology deviance. This instrument was created specifically for this study, and followed DeVellis' (1991) scale development guidelines. The construct measured the use of technology mediums as a vehicle for workplace deviance. Similarly to Robinson and Bennett's (1995) workplace deviance scale, this technology deviance scale sought to measure interpersonal and organizational deviant behaviors; it differs from the workplace deviance scale in that the employee had to use technology as a medium or method of the action / behavior

A factor analysis was conducted, and result was a three-factor model, with a distribution of subscales follows. Details on the scale development process and findings are found in the following section.

Intentional Harm. This construct measured the frequency of an employee's technology deviance with intent to harm. The items used a five-point frequency scale: daily, weekly, monthly, several times a year, and never. Statistical analysis was 
conducted with an aggregate variable (TED_HARM), derived by averaging the respondent scores across the five items. The Cronbach's alpha for this set of items .757.

- Disrupted the company's computer in order to avoid doing work

- Took computer property (i.e., hardware, software, etc.) from work without permission

- Emailed a hurtful message about someone at work

- Purposely used software on the company's computer that you know is unlicensed

- Posted or emailed offensive material via the company's computer

Misuse of Property. This construct measured the frequency of an employee's technology deviance by misusing company property. The items used a five-point frequency scale: daily, weekly, monthly, several times a year, and never. Statistical analysis was conducted with an aggregate variable (TED_MISUSE), derived by averaging the respondent scores across the five items. The Cronbach's alpha for this set of items .783.

- Shared confidential information about the company with an unauthorized person

- Deleted someone's computer files at work without his/her permission

- Used someone's username or password without their knowledge

- Made someone's email or voice message public without his/her permission

- Copied data or information from company's computer without the consent of the organization 
Loafing. This construct measured the frequency of an employee's technology deviance by loafing or working on something not part of their duties. The items used a five-point frequency scale: daily, weekly, monthly, several times a year, and never. Statistical analysis was conducted with an aggregate variable (TED_LOAFING), derived by averaging the respondent scores across the three items. The Cronbach's alpha for this set of items .726 .

- Spent company time surfing the internet instead of working

- Used email access at work for personal matters

- Worked on a personal project during working hours on the company's computer

\begin{tabular}{ll}
\cline { 2 - 2 } Direct Leadership (LMX) & 0.924 \\
Indirect Organizational Leadership (MLQ) (all) & 0.918 \\
Inspirational Motivation & 0.834 \\
Individualized Consideration & 0.801 \\
Intellectual Stimulation & 0.912 \\
Distributive Justice & 0.958 \\
Procedural Justice & 0.890 \\
Person-Organization Fit & 0.893 \\
Perceived Organizational Support & 0.853 \\
Job Satisfaction & 0.810 \\
Technology Deviance (all) & 0.783 \\
Tech Dev - Intentional Harm & 0.757 \\
Tech Dev - Loafing & 0.726 \\
Tech Dev - Misuse of Property & 0.783
\end{tabular}

Table 1 - Cronbach's Alpha of Study Scales 


\section{Developing the Technology Deviance Scale}

As suggested by DeVellis (1991), an item pool was generated using the 2006 FBI/CSI Computer Crime survey (Gordon et al., 2006), the US Secret Service's Employee Threat reports on the Banking and Finance Sectors (Randazzo et al., 2004) as well as on Critical Infrastructure Sectors (Keeney et al., 2005), and finally, Namlu and Odabasi's (2007) Unethical Computer Use Behavior scale. Items in the initial pool were limited to behaviors and / or computer crimes that could be attributed individuals within an organization, and directed at other individuals within the organization or the organization itself. For example, hacking or breaking into a computer system - typically performed by an outsider - was not included even if it is a legitimate computer crime that affects an organization. However, the insider equivalent of 'unauthorized access of a system or exceeding assigned access' was included.

In keeping with the overall study, the format for this measure was a five-point Likert scale from 1 (very unacceptable) to 5 (very acceptable). For the expert review, several professors were consulted, based on their areas of proficiency. The general pool of 31 items was sent to several information systems professors to review the technology / computer crime content of the questions, and to two management / organizational behavior professors to review the behavior content of the questions. All of the professors made suggestions, which resulted in several minor changes and the replacement of items incompatible with the overall purpose of the dissertation research questions. The resulting pool of items contained 21 items, 9 interpersonal items targeting individuals, and 12 organizational items targeting the company. 
The remaining steps in DeVellis' guidelines included the administration the items to a group of participants, evaluating the item responses using statistical analysis such as item-scale correlations, item variances, scale reliability (i.e. Cronbach's alpha) and optimizing the scale length (i.e., factor analysis).

Descriptive Analysis. This assessment was carried out in two Operations Management undergraduate courses on September 7, 2007. The survey was administered on paper, and students were given 15 minutes to complete the survey at the beginning of the class period. Between both classes, 348 surveys were received and 191 useable surveys were kept for statistical analysis. The other surveys were not considered because they were incomplete. The descriptive analysis of the two courses is as follows, the average respondent age is 23 years old, with actual age ranging between 19 and 44 . The gender breakdown was fairly close, male students were $47 \%$ of the participants and $53 \%$ were females. The majority of the students identified themselves as being Hispanic (72\%), with the other races also represented, White (12\%), Black or African American $(7 \%)$, Asian (5\%) and Other (3\%). The majority of the participants were employed at least part-time (52\%) or full-time (34\%).

Scale validation. Statistical analysis was performed on the organizational subscales separately as they are meant to measure different constructs. On the organizational subscale, the alpha for the 12 items was 0.753 which makes the scale reliable and acceptable for future use.

Exploratory Factor Analysis. An exploratory factor analysis was performed to determine how the items would load into components. Suitability of the data for factor 
analysis was determined using the Kaiser-Meyer-Olkin Measure of Sampling Adequacy (KMO) and Bartlett's Test of Sphericity (Bartlett).

Interpersonal EFA. The KMO for the Interpersonal subscale was 0.809, which exceeded the minimum required 0.500. In addition, the Bartlett significance level was 0.00 , which indicates that a significant relationship may exist among the variables. In the factor loadings, two factors loaded for the interpersonal subscale accounting for $53.72 \%$ of the total variance ( $41.16 \%$ and $12.57 \%)$. The two factors that loaded were 'Noninteractional Behavior' (4 items) and 'Interactional Behavior' (4 items). One item (IN_1) loaded highly on both components but because the difference was greater than 0.5 , and both loadings were greater than 0.4 , it was allowed to remain. In addition, one item (IN_3) was removed because it did not load at all.

Organizational EFA. For the organizational subscale, the KMO was 0.760 and Bartlett was also 0.00. In the factor loadings, three factors loaded for the organizational subscale accounting for $55.21 \%$ of the total variance $(30.4 \%, 15.9 \%$ and $8.9 \%)$. The three factors that loaded contained items for 'Intentional Harm' (3 items), 'loafing' (4 items) and 'Misuse of Property' (4 items). One item (OR 2) was removed because it doubleloaded highly on two separate components (intentional harm and misuse of property).

Pilot Test of Technology deviance Scale. To ensure that the final scale was still valid and reliable, the scale was administered in two undergraduate information technology courses during the first week of December 2007. The students were asked to complete the survey online using WebCT. The resulting analysis is as follows $(\mathrm{N}=55)$, the alpha for the interpersonal subscale is 0.732 and for the organizational subscale is 0.787 . 


\section{Detailed Hypotheses}

In the previous chapter, a conceptual model (Figure 6) was presented, outlining the three main components derived from the extant literature in the areas of employee virtuality, leadership, employee perceptions and technology deviance.

The research questions posed at the end of chapter one consider how an employee's degree of viruality would influence other work-related factors such as their relationship with their supervisor, they perceptions of the organization and their propensity for negative workplace behaviors. Taking all of the relevant variables discussed in the prior sections, it is possible to derive the following detailed hypotheses.

\section{Social Interaction}

Social Interaction refers to the methods and frequency of communication between an employee and his or her supervisor. There are four types of communication considered in this study: in-person, email, phone and instant messaging. Based on past research, if an employee and his or her supervisor communicate frequently, then a positive relationship should exist with direct and indirect organizational leadership variables.

H1. The frequency of communication between an employee and his or her supervisor will be positively associated with the quality of their relationship.

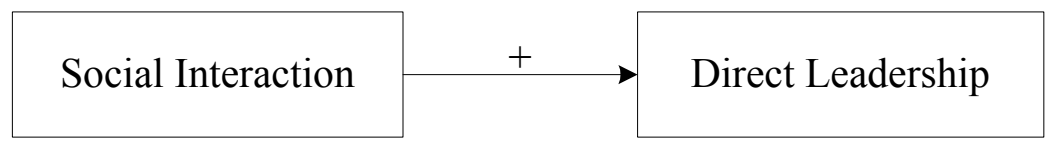


H2. The frequency of communication between an employee and his or her supervisor will be positively associated with the employee's perception of the indirect organizational leadership.

\begin{tabular}{|c|c|c|}
\hline Social Interaction & + \\
\cline { 2 - 2 } & $\begin{array}{c}\text { Indirect Organizational } \\
\text { Leadership }\end{array}$ \\
\hline
\end{tabular}

\section{Physical Proximity}

Physical Proximity refers how much time employee spends in proximity to his or her supervisor. There are five types of locations considered in this study: same building, same complex / facility, same state, same time zone and / or same country. Based on past research, increased time an employee spends in close proximity with his or her supervisor should result in a positive relationship with the direct and indirect organizational leadership variables.

H3. Physical proximity between an employee and his or her supervisor will be positively associated with the employee's perception of their supervisor

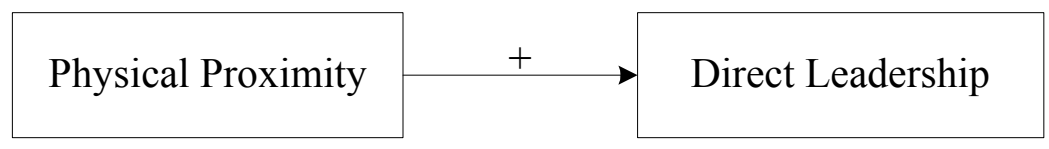

H4. The physical proximity between an employee and his or her supervisor will be positively associated with the employee's perception of the indirect organizational leadership. 


\begin{tabular}{|c|c|c|}
\hline Physical Proximity & $+\begin{array}{c}\text { Indirect Organizational } \\
\text { Leadership }\end{array}$ \\
\cline { 2 - 3 }
\end{tabular}

\section{Direct Leadership}

Direct leadership refers to the quality of the relationship between an employee and their direct supervisor. Based on past research, if an employee and his or her supervisor have a high-quality relationship, then a positive relationship should exist between direct leadership and other organizational factors.

H5. The quality of the relationship between an employee and his or her supervisor will be positively associated with the employee's perception of the indirect organizational leadership.

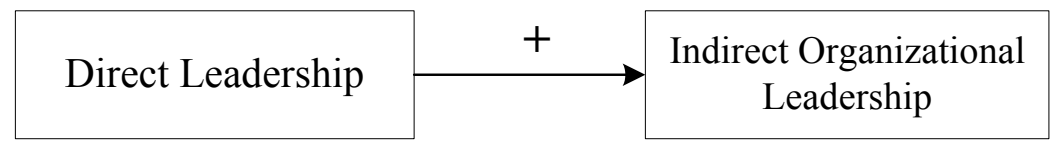

H6. The quality of the relationship between an employee and his or her supervisor will be positively associated with the employee's perception of the organization's procedures and processes (procedural justice).

\begin{tabular}{|l|l|}
\hline Direct Leadership & + \\
\cline { 2 - 2 }
\end{tabular}


H7. The quality of the relationship between an employee and his or her supervisor will be positively associated with the employee's perception of how compensation and rewards are distributed by the organization (distributive justice).

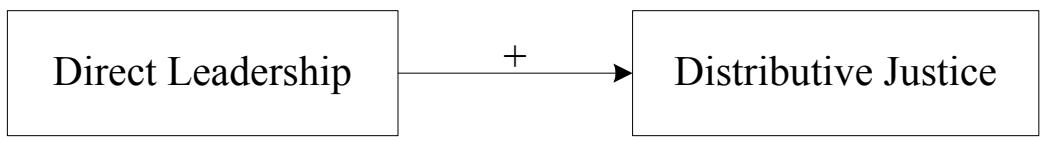

H8. The quality of the relationship between an employee and his or her supervisor will be positively associated with the employee's perception of how well they fit in with the organization's values.

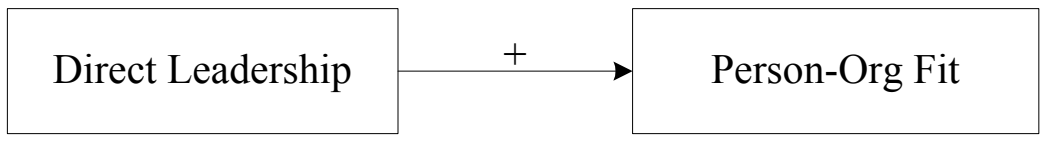

H9. The quality of the relationship between an employee and his or her supervisor will be positively associated with the employee's perception of how well the organization provides the support needed to do their job well.

\begin{tabular}{|l|l|}
\hline Direct Leadership & + \\
Org Support
\end{tabular}

H10. The quality of the relationship between an employee and his or her supervisor will be positively associated with employee job satisfaction.

\begin{tabular}{|l|l|}
\hline Direct Leadership & + \\
\cline { 2 - 2 }
\end{tabular}




\section{Indirect Organizational Leadership}

Indirect organizational leadership refers to the tone and guidance set by senior / executive management. Based on past research, if an employee has a favorable perception of indirect organizational leadership, then a positive relationship should exist.

H11. An employee's perception of the indirect organizational leadership will be positively associated with their perception of the organization's procedures and processes (procedural justice).

\begin{tabular}{|c|c|c|}
\hline $\begin{array}{c}\text { Indirect Organizational } \\
\text { Leadership }\end{array}$ & + & Procedural Justice \\
\cline { 3 - 3 }
\end{tabular}

H12. An employee's perception of the indirect organizational leadership will be positively associated with their perception of how compensation and rewards are distributed by the organization (distributive justice).

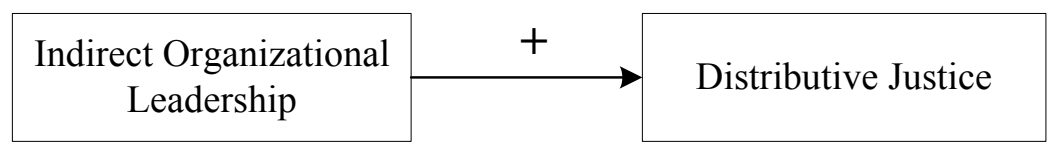

H13. An employee's perception of the indirect organizational leadership will be positively associated with their perception of how well they fit in with the organization's values.

\begin{tabular}{|c|c|c|}
\hline $\begin{array}{c}\text { Indirect Organizational } \\
\text { Leadership }\end{array}$ & + & Person-Org Fit \\
\cline { 3 - 3 }
\end{tabular}


H14. An employee's perception of the indirect organizational leadership will be positively associated with their perception of how well the organization provides the support needed to do their job well.

\begin{tabular}{|c|c|c|}
\hline $\begin{array}{c}\text { Indirect Organizational } \\
\text { Leadership }\end{array}$ & $+\begin{array}{c}\text { Perceived Org } \\
\text { Support }\end{array}$ \\
\cline { 2 - 3 }
\end{tabular}

H15. An employee's perception of the indirect organizational leadership will be positively associated with their sense of job satisfaction.

\begin{tabular}{|c|c|c|}
\hline $\begin{array}{c}\text { Indirect Organizational } \\
\text { Leadership }\end{array}$ & + & Job Satisfaction \\
\cline { 3 - 3 }
\end{tabular}

\section{Organizational Justice}

Organizational justice refers to an employee's sense that he or she is being treated fairly by their organization and its representatives. Two separate measures were used: procedural justice considers the fairness of the processes and procedures put in place by the supervisor or organization, and distributive justice considers the fairness of how compensation is distributed throughout the organization. Based on past research, if an employee feels that he or she is being treated fairly and / or compensated fairly, then a positive relationship should exist with the other organizational variables. However, a negative association would exist with technology deviance. 
H16. An employee's perception of procedural fairness will be positively associated with their perception of on how compensation and rewards are distributed by the organization (distributive justice).

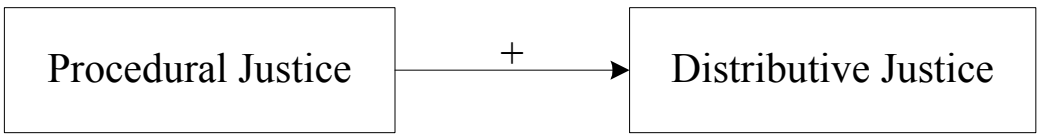

H17. An employee's perception of procedural fairness will be positively associated with their perception of how well they fit in with the organization's values.

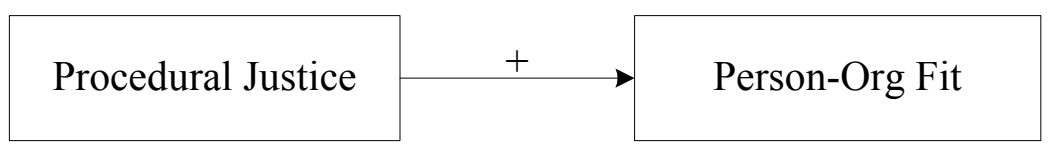

H18. An employee's perception of procedural fairness will be positively associated with their perception of how well the organization provides the support needed to do their job well.

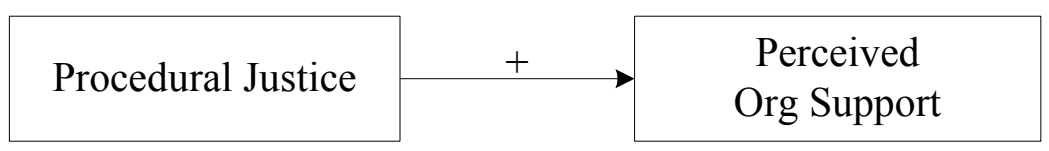

H19. An employee's perception of procedural fairness will be positively associated with their sense of job satisfaction.

\begin{tabular}{|c|c|c|}
\hline Procedural Justice & + & Job Satisfaction \\
\hline
\end{tabular}


H20. An employee's perception of procedural fairness will be negatively associated with a propensity for committing intentional harm against the organization.

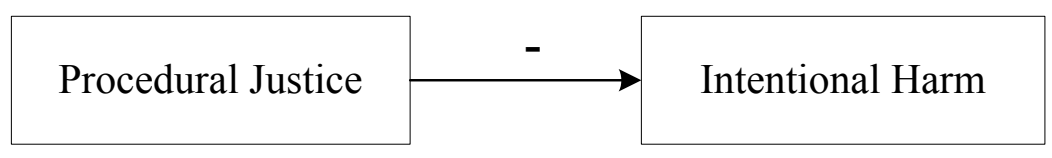

H21. An employee's perception of procedural fairness will be negatively associated with a propensity for misusing an organization's property.

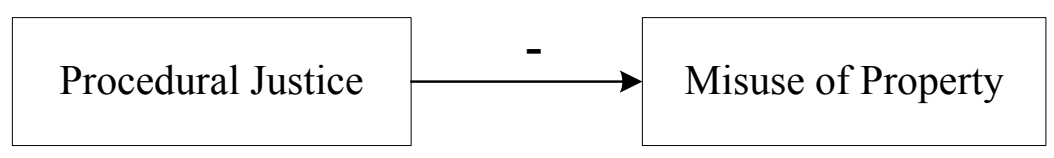

H22. An employee's perception of procedural fairness will be negatively associated with a propensity for working on personal projects during company time.

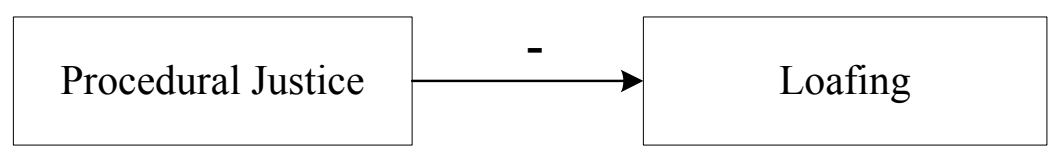

H23. An employee's perception of how fairly compensation and rewards are distributed by the organization will be positively associated with their perception of how well they fit in with the organization's values.

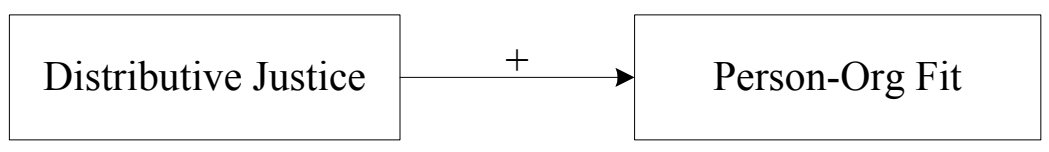


H24. An employee's perception of how fairly compensation and rewards are distributed by the organization will be positively associated with their perception of how well the organization provides the support needed to do their job well.

\begin{tabular}{|l|l|}
\hline Distributive Justice & + \\
\cline { 2 - 3 } & $\begin{array}{c}\text { Perceived } \\
\text { Org Support }\end{array}$ \\
\hline
\end{tabular}

H25. An employee's perception of how fairly compensation and rewards are distributed by the organization will be positively associated with their sense of job satisfaction.

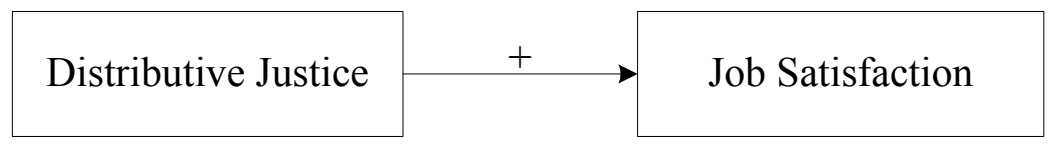

H26. An employee's perception of how fairly compensation and rewards are distributed by the organization will be negatively associated with a propensity for committing intentional harm against the organization.

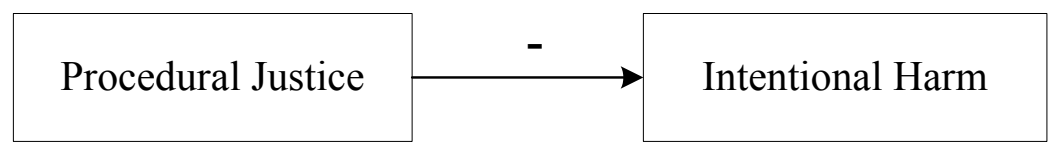

H27. An employee's perception of how fairly compensation and rewards are distributed by the organization will be negatively associated with a propensity for misusing an organization's property.

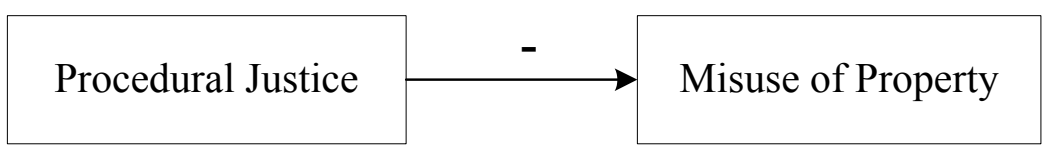


H28. An employee's perception of how fairly compensation and rewards are distributed by the organization will be negatively associated with a propensity for working on personal projects during company time.

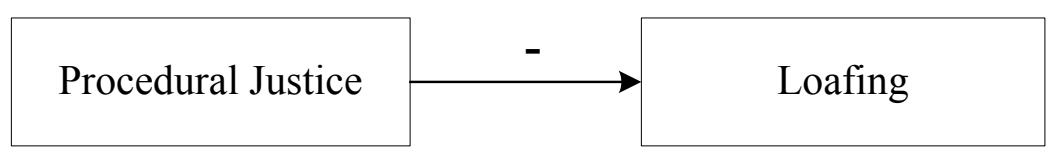

\section{Person-Organizational Fit}

Person-org fit refers to whether an employee thinks that their values match that of the organization. Based on past research, if an employee feels that his or her values are similar to the organization, then a positive relationship should exist with other factors such as perceived organizational support and job satisfaction. However, a negative association would exist with technology deviance.

H29. An employee's perception of how well they fit in with the organization's values will be positively associated with their perception of how well the organization provides the support needed to do their job well.

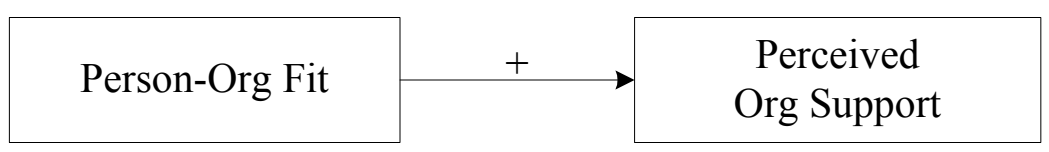

H30. An employee's perception of how well they fit in with the organization's values will be positively associated with their sense of job satisfaction. 


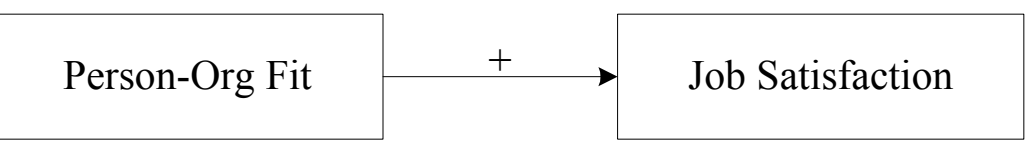

H31. An employee's perception of how well they fit in with the organization's values will be negatively associated with a propensity for committing intentional harm against the organization.

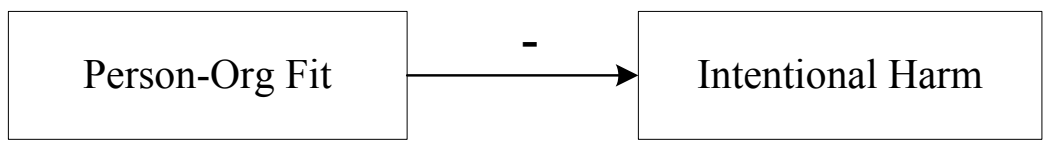

H32. An employee's perception of how well they fit in with the organization's values will be negatively associated with a propensity for misusing an organization's property.

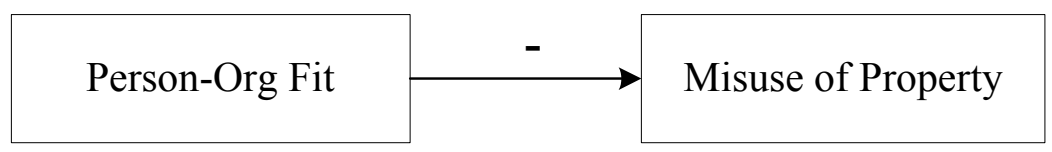

H33. An employee's perception of how well they fit in with the organization's values will be negatively associated with a propensity for working on personal projects during company time.

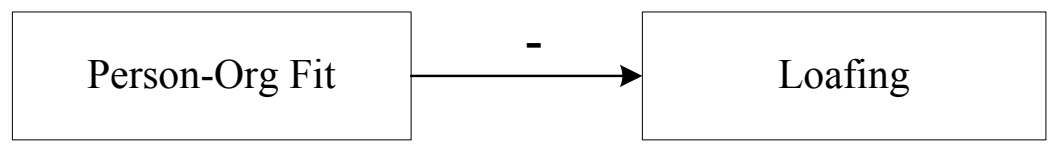




\section{Perceived Organizational Support}

Perceived Organizational Support refers to whether an employee thinks that they are getting the assistance needed to perform their job successfully. Based on past research, if an employee feels that he or she is receiving backing and cooperation from the organization to do a good job, then a positive relationship should exist with other factors such as job satisfaction. However, a negative association would exist with technology deviance.

H34. An employee's perception of how well the organization provides the support needed to do their job well will be positively associated with their sense of job satisfaction.

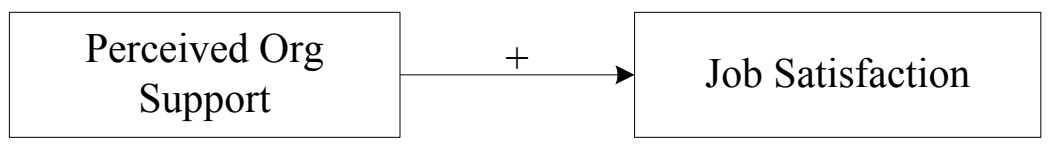

H35. An employee's perception of how well the organization provides the support needed to do their job well will be negatively associated with a propensity for committing intentional harm against the organization.

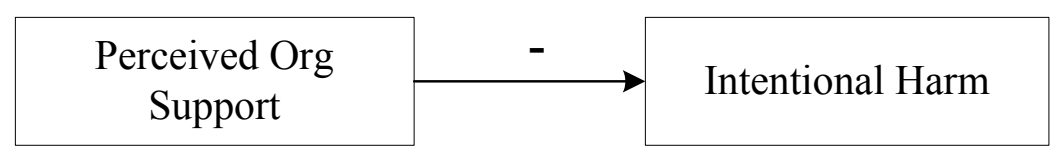

H36. An employee's perception of how well the organization provides the support needed to do their job well will be negatively associated with a propensity for misusing an organization's property. 


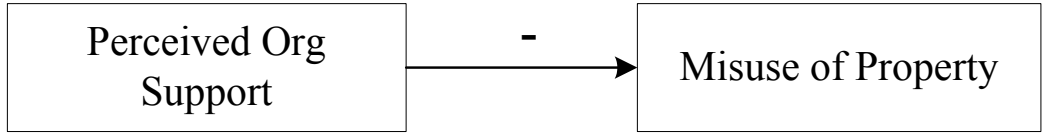

H37. An employee's perception of how well the organization provides the support needed to do their job well will be negatively associated with a propensity for working on personal projects during company time.

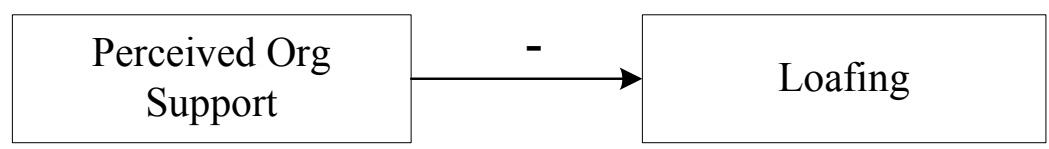

H38. An employee's job satisfaction will be negatively associated with a propensity for misusing an organization's property.

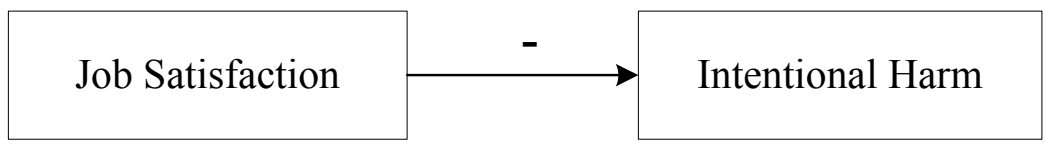

H39. An employee's job satisfaction will be negatively associated with a propensity for misusing an organization's property.

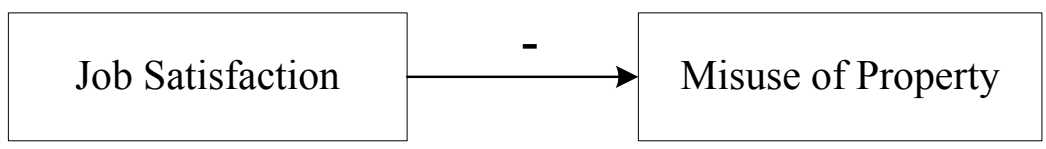

H40. An employee's job satisfaction will be negatively associated with a propensity for working on personal projects during company time.

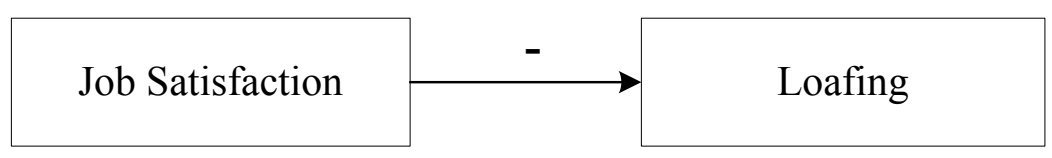




\section{Methods}

Since this study tries to capture the effects of employee interaction, leadership and organizational factors, the target population was employed individuals.

\section{Sampling and Procedure}

The sample for this study was compiled from three sources: graduate business students at a South Florida university and members of two organizations - the $\mathrm{PhD}$ Project and the Academy of Management. Between September and December of 2008, participants were sent an email requesting that they fill out the study questionnaire.

In total, 586 surveys were received, of which 16 exited the survey or did not give consent to use the information. The remaining 570 gave consent and/or attempted to complete all of the questions in the questionnaire.

The survey contained a total of sixty eight items (excluding demographic and consent questions). On closer inspection, an additional 195 surveys had sufficient data missing as to render the overall survey ineffective. Therefore, only 375 surveys were retained for further analysis. The response rate was $26 \%$.

The Mahalanobis distance was calculated via linear regression analysis. Using the chi-square for $\mathrm{df}=68$ of 109.791 , no outliers were detected.

\section{Demographic Information}

The survey was administered online via a third party host site - Survey Monkey. Demographic information was collected age, gender, ethnic background, education, employment status, years working for their supervisor, years working at the same 
organization, profession type and level of computer expertise. Table 2 presents the demographic information for the participants of the survey.

\section{Gender}

Male

Female Age

17 and under

$18-24$

$25-34$

$35-44$

$45-54$

55 and over

No response

Ethnic Background

Asian

Black

Hispanic

White

Other

\section{Education}

Associates

Bachelors

Master

Doctorate

Non-degree

Other

Employment Status

Unemployed

Employed, Part

Employed, Full

Self-Emp, Part

Self-Emp, Full
$144 \quad 38 \%$

$231 \quad 62 \%$

$\begin{array}{rr}1 & 0 \% \\ 22 & 6 \% \\ 116 & 31 \% \\ 118 & 31 \% \\ 91 & 24 \% \\ 25 & 7 \% \\ 2 & 1 \%\end{array}$

$18 \quad 5 \%$

$143 \quad 38 \%$

$76 \quad 20 \%$

$93 \quad 25 \%$

45

\begin{abstract}
$12 \%$
\end{abstract}

$6 \quad 2 \%$

$35 \quad 9 \%$

$177 \quad 47 \%$

$92 \quad 25 \%$

$61 \quad 16 \%$

$4 \quad 1 \%$

$\begin{array}{rr}9 & 2 \% \\ 53 & 14 \% \\ 305 & 81 \% \\ 1 & 0 \% \\ 7 & 2 \%\end{array}$

\section{Occupation Type}

Professional

Service provider

$223 \quad 59 \%$

Manager

Technician

Clerical

Sales

Production

Other

$\begin{array}{rr}8 & 2 \% \\ 46 & 12 \% \\ 9 & 2 \% \\ 8 & 2 \% \\ 13 & 3 \% \\ 2 & 1 \% \\ 66 & 18 \%\end{array}$

\section{Computer Experience}

$\begin{array}{lrr}\text { Beginner } & 5 & 1 \% \\ \text { Intermediate } & 75 & 20 \% \\ \text { Advance } & 226 & 60 \% \\ \text { Expert } & 66 & 18 \% \\ \text { No response } & 3 & 1 \%\end{array}$

Years with the Organization

$<6$ mths

$39 \quad 10 \%$

6 mths to year $\quad 27 \quad 7 \%$

1 to 2 yrs $67 \quad 18 \%$

2 to 4 yrs $\quad 92 \quad 25 \%$

4 to 6 yrs $\quad 56 \quad 15 \%$

6 to $10 \mathrm{yrs} \quad 47 \quad 13 \%$

10 to $15 \mathrm{yrs} \quad 25 \quad 7 \%$

$>15$ yrs 22

Years with Current Supervisor

$<6$ mths

$72 \quad 19 \%$

6 mths to year $\quad 57 \quad 15 \%$

1 to 2 yrs $\quad 88 \quad 23 \%$

2 to 4 yrs $\quad 84 \quad 22 \%$

4 to 6 yrs $\quad 38 \quad 10 \%$

6 to 10 yrs $\quad 20 \quad 5 \%$

10 to $15 \mathrm{yrs} \quad 8 \%$

$>15$ yrs $\quad 8 \quad 2 \%$

Table 2 - Demographic information of the participants 


\section{Data Analysis Preparation}

Before the statistical analysis could be conducted, the data were screened for accuracy and completeness. At the end of the collection period, a complete file was downloaded from Survey Monkey. Because the survey was conducted online, there was no manual entry needed.

The data were assessed for completeness. Surveys with too many missing elements were removed from the final sample. A frequency analysis was conducted to ensure minimum / maximum range was valid, and the data were checked for skewness.

The data file was uploaded into SPSS 15, and the variables were categorized as nominal, ordinal or scale as appropriate. In addition, the variables were labeled appropriately to make the SPSS output easier to interpret.

This study utilized univariate, multivariate and path analytic methods to investigate the causal relationships between the variables. Individual variables were tested using t-tests, ANOVAs and multiple regressions, then grouped into their specific scales. The scales were tested using univariate and multivariate analysis.

Analysis of the data follows in the next section. 


\section{Data Analysis}

\section{Factor Analysis}

A factor analysis was conducted using all of the items in the questionnaire. All of the scales loaded accordingly. Since all of the items, except for technology deviance, came from established scales in the management literature, they were retained in their original groupings for future analysis.

However, the fourteen items that make up the technology deviance scale were subjected to a principal component analysis (PCA) using SPSS. Prior to performing PCA, the suitability of the data for a factor analysis was assessed. Inspection of the correlation matrix revealed the presence of many coefficients of .3 and above. The Kaiser-MeyerOlkin value was .853 , exceeding the recommended value of .6 and Bartlett's Test of Sphericity reached statistical significance, supporting the factorability of the correlation matrix.

Using a varimax rotation, principal component analysis revealed the presence of three components with eigenvalues exceeding 1, explaining $36.6 \%, 13.3 \%$ and $8.8 \%$ of the variance respectively. An inspection of the screeplot revealed a clear break after the third component. Therefore, the three components were retained for further analysis.

The rotated solution revealed the presence of a simple structure, with the three components showing a number of strong loadings and the variables loading substantially on each of the component. Two items did not load at all, and were excluded from further analysis. 


\begin{tabular}{lcc} 
Components & $\begin{array}{c}\text { Variance } \\
\text { Explained }\end{array}$ & $\begin{array}{c}\text { Cronbach's } \\
\text { Alpha }\end{array}$ \\
\hline Tech Dev - Intentional Harm & $36.6 \%$ & 0.757 \\
Tech Dev - Misuse of Property & $13.3 \%$ & 0.783 \\
Tech Dev - Loafing & $8.8 \%$ & 0.726 \\
\cline { 2 - 2 } & $58.7 \%$ &
\end{tabular}

Table 3 - Component Loadings for Technology Deviance scale

The first component, intentional harm, consisted of items relating to actions that were proactively meant to harm the organization such as disrupting the company's computers, taking computer property without permission and posting offensive material in the company's computers.

The second component, misuse of property, consists of items where employees harmed the organization as a by product of their initial action. For example, copying proprietary electronic data or information without the consent of the organization or using a coworker's username or password without their knowledge.

The third component, loafing, consisted of items where the employee spent company time working on personal projects instead of doing the work. For example, surfing the internet at work or using email access at work for personal matters.

\section{Correlations}

The original model proposed a positive association between all of the factors except for the technology deviance variables. The actual relationships between the variables were investigated using Pearson correlation coefficient. A total of 21 factors were analyzed. 


\begin{tabular}{|c|c|c|c|c|c|c|c|c|c|c|c|c|c|c|c|c|c|c|c|c|}
\hline & \begin{tabular}{|c|} 
In \\
Person \\
\end{tabular} & Email & Phone & \begin{tabular}{|c|} 
Instant \\
Messag \\
\end{tabular} & \begin{tabular}{|c|} 
Comp \\
Facility \\
\end{tabular} & Locat & $\begin{array}{l}\text { Time } \\
\text { Zone } \\
\end{array}$ & State & Country & \begin{tabular}{|l|}
$\begin{array}{c}\text { Direct } \\
\text { Leader }\end{array}$ \\
\end{tabular} & \begin{tabular}{|c|} 
Inspir \\
Motivat \\
\end{tabular} & \begin{tabular}{|l|} 
Individ \\
Consid \\
\end{tabular} & \begin{tabular}{|l|} 
Intellect \\
Stimulat \\
\end{tabular} & $\begin{array}{l}\text { Distrib } \\
\text { Justice } \\
\end{array}$ & $\begin{array}{l}\text { Proced } \\
\text { Justice } \\
\end{array}$ & \begin{tabular}{|l|} 
Person \\
Org Fit \\
\end{tabular} & \begin{tabular}{|c|} 
Perc Org \\
Supp \\
\end{tabular} & $\begin{array}{c}\text { Job } \\
\text { Satisf } \\
\end{array}$ & \begin{tabular}{|c|}
$\begin{array}{c}\text { Intention } \\
\text { Harm }\end{array}$ \\
\end{tabular} & \begin{tabular}{|c|} 
Misuse \\
Property \\
\end{tabular} \\
\hline \multicolumn{21}{|l|}{ In Person } \\
\hline Email & $\begin{array}{l}0.46 \\
0.00\end{array}$ & & & & & & & & & & & & & & & & & & & \\
\hline Phone & $\begin{array}{l}0.16 \\
0.00\end{array}$ & $\begin{array}{l}0.11 \\
0.02\end{array}$ & & & & & & & & & & & & & & & & & & \\
\hline $\begin{array}{c}\text { Instant } \\
\text { Message }\end{array}$ & $\begin{array}{l}0.03 \\
0.28\end{array}$ & $\begin{array}{c}-0.03 \\
0.27\end{array}$ & $\begin{array}{l}0.09 \\
0.04\end{array}$ & & & & & & & & & & & & & & & & & \\
\hline $\begin{array}{c}\text { Comp } \\
\text { Facility }\end{array}$ & $\begin{array}{l}0.31 \\
0.00\end{array}$ & $\begin{array}{l}0.19 \\
0.00\end{array}$ & $\begin{array}{l}0.16 \\
0.00\end{array}$ & $\begin{array}{l}0.06 \\
0.13\end{array}$ & & & & & & & & & & & & & & & & \\
\hline Location & $\begin{array}{l}0.30 \\
0.00\end{array}$ & $\begin{array}{l}0.12 \\
0.01\end{array}$ & $\begin{array}{l}0.20 \\
0.00\end{array}$ & $\begin{array}{l}0.08 \\
0.06\end{array}$ & $\begin{array}{l}0.51 \\
0.00\end{array}$ & & & & & & & & & & & & & & & \\
\hline $\begin{array}{l}\text { Time } \\
\text { Zone }\end{array}$ & $\begin{array}{l}0.04 \\
0.20\end{array}$ & $\begin{array}{l}0.05 \\
0.17\end{array}$ & $\begin{array}{l}0.15 \\
0.00\end{array}$ & $\begin{array}{l}0.06 \\
0.12\end{array}$ & $\begin{array}{l}0.28 \\
0.00\end{array}$ & $\begin{array}{l}0.48 \\
0.00\end{array}$ & & & & & & & & & & & & & & \\
\hline State & $\begin{array}{l}0.08 \\
0.07\end{array}$ & $\begin{array}{l}0.02 \\
0.32 \\
\end{array}$ & $\begin{array}{l}0.14 \\
0.00\end{array}$ & $\begin{array}{l}0.07 \\
0.09\end{array}$ & $\begin{array}{l}0.29 \\
0.00\end{array}$ & $\begin{array}{l}0.62 \\
0.00 \\
\end{array}$ & $\begin{array}{l}0.74 \\
0.00 \\
\end{array}$ & & & & & & & & & & & & & \\
\hline Country & $\begin{array}{l}0.09 \\
0.05\end{array}$ & $\begin{array}{l}0.07 \\
0.09\end{array}$ & $\begin{array}{l}0.14 \\
0.00\end{array}$ & $\begin{array}{l}0.07 \\
0.10\end{array}$ & $\begin{array}{l}0.14 \\
0.00\end{array}$ & $\begin{array}{l}0.23 \\
0.00\end{array}$ & $\begin{array}{l}0.40 \\
0.00\end{array}$ & $\begin{array}{l}0.34 \\
0.00\end{array}$ & & & & & & & & & & & & \\
\hline $\begin{array}{l}\text { Direct } \\
\text { Leader }\end{array}$ & $\begin{array}{l}0.08 \\
0.06\end{array}$ & $\begin{array}{l}0.09 \\
0.04\end{array}$ & \begin{tabular}{c|}
-0.07 \\
0.10
\end{tabular} & $\begin{array}{c}-0.02 \\
0.34\end{array}$ & $\begin{array}{c}-0.03 \\
0.29\end{array}$ & $\begin{array}{l}-0.03 \\
0.26\end{array}$ & $\begin{array}{c}-0.03 \\
0.31\end{array}$ & $\begin{array}{l}0.01 \\
0.44\end{array}$ & $\begin{array}{l}-0.07 \\
0.09\end{array}$ & & & & & & & & & & & \\
\hline \begin{tabular}{|c|} 
Inspir \\
Motivat
\end{tabular} & $\begin{array}{l}0.12 \\
0.01\end{array}$ & $\begin{array}{l}0.09 \\
0.04\end{array}$ & $\begin{array}{l}-0.03 \\
0.27 \\
\end{array}$ & $\begin{array}{c}-0.05 \\
0.19 \\
\end{array}$ & $\begin{array}{l}0.06 \\
0.14\end{array}$ & $\begin{array}{l}-0.05 \\
0.16 \\
\end{array}$ & $\begin{array}{c}-0.07 \\
0.10 \\
\end{array}$ & $\begin{array}{c}-0.02 \\
0.39 \\
\end{array}$ & $\begin{array}{l}-0.06 \\
0.13 \\
\end{array}$ & $\begin{array}{l}0.23 \\
0.00\end{array}$ & & & & & & & & & & \\
\hline \begin{tabular}{|c|} 
Individ \\
Consider
\end{tabular} & $\begin{array}{l}0.07 \\
0.10\end{array}$ & $\begin{array}{l}0.07 \\
0.10\end{array}$ & \begin{tabular}{|c|}
-0.08 \\
0.07 \\
\end{tabular} & $\begin{array}{l}0.00 \\
0.49\end{array}$ & $\begin{array}{c}-0.06 \\
0.12\end{array}$ & $\begin{array}{c}-0.10 \\
0.02\end{array}$ & $\begin{array}{c}-0.08 \\
0.07\end{array}$ & $\begin{array}{c}-0.11 \\
0.01\end{array}$ & $\begin{array}{l}-0.07 \\
0.07\end{array}$ & $\begin{array}{l}0.35 \\
0.00\end{array}$ & $\begin{array}{l}0.62 \\
0.00\end{array}$ & & & & & & & & & \\
\hline \begin{tabular}{|l|} 
Intellect \\
Stimulat \\
\end{tabular} & $\begin{array}{l}0.13 \\
0.01\end{array}$ & $\begin{array}{l}0.15 \\
0.00\end{array}$ & \begin{tabular}{|c|}
-0.09 \\
0.05 \\
\end{tabular} & $\begin{array}{l}-0.05 \\
0.16\end{array}$ & $\begin{array}{l}0.02 \\
0.34\end{array}$ & $\begin{array}{c}-0.09 \\
0.04\end{array}$ & $\begin{array}{c}-0.10 \\
0.03 \\
\end{array}$ & $\begin{array}{c}-0.08 \\
0.07 \\
\end{array}$ & $\begin{array}{c}-0.04 \\
0.21 \\
\end{array}$ & $\begin{array}{l}0.31 \\
0.00\end{array}$ & $\begin{array}{l}0.52 \\
0.00\end{array}$ & $\begin{array}{l}0.64 \\
0.00\end{array}$ & & & & & & & & \\
\hline $\begin{array}{l}\text { Distrib } \\
\text { Justice }\end{array}$ & $\begin{array}{c}-0.05 \\
0.19\end{array}$ & $\begin{array}{l}0.01 \\
0.42\end{array}$ & \begin{tabular}{l|}
0.02 \\
0.38
\end{tabular} & $\begin{array}{c}-0.01 \\
0.44\end{array}$ & $\begin{array}{c}-0.09 \\
0.03\end{array}$ & $\begin{array}{c}-0.11 \\
0.01\end{array}$ & $\begin{array}{c}-0.08 \\
0.06\end{array}$ & $\begin{array}{c}-0.07 \\
0.09\end{array}$ & $\begin{array}{c}-0.04 \\
0.25\end{array}$ & $\begin{array}{l}0.34 \\
0.00\end{array}$ & $\begin{array}{l}0.28 \\
0.00\end{array}$ & $\begin{array}{l}0.35 \\
0.00\end{array}$ & $\begin{array}{l}0.31 \\
0.00\end{array}$ & & & & & & & \\
\hline $\begin{array}{l}\text { Proced } \\
\text { Justice }\end{array}$ & $\begin{array}{l}0.04 \\
0.20\end{array}$ & $\begin{array}{l}0.13 \\
0.01\end{array}$ & \begin{tabular}{|c|}
-0.03 \\
0.25 \\
\end{tabular} & $\begin{array}{l}-0.04 \\
0.22\end{array}$ & $\begin{array}{c}-0.08 \\
0.07\end{array}$ & $\begin{array}{c}-0.08 \\
0.06\end{array}$ & $\begin{array}{c}-0.06 \\
0.14\end{array}$ & $\begin{array}{c}-0.03 \\
0.27\end{array}$ & $\begin{array}{c}-0.02 \\
0.32\end{array}$ & $\begin{array}{l}0.43 \\
0.00\end{array}$ & $\begin{array}{l}0.43 \\
0.00\end{array}$ & $\begin{array}{l}0.57 \\
0.00\end{array}$ & $\begin{array}{l}0.56 \\
0.00\end{array}$ & $\begin{array}{l}0.49 \\
0.00\end{array}$ & & & & & & \\
\hline $\begin{array}{l}\text { Person } \\
\text { Org Fit }\end{array}$ & $\begin{array}{l}0.02 \\
0.38\end{array}$ & $\begin{array}{l}0.06 \\
0.14\end{array}$ & \begin{tabular}{|c|}
-0.07 \\
0.08 \\
\end{tabular} & $\begin{array}{l}0.03 \\
0.31\end{array}$ & $\begin{array}{c}-0.04 \\
0.20\end{array}$ & $\begin{array}{c}-0.14 \\
0.00\end{array}$ & $\begin{array}{c}-0.09 \\
0.04\end{array}$ & $\begin{array}{r}-0.08 \\
0.05\end{array}$ & $\begin{array}{c}-0.06 \\
0.12\end{array}$ & $\begin{array}{l}0.40 \\
0.00\end{array}$ & $\begin{array}{l}0.46 \\
0.00\end{array}$ & $\begin{array}{l}0.55 \\
0.00\end{array}$ & $\begin{array}{l}0.53 \\
0.00\end{array}$ & $\begin{array}{l}0.47 \\
0.00\end{array}$ & $\begin{array}{l}0.57 \\
0.00\end{array}$ & & & & & \\
\hline Perc Org & 0.06 & 0.06 & \begin{tabular}{|l|}
-0.08 \\
\end{tabular} & 0.04 & -0.07 & -0.09 & -0.05 & -0.02 & 0.02 & 0.47 & 0.43 & 0.59 & 0.52 & $\overline{0.53}$ & 0.63 & 0.63 & & & & \\
\hline Support & 0.12 & 0.11 & 0.06 & 0.23 & 0.09 & 0.03 & 0.16 & 0.37 & 0.36 & 0.00 & 0.00 & 0.00 & 0.00 & 0.00 & 0.00 & 0.00 & & & & \\
\hline \begin{tabular}{|c|} 
Job \\
Satisfac
\end{tabular} & $\begin{array}{l}0.00 \\
0.49\end{array}$ & $\begin{array}{l}0.03 \\
0.29\end{array}$ & \begin{tabular}{|c|}
-0.07 \\
0.10 \\
\end{tabular} & $\begin{array}{l}0.02 \\
0.36\end{array}$ & $\begin{array}{c}-0.09 \\
0.05\end{array}$ & $\begin{array}{c}-0.13 \\
0.01\end{array}$ & $\begin{array}{c}-0.08 \\
0.06\end{array}$ & $\begin{array}{c}-0.06 \\
0.14\end{array}$ & $\begin{array}{l}-0.09 \\
0.04\end{array}$ & $\begin{array}{l}0.55 \\
0.00\end{array}$ & $\begin{array}{l}0.32 \\
0.00\end{array}$ & $\begin{array}{l}0.47 \\
0.00\end{array}$ & $\begin{array}{l}0.44 \\
0.00\end{array}$ & $\begin{array}{l}0.62 \\
0.00\end{array}$ & $\begin{array}{l}0.56 \\
0.00\end{array}$ & $\begin{array}{l}0.62 \\
0.00\end{array}$ & $\begin{array}{l}0.65 \\
0.00\end{array}$ & & & \\
\hline \begin{tabular}{|c|} 
Intention \\
Harm
\end{tabular} & $\begin{array}{l}0.04 \\
0.23\end{array}$ & $\begin{array}{l}0.03 \\
0.26\end{array}$ & \begin{tabular}{|c|}
-0.04 \\
0.24
\end{tabular} & $\begin{array}{c}-0.02 \\
0.33\end{array}$ & $\begin{array}{c}-0.07 \\
0.08\end{array}$ & $\begin{array}{c}-0.03 \\
0.28\end{array}$ & $\begin{array}{l}0.00 \\
0.49\end{array}$ & $\begin{array}{c}-0.01 \\
0.40\end{array}$ & $\begin{array}{c}-0.09 \\
0.04\end{array}$ & $\begin{array}{l}0.02 \\
0.37\end{array}$ & $\begin{array}{l}0.05 \\
0.15\end{array}$ & $\begin{array}{l}0.05 \\
0.19\end{array}$ & $\begin{array}{l}0.06 \\
0.12\end{array}$ & $\begin{array}{l}0.06 \\
0.12\end{array}$ & $\begin{array}{c}-0.10 \\
0.02\end{array}$ & $\begin{array}{l}0.05 \\
0.15\end{array}$ & $\begin{array}{l}0.00 \\
0.47\end{array}$ & $\begin{array}{l}0.04 \\
0.22\end{array}$ & & \\
\hline Misuse & 0.06 & 0.04 & -0.04 & -0.02 & 0.01 & 0.05 & -0.03 & 0.01 & -0.02 & 0.07 & 0.05 & 0.02 & 0.06 & 0.02 & 0.08 & 0.02 & -0.03 & 0.06 & 0.48 & \\
\hline Property & 0.14 & 0.23 & 0.23 & 0.32 & 0.45 & 0.19 & 0.28 & 0.42 & 0.35 & 0.09 & 0.15 & 0.32 & 0.14 & 0.36 & 0.07 & 0.32 & 0.27 & 0.11 & 0.00 & \\
\hline Loafing & $\begin{array}{l}0.06 \\
0.12\end{array}$ & $\begin{array}{l}0.08 \\
0.07\end{array}$ & $\begin{array}{l}0.04 \\
0.25\end{array}$ & $\begin{array}{c}-0.04 \\
0.23\end{array}$ & $\begin{array}{l}0.02 \\
0.33\end{array}$ & $\begin{array}{c}-0.04 \\
0.25\end{array}$ & $\begin{array}{c}-0.03 \\
0.27\end{array}$ & $\begin{array}{r}-0.05 \\
0.16\end{array}$ & $\begin{array}{c}-0.03 \\
0.29\end{array}$ & $\begin{array}{c}-0.01 \\
0.39\end{array}$ & $\begin{array}{l}0.00 \\
0.49\end{array}$ & $\begin{array}{l}0.00 \\
0.48\end{array}$ & $\begin{array}{l}0.07 \\
0.09\end{array}$ & $\begin{array}{c}-0.06 \\
0.13\end{array}$ & $\begin{array}{c}-0.07 \\
0.08\end{array}$ & $\begin{array}{c}-0.10 \\
0.03\end{array}$ & $\begin{array}{c}-0.06 \\
0.13\end{array}$ & $\begin{array}{c}-0.08 \\
0.06\end{array}$ & $\begin{array}{l}0.24 \\
0.00\end{array}$ & $\begin{array}{l}0.22 \\
0.00\end{array}$ \\
\hline
\end{tabular}

Table 4 - Study Correlations 


\section{Degree of Virtuality}

All of the social interaction variables had a positive, significant correlation $(\mathrm{p}<.05)$ with the physical proximity variables except for one - instant messaging with supervisor.

A few interesting analogies can be drawn from the correlations. Phone communication (synchronous) was positively correlated with all of the physical proximity variables, despite email communication (asynchronous) being more convenient when the employee and the supervisor were not based out of the same country or time zone. In addition, the three forms of communication - in person, email and phone - were found to be significant when the employee and the supervisor were based from the same building or same location (i.e., complex). This could be an indication that physical proximity does beget higher frequency and variability of communication.

Leadership and perception factors. The 'in person' item had a positively, significant relationship with inspirational motivation and intellectual stimulation. The email item had a positively, significant relationship with direct leadership, inspirational motivation and intellectual stimulation.

However, phone interaction had a negatively, significant relationship with intellectual stimulation, and instant message interaction had no significant correlation with any of the leadership factors.

With the perception factors, only procedural justice had a significant relationship with email interaction. Unexpectedly, the physical proximity had negatively, significant relationships with several leadership and perception factors including individualized consideration, intellectual stimulation, distributive justice, person-organization fit, 
perceived organizational support and job satisfaction. Only procedural justice had no significant relationship with the physical proximity factors.

\section{Direct and Indirect organizational leadership}

All of the direct and indirect organizational leadership factors (inspirational motivation, intellectual stimulation and individualized consideration) were positive, significantly correlated with the perception factors $(p<.000)$ : distributive justice, procedural justice, person-organization fit, perceived organizational support and job satisfaction. This is consistent with existing research.

\section{Technology Deviance Factors}

Of the technology deviance factors, intentional harm had a significantly, negative relationship with 'based in same country' and procedural justice. Loafing only had a significantly, negative relationship with person-organization fit. Misuse of property did not have a significant correlation with any factor.

Amongst the technology deviance factors, all three were positively, significantly correlated.

\section{Instances of Technology Deviance}

Oftentimes, research that deals with negative behaviors or attitudes suffer from 'social desirability' concerns; specifically, the concern that respondents will not feel comfortable admitting to negative behaviors, even if they manifest the behavior. Due to 
this concern, a dummy variable was created to measure whether a specific behavior (i.e., individual item) has been acknowledged.

\begin{tabular}{|c|c|c|c|}
\hline \multicolumn{2}{|c|}{ Intentional Harm } & \multirow{2}{*}{$\begin{array}{c}\text { Admission } \\
8\end{array}$} & \multirow{2}{*}{$\begin{array}{c}\begin{array}{c}\text { \% of } \\
\text { Responses }\end{array} \\
2 \%\end{array}$} \\
\hline th1 & Disrupted the company's computer in order to avoid doing work & & \\
\hline th2 & $\begin{array}{l}\text { Taken computer property (i.e., hardware, software, etc.) from } \\
\text { work without permission }\end{array}$ & 24 & $6 \%$ \\
\hline th3 & $\begin{array}{l}\text { Shared confidential information about the company with an } \\
\text { unauthorized person }\end{array}$ & 33 & $9 \%$ \\
\hline th4 & $\begin{array}{l}\text { Delete someone's computer files at work without his/her } \\
\text { permission }\end{array}$ & 10 & $3 \%$ \\
\hline th5 & Used someone's username or password without their knowledge & 14 & $4 \%$ \\
\hline th6 & $\begin{array}{l}\text { Made someone's email or voice message public without his/her } \\
\text { permission }\end{array}$ & 25 & $7 \%$ \\
\hline th7 & Email a hurtful message about someone at work & 27 & $7 \%$ \\
\hline \multicolumn{4}{|c|}{ Misuse of Property } \\
\hline $\operatorname{tm} 1$ & $\begin{array}{l}\text { Copy data or information from company's computer without the } \\
\text { consent of the organization }\end{array}$ & 42 & $11 \%$ \\
\hline $\operatorname{tm} 2$ & $\begin{array}{l}\text { Use software on the company's computer that you know is } \\
\text { unlicensed }\end{array}$ & 56 & $15 \%$ \\
\hline $\operatorname{tm} 3$ & $\begin{array}{l}\text { Copy information from another source (i.e., internet) instead of } \\
\text { doing the work yourself }\end{array}$ & 57 & $15 \%$ \\
\hline $\operatorname{tm} 4$ & Posted or emailed offensive material via the company's computer & 21 & $6 \%$ \\
\hline \multicolumn{4}{|c|}{ Loafing } \\
\hline tll & Spend company time surfing the internet instead of working & 307 & $82 \%$ \\
\hline t12 & Use email access at work for personal matters & 326 & $87 \%$ \\
\hline $\mathrm{tl} 3$ & $\begin{array}{l}\text { Work on a personal project during working hours on the } \\
\text { company's computer }\end{array}$ & 225 & $60 \%$ \\
\hline
\end{tabular}

\section{Table 5 - Respondent Admission to Technology Deviance}

Table 5 shows the breakdown of the individual questions and the number of respondents that admitted to the behavior in the past twelve months. The percentage of respondents, who admitted to intentionally harming the organization, ranged from $2 \%$ to $9 \%$. These numbers can be of big concern to an organization's leadership because it 
demonstrates that employees are willing share confidential information with unauthorized persons, made peer or supervisor messages public without consent and emailed hurtful messages at work. All of these factors leave an organization vulnerable to potential legal liability.

In the 'misuse of property' category, the percentages increased, and ranged from $6 \%$ to $15 \%$. Employees in the sample admitted to copying data from the organization's computer with authorization, copying information from an outside source and passing it off as their own (plagiarism), posting offensive information on the company's computers and using unlicensed software at work. Each of these factors contribute to a hostile, work environment as well as leaving the organization exposed and vulnerable to lawsuits from employees and external players.

Finally, the loafing category was the most alarming. More than half of the respondents acknowledge spending paid, company time doing something other than work. For example, over $80 \%$ admitted to using company resources (i.e., internet and email access) to avoid work. In addition to the impacting the company's performance, these employees are stealing resources and money (i.e., wages) from the organization.

\section{Path Analysis}

Path analysis regressions were conducted to ascertain the causal effects between employee interaction, leadership, perceptions and technology deviance. Twenty six paths (Figure 7) were found to be significant $(p<.10)$. 


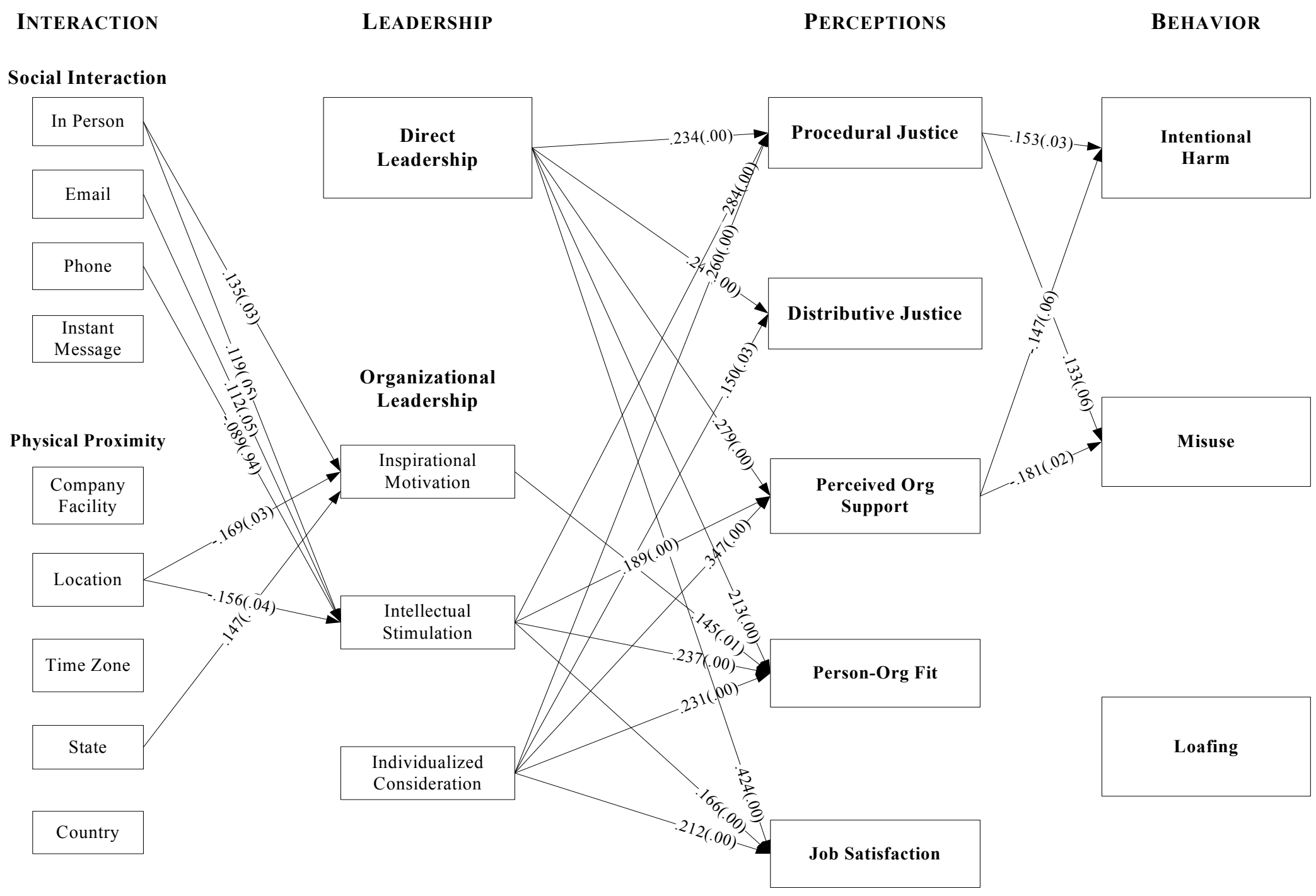

Figure 7 - Path Analysis of Research Model 


\section{Social Interaction}

The four significant paths found between social interaction and organizational leadership, of which three were positive: in-person and inspirational motivation (beta $=$ $.135, \mathrm{p}=.030)$, in-person interaction and intellectual stimulation $($ beta $=.119, \mathrm{p}=.05 \mathrm{e})$, email interaction and intellectual stimulation (beta $=.112, \mathrm{p}=.053$ ). The path between phone interaction and intellectual stimulation was negative (beta $=-.089, \mathrm{p}=.094)$.

\section{Physical Proximity}

The two of significant paths found between physical proximity and organizational leadership were negative: location and inspirational motivation (beta $=-.169, \mathrm{p}=.025)$ and location and intellectual stimulation (beta $=-.156, \mathrm{p}=.037$ ). The third path between state and inspirational motivation (beta $=.147, \mathrm{p}=.090$ ), was positive.

\section{Direct Leadership}

The five significant paths found between direct leadership and the employee perceptions were positive: direct leadership and procedural justice (beta $=.234, \mathrm{p}=.000$ ), distributive justice (beta $=.242, \mathrm{p}=.000)$, person-organization fit (beta $=.213, \mathrm{p}=.000)$, perceived organizational support (beta $=.279, \mathrm{p}=.000)$, and job satisfaction (beta $=.424$, $\mathrm{p}=.000)$.

\section{Organizational Leadership}

Ten positive, significant paths were found between organizational leadership and the employee perceptions. One path was found for inspirational motivation and person- 
organization fit (beta $=.145, \mathrm{p}=.006)$.

Four significant paths were found for intellectual stimulation: procedural justice $($ beta $=.284, \mathrm{p}=.000)$, perceived organizational support $($ beta $=.189, \mathrm{p}=.000)$, personorganization fit (beta $=.247, \mathrm{p}=.000)$ and job satisfaction $($ beta $=.166, \mathrm{p}=.002)$.

Five significant paths were found for individualized consideration: distributive justice $($ beta $=.150, \mathrm{p}=.029)$, procedural justice $($ beta $=.260, \mathrm{p}=.000)$, perceived organizational support $($ beta $=.347, \mathrm{p}=.000)$, person-organization fit (beta $=.231, \mathrm{p}=$ $.000)$ and job satisfaction (beta $=.212, \mathrm{p}=.000)$.

\section{Employee Perceptions}

Two positive, significant paths found for procedural justice: one with deviance intentional harm $($ beta $=.153, \mathrm{p}=.031)$ and the other with deviance - misuse of property (beta $=.133, \mathrm{p}=.062)$. The two negative, significant paths were for perceived organizational support: deviance - intentional harm (beta $=-.147, \mathrm{p}=.062)$ and perceived organizational support and deviance - misuse $($ beta $=-.181, p=.021)$.

\section{Stepwise Regression}

Beyond the variables that were significant as part of the path analysis, a stepwise regression analysis was conducted to assess the ability of the interaction and perception variables factors to predict propensity for deviant behavior. Preliminary analyses were conducted to ensure no violation of normality, linearity, multicollinearity and homoscedasiticy. 
All of the independent variables were entered into a stepwise regression with each of the dependent deviance variables. Only one dependent variable had a significant factor load. Procedural justice explained $1 \%$ of the variance for intentional harm, $\mathrm{R}$ square $=$ $.011, F(1,370)=4.116, p<.000$.

\section{T-Tests for Gender and Employment Status}

\section{Gender Differences}

A series of independent-samples $t$ test was conducted to evaluate the role of gender, if any, in this study. The $t$ tests were significant for in-person and phone interaction with the supervisor, as well as for facility proximity, intentional harm and misuse of property. The findings are summarized in Table 6.

\begin{tabular}{|c|c|c|c|c|c|c|c|}
\hline \multirow{2}{*}{\multicolumn{8}{|c|}{$\frac{\text { Variable }}{\text { In-person Interaction }}$}} \\
\hline & & & & & & & \\
\hline Male & 2.97 & 1.45 & \multirow{2}{*}{-1.989} & \multirow{2}{*}{0.048} & \multirow{2}{*}{-0.620} & \multirow{2}{*}{-0.003} & \multirow{2}{*}{0.010} \\
\hline Female & 3.28 & 1.52 & & & & & \\
\hline \multicolumn{8}{|c|}{ Email Interaction } \\
\hline Male & 2.70 & 1.83 & \multirow{2}{*}{-2.932} & \multirow{2}{*}{0.004} & \multirow{2}{*}{-0.976} & \multirow{2}{*}{-0.192} & \multirow{2}{*}{0.023} \\
\hline Female & 3.29 & 1.95 & & & & & \\
\hline \multicolumn{8}{|c|}{ Same Company Facility } \\
\hline Male & 3.76 & 1.14 & \multirow{2}{*}{-2.821} & \multirow{2}{*}{0.005} & \multirow{2}{*}{-0.567} & \multirow{2}{*}{-0.101} & \multirow{2}{*}{0.021} \\
\hline Female & 4.09 & 1.10 & & & & & \\
\hline \multicolumn{8}{|c|}{ Deviance - Intentional Harm } \\
\hline Male & 1.22 & 0.63 & \multirow{2}{*}{2.305} & \multirow{2}{*}{0.022} & \multirow{2}{*}{0.019} & \multirow{2}{*}{0.239} & \multirow{2}{*}{0.014} \\
\hline Female & 1.09 & 0.30 & & & & & \\
\hline \multicolumn{8}{|c|}{ Deviance - Misuse of Property } \\
\hline Male & 1.13 & 0.51 & \multirow{2}{*}{2.222} & \multirow{2}{*}{0.028} & \multirow{2}{*}{0.011} & \multirow{2}{*}{0.184} & \multirow{2}{*}{0.013} \\
\hline Female & 1.03 & 0.18 & & & & & \\
\hline
\end{tabular}

Table 6 - $t$ test summary for Gender and Technology Deviance

For in-person interaction, the difference between men $(M=2.97, S D=1.45)$ and women, $M=3.28, S D=1.52 ; t(315.62)=-1.989, p=.048$ (two tailed). The $95 \%$ 
confidence interval for the difference in means ranged from -.620 to -.003. The magnitude of the difference in the means was small (eta squared $=.010$ ).

For phone interaction, the difference between men $(M=2.70, S D=1.83)$ and women, $M=3.29, S D=1.95 ; t(317.28)=-2.932, p=.004$ (two tailed). The $95 \%$ confidence interval for the difference in means ranged from -.976 to -.192. The magnitude of the difference in the means was small (eta squared $=.023$ ).

For same facility proximity, the difference between men $(M=3.76, S D=1.14)$ and women, $M=4.09, S D=1.10 ; t(373)=-2.821, p=.005$ (two tailed). The $95 \%$ confidence interval for the difference in means ranged from -.567 to -.101 . The magnitude of the difference in the means was small (eta squared $=.021$ ).

For intentional harm deviance, the difference between men $(M=1.22, S D=0.63)$ and women, $M=1.09, S D=0.30 ; t(183.45)=-2.305, p=.022($ two tailed $)$. The $95 \%$ confidence interval for the difference in means ranged from .019 to .239 . The magnitude of the difference in the means was small (eta squared $=.014$ ).

For misuse of property deviance, the difference between men $(M=1.13, S D=$ 0.51 ) and women, $M=1.03, S D=0.18 ; t(166.72)=2.222, p=.028$ (two tailed). The $95 \%$ confidence interval for the difference in means ranged from .011 to .184. The magnitude of the difference in the means was small (eta squared $=.013$ ).

\section{Employment Status Differences}

An independent-samples $t$ test was conducted to evaluate the role of employment status, if any, in this study. The $t$ tests were significant for in-person and phone 
interaction with the supervisor, as well as for facility proximity, intentional harm and misuse of property. The findings are summarized in Table 7.

\begin{tabular}{|c|c|c|c|c|c|c|c|}
\hline \multirow{2}{*}{\multicolumn{8}{|c|}{$\begin{array}{l}\text { Variable } \\
\text { Same Company Facility }\end{array}$}} \\
\hline & & & & & & & \\
\hline Part-time & 3.61 & 1.26 & \multirow{2}{*}{-2.724} & \multirow{2}{*}{0.008} & \multirow{2}{*}{-0.761} & \multirow{2}{*}{-0.119} & \multirow{2}{*}{0.020} \\
\hline Full-time & 4.05 & 1.08 & & & & & \\
\hline \multicolumn{8}{|c|}{ 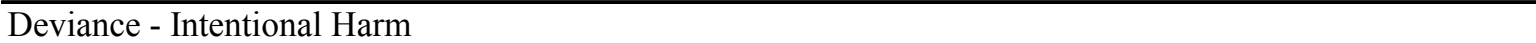 } \\
\hline Part-time & 1.30 & 0.74 & \multirow{2}{*}{2.176} & \multirow{2}{*}{0.033} & \multirow{2}{*}{0.017} & \multirow{2}{*}{0.377} & \multirow{2}{*}{0.013} \\
\hline Full-time & 1.10 & 0.35 & & & & & \\
\hline \multicolumn{8}{|c|}{ Deviance - Misuse of Property } \\
\hline Part-time & 1.21 & 0.67 & \multirow{2}{*}{2.126} & \multirow{2}{*}{0.037} & \multirow{2}{*}{0.011} & \multirow{2}{*}{0.333} & \multirow{2}{*}{0.012} \\
\hline Full-time & 1.04 & 0.20 & & & & & \\
\hline
\end{tabular}

Table 7 - $t$ test summary for Employment Status and Technology Deviance

For same facility proximity, the difference between part-time employees $(M=$ 3.61, $S D=1.26)$ and full-time employees, $M=4.05, S D=1.08 ; t(95.32)=-2.724, p=$ .008 (two tailed). The 95\% confidence interval for the difference in means ranged from .761 to -.119 . The magnitude of the difference in the means was small (eta squared $=$ $.020)$.

For intentional harm deviance, the difference between part-time employees $(M=$ $1.30, S D=0.74)$ and full-time employees, $M=1.10, S D=0.35 ; t(77.35)=2.176, p=$ .017 (two tailed). The 95\% confidence interval for the difference in means ranged from .017 to .377 . The magnitude of the difference in the means was small (eta squared $=$ $.013)$.

For misuse of property deviance, the difference between part-time employees ( $M$ $=1.21, S D=0.67)$ and full-time employees, $M=1.04, S D=0.20 ; t(72.75)=2.126, p=$ 
.037 (two tailed). The 95\% confidence interval for the difference in means ranged from .011 to .333 . The magnitude of the difference in the means was small (eta squared $=$ $.012)$.

\section{Analysis of Variance}

A series of one-way between-groups analysis of variance were conducted to explore the impact of technology deviance on age, race, computer experience, education and social interaction and physical proximity. Table 8 shows the variables there had a significant impact on the different technology deviance factors. 


\section{Technology Deviance - Intentional Harm}

\begin{tabular}{|c|c|c|c|c|c|c|}
\hline TED_HARM & $M$ & $S D$ & df & $\boldsymbol{F}$ & p value & $\begin{array}{c}\text { eta } \\
\text { squared }\end{array}$ \\
\hline \multicolumn{3}{|c|}{ Instant Messaging communication with supervisor } & 5 & 2.741 & 0.019 & 0.04 \\
\hline Once a Day & 1.545 & 1.214 & & & & \\
\hline Several Times a Day & 1.122 & 0.398 & & & & \\
\hline Once a Day & 1.545 & 1.214 & & & & \\
\hline Once a Month & 1.200 & 0.775 & & & & \\
\hline Based in Same Country as supervisor & & & 3 & 6.295 & 0.000 & 0.05 \\
\hline $25 \%$ & 2.500 & 2.121 & & & & \\
\hline $50 \%$ & 1.000 & 0.000 & & & & \\
\hline $25 \%$ & 2.500 & 2.121 & & & & \\
\hline $75 \%$ & 1.111 & 0.487 & & & & \\
\hline $25 \%$ & 2.500 & 2.121 & & & & \\
\hline $100 \%$ & 1.132 & 0.428 & & & & \\
\hline Computer Experience & & & 3 & 7.003 & 0.000 & $\overline{0.05}$ \\
\hline Beginners & 2.000 & 1.732 & & & & \\
\hline Intermediates & 1.093 & 0.293 & & & & \\
\hline Beginners & 2.000 & 1.732 & & & & \\
\hline Advanced & 1.115 & 0.416 & & & & \\
\hline Beginners & 2.000 & 1.732 & & & & \\
\hline Experts & 1.197 & 0.503 & & & & \\
\hline Degree Completed & & & 5 & 4.045 & 0.001 & 0.05 \\
\hline Associates & 1.667 & 1.633 & & & & \\
\hline Bachelors & 1.029 & 0.169 & & & & \\
\hline Associates & 1.667 & 1.633 & & & & \\
\hline Professional Degree & 1.076 & 0.305 & & & & \\
\hline Other & 1.750 & 0.500 & & & & \\
\hline Bachelors & 1.029 & 0.169 & & & & \\
\hline
\end{tabular}

Table 8 - Analysis of variance for Technology Deviance - Intentional Harm

Instant messaging with supervisor. Respondents of the social interaction item (sd4) were divided into six groups according to method of communication: several times a day, once a day, several times a week, once a week, once a month or never. There was a statistically significant difference at the $\mathrm{p}<.05$ level in TED_HARM scales for three of the groups: $F(5)=2.741, p=.019$. The difference in mean scores between the groups was moderate. The effect size, calculated using eta squared, was .04 (moderate effect). 
Post-hoc comparisons indicate that the mean score for 'once a day' was significantly different from 'several times a day' and 'once a month'.

Based in the same country. Respondents of the physical proximity item (gd5) were divided into five groups according to the amount of time the employee and supervisor were based in the same country: never, $25 \%$ of the time, $50 \%$ of the time, $75 \%$ of the time, and $100 \%$ of the time. There was a statistically significant difference at the $\mathrm{p}$ $<.05$ level in the TED_HARM scale for three of the groups: $F(3)=6.925, p=.000$. The difference in mean scores between the groups was moderate. The effect size, calculated using eta squared, was .05 (moderate effect). Post-hoc comparisons indicate that the mean score for those being in the same country as their supervisor for $25 \%$ of the time was significantly different those at $50 \%$ of the time, $75 \%$ of the time and $100 \%$ of the time.

Computer experience. Respondents of the computer experience item (comp_exp) were divided into four groups according to their self-identified level of computer experience: beginner, intermediate, advanced and expert. There was a statistically significant difference at the $\mathrm{p}<.05$ level in TED_HARM scales for all four groups: $F(3)=7.003, p=.000$. The difference in mean scores between the groups was moderate. The effect size, calculated using eta squared, was .05 (moderate effect). Posthoc comparisons indicate that the mean score for 'beginners' was significantly different from 'intermediates', 'advanced' and 'experts'.

Degree completed. Respondents of the 'degree completed' item (degree) were divided into six groups according to educational degree level: Associates, Bachelors, Masters, Professional degree (i.e., Doctorate) and no degree. There was a statistically 
significant difference at the $\mathrm{p}<.05$ level in TED_HARM scales for all four groups: $F$ (5) $=4.045, p=.001$. The difference in mean scores between the groups was moderate.

\section{Technology Deviance - Misuse of Property}

\begin{tabular}{|c|c|c|c|c|c|c|}
\hline TED_MISUSE & $M$ & $S D$ & df & $\boldsymbol{F}$ & p value & $\begin{array}{c}\text { eta } \\
\text { squared }\end{array}$ \\
\hline Age & & & 4 & 2.988 & 0.019 & 0.03 \\
\hline $18-24$ & 1.280 & 0.843 & & & & \\
\hline $35-44$ & 1.042 & 0.241 & & & & \\
\hline $18-24$ & 1.280 & 0.843 & & & & \\
\hline $45-54$ & 1.033 & 0.180 & & & & \\
\hline Computer Experience & & & 3 & 9.472 & 0.000 & 0.07 \\
\hline Beginners & 1.800 & 1.789 & & & & \\
\hline Intermediates & 1.013 & 0.115 & & & & \\
\hline Beginners & 1.800 & 1.789 & & & & \\
\hline Advanced & 1.058 & 0.285 & & & & \\
\hline Beginners & 1.800 & 1.789 & & & & \\
\hline Experts & 1.136 & 0.388 & & & & \\
\hline Degree Completed & & & 5 & 40.910 & 0.001 & 0.05 \\
\hline Associates & 1.667 & 1.633 & & & & \\
\hline Bachelors & 1.029 & 0.169 & & & & \\
\hline Associates & 1.667 & 1.633 & & & & \\
\hline Masters & 1.062 & 0.304 & & & & \\
\hline Associates & 1.667 & 1.633 & & & & \\
\hline Professional Degree & 1.054 & 0.228 & & & & \\
\hline Associates & 1.667 & 1.633 & & & & \\
\hline Non-degree & 1.082 & 0.331 & & & & \\
\hline
\end{tabular}

Table 9 - Analysis of variance for Technology Deviance - Misuse of Property

Participant's age. Respondents of the age item (age) were divided into five groups: $18-24,25-34,35-44,45-54$ and $55+$. There was a statistically significant difference at the $\mathrm{p}<.05$ level in TED_MISUSE scales for three of the groups: $F(4)=$ 2.988, $p=.019$. The difference in mean scores between the groups was moderate. The effect size, calculated using eta squared, was .03 (small effect). Post-hoc comparisons indicate that the mean score for the ' $18-24$ ' group was significantly different from the '35-44' group and the '45-54' group. 
Computer experience. Respondents of the computer experience item (comp_exp) were divided into four groups according to their self-identified level of computer experience: beginner, intermediate, advanced and expert. There was a statistically significant difference at the $\mathrm{p}<.05$ level in TED_MISUSE scales for all four groups: $F(3)=9.472, p=.000$. The difference in mean scores between the groups was moderate. The effect size, calculated using eta squared, was .07 (moderate effect). Posthoc comparisons indicate that the mean score for 'beginners' was significantly different from 'intermediates', 'advanced' and 'experts'.

Degree completed. Respondents of the 'degree completed' item (degree) were divided into six groups according to educational degree level: Associates, Bachelors, Masters, Professional degree, no degree and 'other' degree. There was a statistically significant difference at the $p<.05$ level in TED_MISUSE scales for five of the groups: $F(5)=40.910, p=.001$. The difference in mean scores between the groups was moderate. The effect size, calculated using eta squared, was .05 (moderate effect). Posthoc comparisons indicate that the mean score for Associate graduates was significantly different from Bachelors, Masters, Professional graduates and those with 'no degrees'. 


\section{Technology Deviance - Loafing}

\begin{tabular}{|c|c|c|c|c|c|c|}
\hline TED_LOAF & $M$ & $S D$ & df & $\boldsymbol{F}$ & p value & $\begin{array}{c}\text { eta } \\
\text { squared }\end{array}$ \\
\hline Email communication with supervisor & & & 5 & 2.670 & 0.022 & 0.03 \\
\hline Once a Day & 1.695 & 0.676 & & & & \\
\hline Several Times a Day & 1.313 & 0.479 & & & & \\
\hline \multicolumn{3}{|c|}{ Instant Messaging communication with supervisor } & 5 & 2.235 & 0.050 & 0.03 \\
\hline Once a Day & 3.545 & 1.036 & & & & \\
\hline Never & 2.600 & 1.242 & & & & \\
\hline Once a Week & 3.538 & 0.967 & & & & \\
\hline Never & 2.600 & 1.242 & & & & \\
\hline Once a Month & 3.438 & 1.031 & & & & \\
\hline Never & 2.600 & 1.242 & & & & \\
\hline$\overline{\text { Age }}$ & & & 4 & 6.509 & 0.000 & 0.07 \\
\hline $25-34$ & 3.345 & 1.064 & & & & \\
\hline $35-44$ & 2.805 & 1.088 & & & & \\
\hline $25-34$ & 3.345 & 1.064 & & & & \\
\hline $45-54$ & 2.758 & 1.158 & & & & \\
\hline $25-34$ & 3.345 & 1.064 & & & & \\
\hline $55+$ & 2.560 & 1.193 & & & & \\
\hline Ethnic Background & & & 4 & 2.892 & 0.022 & 0.03 \\
\hline Black / African American & 3.056 & 1.185 & & & & \\
\hline Others & 2.489 & 1.180 & & & & \\
\hline Whites / Caucasian & 3.118 & 1.092 & & & & \\
\hline Others & 2.489 & 1.180 & & & & \\
\hline
\end{tabular}

Table 10 - Analysis of variance for Technology Deviance - Loafing

Emailing supervisor. Respondents of the social interaction item (sd2) were

divided into six groups according to method of communication: several times a day, once a day, several times a week, once a week, once a month or never. There was a statistically significant difference at the $\mathrm{p}<.05$ level in TED_LOA $F$ scale: $F(5)=2.670, p=.022$. The difference in mean scores between the groups was moderate. The effect size, calculated using eta squared, was .03 (small effect). Post-hoc comparisons indicate that the mean score for 'once a day' was significantly different from those that communicated with the supervisors 'several times a day'. 
Instant messaging with supervisor. Respondents of the social interaction item (sd4) were divided into six groups according to method of communication: several times a day, once a day, several times a week, once a week, once a month or never. There was a statistically significant difference at the $\mathrm{p}<.05$ level in TED_LOA $F$ scale: $F(5)=2.235$, $p=.050$. The difference in mean scores between the groups was moderate. The effect size, calculated using eta squared, was .03 (small effect). Post-hoc comparisons indicate that the mean score for 'never' was significantly different from those that communicated with the supervisors 'once a day', 'once a week', and 'once a month'.

Participant's age. Respondents of the age item (age) were divided into five groups: $18-24,25-34,35-44,45-54$ and $55+$. There was a statistically significant difference at the $\mathrm{p}<.05$ level in TED_LOA $F$ scales for three of the groups: $F(4)=$ $6.509, p=.000$. The difference in mean scores between the groups was moderate. The effect size, calculated using eta squared, was .07 (moderate effect). Post-hoc comparisons indicate that the mean score for the '25-34' group was significantly different from the '35-44' group,'45-54' group and the '55+' group.

Participant's ethnic background. Respondents of the ethnic background item (race) were divided into five groups: Asian, Black or African American, Hispanic, White / Caucasian and Other. There was a statistically significant difference at the $\mathrm{p}<.05$ level in TED_LOAF scales for three of the groups: $F(4)=2.892, p=.022$. The difference in mean scores between the groups was moderate. The effect size, calculated using eta squared, was .03 (small effect). Post-hoc comparisons indicate that the mean score for the 'Other' group was significantly different from the 'Black or African American' group and the 'White / Caucasian' group. 


\section{Conclusions}

The results of the univariate and multivariate analysis found supporting evidence for the research questions posed early on in this study. The three research areas that anchored this study were (1) the effects of social interaction and physical proximity between employee and supervisor, (2) the impact of leadership on employee perceptions, and (3) what factors or characteristics encouraged incidents of technology deviance in the workplace.

The significant factors are discussed in greater detail throughout this section.

\section{Implications for Management}

As management finds ways to adopt policies that are beneficial to the organization and its employees, it becomes even more important for them to have an understanding of how their decisions at the top can set off unintended events at the employee level (Lawler \& Worley, 2006). In the following section, the research questions and study findings are coupled to demonstrate a causal relationship between employee virtuality, leadership, employee perceptions and technology deviance.

\section{Employee Virtuality}

The findings related to this research question point to several ways in which employees were affected by the method and frequency of communication, and with physical proximity to their direct supervisor. Of particular interest to managers and practioners is the evidence that social interaction and physical proximity individually do 
not have as great an impact as when the two factors are combined. This demonstrates that focusing on one form of interaction alone is not enough to foster and maintain the type of employee relation that is so vital to an organization's performance. Therefore, it behooves management to create an environment where both types of interaction (social and physical) can be facilitated (Gilliam \& Oppenheim, 2006; Henttonen \& Blomqvist, 2005).

A conclusion that can be drawn from the data is that employee virtuality has a greater influence on an individual's perception of the organization than it does of their own direct supervisor. This is surprising considering that the literature points to a greater coupling in the relationship between employees and direct supervisors (Virick, 2002), and a circuitous relationship between an employee and the indirect organizational leaders (i.e., organization's culture) (Greenberg, Ashton-James, \& Ashkanasy, 2007).

In terms of physical proximity, the expected relationship between the personal form of communication (face-to-face) and the employee being in the same facility or location was found. This demonstrates that physical proximity does advance the opportunity for the employee and the supervisor to interact in a manner that creates a social bond. Prior research has found that this type of socialization can be beneficial to both parties since it produces a sense of familiarity and trust in an otherwise impersonal environment.

Another form of interaction that found significant support was that of email. Surprisingly, individuals that utilized emailing as a form of communication with their supervisors tended to be located in the same building or location as the manager. This finding was a little counterintuitive in the sense that frequent emailing (asynchronous 
communication) would have been more beneficial for employees not located in the same facility as the supervisor. However, it can be seen as a sign of the times that employees have taken to emailing as a convenient way to communicate, irrespective of proximity or distance. Furthermore, there was a correlation between those emailers and a perception that the indirect organizational leaders promoted intellectual growth. Again, a gender difference was found, and like face-to-face communications, women tended to use this form of interaction more frequently than men.

By far the most interesting finding was the persistent popularity of phone as a method of communication. Despite being a traditional form of interaction (as opposed to more modern methods such as email and instant messaging), phone communication was found to correlate strongly at every level of physical proximity - location, facility, state, country and time zone. Even though this is a synchronous tool, and therefore, harder to arrange between parties not in the same country or time zone, it's maturity and ubiquity allowed it to be the most common form of communication for respondents of this study.

Finally, the physical proximity factors were a little surprising. The relationships between the various locations and other factors, such as leadership, organizational justice and employee perceptions, were found to be negatively significant (Caballer et al., 2005). For example, the relationship between employees based in the same location as the supervisor was negatively correlated with individualized consideration, distributive justice and person-organization fit. Additionally, the relationship between individuals based in the same state as the supervisor and individualized consideration was also negatively significant. 
Whether this is a case of 'familiarity breeds contempt' or not, it is demonstrative that physical proximity by itself is not enough to foster a healthy, supportive relationship between employee and supervisor (Majchrzak, Malhotra, Stamps, \& Lipnack, 2004).

Proximity and quality social interaction are required to promote a good rapport between individuals in the workplace.

Two other findings, gender and employment status difference, were established. A significant difference was found between men and women for employees based in the same location, and between part-time and full-time employees located in the same building or facility.

\section{Leadership Dynamic}

As expected, direct leadership was found to strongly influence indirect organizational leadership as well as all of the employee perceptions factors - distributive justice (Bhal \& Ansari, 2007), procedural justice (Ansari, Hung, \& Aafaqi, 2007), person-organization fit (Chatman, 1989; Morley, 2007), perceived organization support (Erdogan \& Enders, 2007; Vandenberghe et al., 2007) and job satisfaction (Golden \& Veiga, 2008). This finding demonstrates the considerable impact that all leaders have on how employees feel about their jobs, their role in the company, and the organization as a whole.

As mentioned above, social interaction and physical proximity influenced how employees felt about their indirect organizational leaders (Hambley et al., 2007). Much like direct leadership, indirect organizational leadership was significantly influenced an employee's perception of fairness and justice. In addition, positive perception of the 
indirect organizational leadership also gave the employee a sense of belonging as well as increased satisfaction with their employment situation.

Furthermore, two organizational factors were found to influence an employee's propensity for technology deviance: procedural justice and perceived organizational support.

The relationship between procedural justice and deviant behavior (Henle, 2005) was expected since it has been in the extant literature as a direct contributor to deviance in numerous studies. This ties back to Brockner's (1995) finding that even when a procedural outcome was negative (i.e., lay-offs), how the employee was treated during the process mitigated the anger and resentment the individual felt towards the organization and his or her supervisor.

What was surprising was that distributive justice was not statistically significantly. Often times, an employee's sense of sharing in the rewards of the organization can influence whether they manifest citizen or deviant behavior at work.

The second organizational factor that contributed directly to intentional harm was the lack of perceived organizational support (Ferris, Brown, \& Heller, 2009). In an everchanging world where the employee's role and responsibilities keep shifting, individuals are looking to the organization for help and guidance. When this backing is missing or they find that the organization is making it hard for them to carry out their jobs, resentment and hopelessness builds. Employees who feel like they are 'swimming against the tide' are less engaged and increasingly disenfranchised (Liao et al., 2004). As this study found, employees who did not feel that they were being supported by their organization were more likely to engage in deviant behavior. 


\section{Technology Deviance}

Often in deviance research, there is the belief that employees will not admit to socially undesirable behaviors (Bennett \& Robinson, 2000). In the case of this study, a response matrix was created to see whether or not respondents admitted to any kind of

deviant behavior in the previous twelve months. Of the three categories, intentional harm had the least admissions and loafing had the greatest amount.

Despite having lower numbers, there was still enough evidence of intentional harm to be startling. For example, respondents admitted to sharing confidential information about the company with unauthorized personnel, making a co-worker's email messages public without their knowledge or consent and emailing hurtful messages to a co-worker.

Misuse of property had higher numbers than intentional harm, which opens up the possibility that employees are harming the organization inadvertently, but their actions still put the company at risk. For example, respondents admitted to copying information from another source and passing off as their own (plagiarism), using unlicensed software on their work computers, and copying data from the company computers without the organization's consent.

Finally, the findings related to loafing were startling because the behavior was so pervasive and not specifically influenced by any leadership or organizational factor. The range of admission to the behavior was very high $-62 \%$ to $87 \%$, which indicate that a majority of the respondents are working on personal matters when they should be performing their functions and responsibilities. This should be of extreme concern to 
management because this can directly impact a company's performance, productivity and even increase technology costs (Lara, 2006; Lim, 2002).

On the performance side, if employees are spending company time on non-work efforts, the organization is paying for work that is not being carried out, or it is being done but at a slower pace. This can impact the organization's bottom line directly, and over time, can harm the organization's revenue and profits.

On the technology side, companies have a limited amount of capital to invest in upgrading and maintaining their technology infrastructure (Chudoba et al., 2005). If a large number of employees are spending time online (extrapolated from the findings), then the organization's technical resources (i.e., servers and bandwidth) are being taxed by non-work usage. This will cause the organization to spend additional capital on increasing their technology infrastructure to accommodate the legitimate business traffic.

\section{Potential Legal Risk to Organization}

Throughout the study, several key technology deviance findings have been highlighted because of the potential harm to the organization. Theoretically, even if the deviance was limited to a specific behavior in isolation, which is still detrimental but localized, there are additional risks that come into play as a by-product of the initial behavior.

In addition to the loss of productivity and revenue, the increase in technology and labor cost mentioned in the previous section, companies run the risk of being legally liable because of their employee's deviant behavior. Specific risk factors include (1) employees sharing confidential information with unauthorized persons, (2) the resulting 
loss of income due to proprietary information being shared without permission, (3) potential bad publicity as a result of an employee plagiarizing information, (4) the creation of a hostile work environment, and (5) the potential risk of a software licensing audits.

\section{Implication for Research and Theory}

Several theories are advanced in this study, and they deal with the relative age of employees in the workforce, increased familiarity with technology, employment status, level of education, and gender.

\section{Age}

In two of three deviance factors, an employee's age group was a significant factor. The two younger age groups, 18-24 and 25-34, had higher instances of misuse of property and loafing than their elders (i.e., 35-44, 45-54 and 55 and over).

Recent studies are starting to show that the younger generations have a different outlook on work and personal life issues (Alsop, 2008). For example, Generation X and Generation Y (also called the Millennial Generation) have seamlessly adopted technology that allows them to stay informed around the clock; something that their parents and grandparents do not fully understand or share (Gorman, Nelson, \& Glassman, 2004).

This '24/7' culture has also contributed to a blurring of the boundaries between work and life for many employees (Hanson, 2007). Today, many employees find that they are expected to field work phone calls and / or email even during their time-off. This 
blurring of the work-life boundaries creates a sense that the reverse is also acceptable and that employees can divert attention to personal matters at work (i.e., loafing).

Another factor that distinguishes the generations is an employee's attitude towards work and employers (or the organization). The older generations tend to stay with one company, and are very committed to the well-being of said organization (Smola $\&$ Sutton, 2002). On the other hand, younger employees are more mobile. They go where the opportunity is and will work for an average of 5 to 10 different organizations in their professional lifetime. This shifting in loyalties may cause a younger employee to not engage as thoroughly with any one company.

Another area that is influenced by an employee's age is risk aversion (Huntley, 2006). Younger employees feel that they have decades to find a long-term employment situation and accumulate wealth. However, as the employee gets older, they will be less likely to move from their existing position, lose whatever seniority has been earned, and possibly, lose part of their retirement or pension.

Therefore, when you consider the personalities and characteristics of the new generations joining the workforce and the innovation in communication technologies being adopted, a significant contribution of this study is the identification of a new type of employee; one that academics and practioners are now beginning to study.

\section{Technology in the workplace}

When executives and researchers are asked about the likely technical threats to an organization, hackers and foreign entities tend to be placed at the top of the list. However, ongoing research continues to demonstrate that 'insiders' can pose a greater threat than 
'outsiders' (Stiennon, 2006; Willison, 2006). If one considers that outsiders can be stopped at the perimeter of a company's system environment through the use of firewalls, encryption and monitoring tools, then the threat diminishes significantly.

However, insiders are another matter altogether. Insiders already have legitimate access to the system, are familiar with the organization's security apparatus and routinely work with sensitive, proprietary information as part of their duties and responsibilities (Greenemeier, 2006).

In addition, studies have demonstrated that an employee does not need to exceed their authority to significantly harm the organization (Heck, 2007). In this study, employees with 'beginner' computer skills tended to be more deviant than their counterparts with more computer skills. This further reinforces that the mainstream's stereotype of the highly skilled hacker or disgruntled programmer as the predominant threat is simply misguided and negligently short-sighted.

This leads to the realization that the technology that facilitates commerce around the world and allows companies to produce product and service innovations can also amplify instances of deviance by causing greater damage in terms of frequency and severity (Cole \& Ring, 2006; Heck, 2007).

Therefore, a contribution of the study is the recognition that technology and technology-deviance is not the sole domain of the IT department. Employees and supervisors at all levels and in all departments need to be concerned with and cognizant of the dangers inherent in violating organizational norms using technology. 


\section{Employment status}

Another distinction found in this study is that of employment status. Part time employees were more likely to perpetrate intentional harm and misuse of property than full-time employees.

There are several factors that can contribute a part time employee feeling resentful or disengaged from the organization, and they include being treated like an outsider or not being a full member of the 'team', feeling as if they have very little vested in the organization's success and the sense that they have very little too lose if the organization is harmed (Stamper \& Masterson, 2002).

Several studies have looked into whether or not all employees are treated the same way by their supervisors and / or the organization as a whole. In several cases, it has been found that organizations will limit extracurricular or company-sponsored activities to 'fulltime' employees. Without realizing it, this subtle distinction can contribute to a part-time employee feeling alienated and disengaged from the organization (Sarros et al., 2002).

In addition, past research has demonstrated that when individuals are unhappy with their employment situation, they tend to be more careless with their work, and less interested in seeing that the organization's goals are achieved (Bolin \& Heatherly, 2001; Judge et al., 2006). So, rather than benefiting from an engaged employee (regardless of their part-time status), companies have groups of individuals that are more likely to engage in deviant behavior.

This sentiment can be dangerous to the degree that most part-timers are often given the same responsibilities and access to the organization as their full-time 
counterparts (Aquino \& Douglas, 2003). Therefore, they have the same ability to harm the organization when they're feeling slighted or offended at their 'outsider' status. In addition, because part-timers are compensated differently (i.e., no benefits, paid time off, etc.), there is the additional sense that their work is not appreciated or rewarded in the same manner as the fulltime employees.

\section{Degree / level of education}

During the analysis for intentional harm and misuse of property, participants with lower education levels were found to be more deviant than those individuals that had completed higher degrees. On the surface, there doesn't seem to be a substantiated reason for this finding. However, further consideration reveals that higher education (i.e., bachelors, masters, professional degree, etc.) provide more than just a degree, such as confidence and self-assurance, increased potential for growth and advancement and a professional code of conduct (Kidwell \& Kochanowski, 2005)

As it applies to this finding, it is easy to see how in the competitive employment market, individuals with degrees and marketable skills would be more respected and sough-after. This could have the potential for making lower-skilled employees feel inferior and uncertain about their place within the organization (Ferris et al., 2009). These feelings of inadequacy and resentment can cause an individual to become dissatisfied and disengaged in the workplace - all motivators and contributing factors that can lead to deviance.

From another perspective, there is a certain level of critical analysis and complex belief system that can be attained as part of higher education, which can make an 
individual adopt a professional code of conduct (Lucas \& Friedrich, 2005). For example, most undergraduate and graduate programs reinforce ethical thought, attitude and behavior throughout their curriculum. Someone not exposed to that knowledge could potentially have a different decision-making process - one that favors immediate outcomes at the detriment of evaluating all of the possible outcomes and consequences.

\section{Gender}

Very few deviance studies have looked for or found a marked difference in how men and women manifest deviant behavior in the workplace. However, in this study, men admitted to deviant behavior, in the forms of intentional harm and misuse of property, more often than women.

Past psychology and sociology research has discovered that men tend to react differently to instances of negative or stressful events (Henle, Giacalone, \& Jurkiewicz, 2005); specifically, they are more prone to seek revenge for being slighted or offended, they can be more aggressive in their attitudes and behaviors, and they will act in such a way as to 'save face' when faced with a situation were they are suddenly out of control (Martinko, Harvey, \& Gundlach, 2007). Theses characteristics may contribute a sense of powerlessness that demands retribution as a way to 'even the score'.

\section{Limitations}

Several limitations were noted in this study. First, the study was conducted across multiple organizations. It is possible that different results could be obtained by focusing on participants from one organization or one department. In particular, it would be 
interesting to see the leadership and deviance results for multiple employees reporting to the same supervisor.

Another limitation was that the majority of the respondents came from an academic setting. By administering the questionnaire in other industries, it would be possible to see if the findings are similar or different by business types.

A third limitation of the study was that the respondents were all from the U.S. By expanding the research to other countries, there exists the potential to determine whether technology deviance attitudes and behavior is more prevalent in the U.S. or if it is behavior also found in other cultures across the world and to what degree. Because globalization continues to flourish, having a better understanding of how other cultures see the role of leaders and deviance is essential to successfully increasing an organization's business in the global market.

\section{Significance of Study and Future Research}

The chief contribution of this study is understanding how virtual employees, leaders and technology interact to create a safer or riskier environment for organizations. The interactions between the three actors demonstrate that neither technology nor human capital are passive artifacts; rather there exists interdependence between the three actors that has to be further studied and analyzed.

In addition, technology is no longer the sole domain of the technology department; instead, it has to be incorporated into the organizational behavior research so that a better picture of evolving workplace behaviors can emerge. The emphasis of this study is not about the technology only; rather, it is about the how the tension between 
individuals and leadership can facilitate incidents of workplace deviance, and how technology exacerbates this causal relationship in terms of frequency and severity.

As a result, there are numerous avenues for future research that have been briefly mentioned in this paper, and hold promise in furthering our understanding of the harm that occurs when employees and leaders are in discord or at cross-purpose. The first area that deserves a closer look is how management can do a better job of preventing organizational members from alienating virtual employees. While there is a plethora of literature on negative or stressor events, organizational justice, revenge and sabotage, management is still having a hard time conveying a message of courtesy and inclusion throughout the organization. Whether management learns to communicate more effectively with individuals or address how peers treat each other at work, a consistent message needs to be embedded into the organization's culture that all individuals needs to be treated with dignity and civility at all times (zero tolerance).

The second area of importance to management is the relationship between the 'decision to act' and the level of 'opportunity' available within the organization. While much research has been done on traditional decision-making, further consideration should be given to the individual's cognitive process(es) while he or she is 'deciding to act' in the midst of anger and hurt. Management needs to clearly understand the actionreaction sequence that occurs when individuals are offended or upset by work-related stressors. In addition, there is the interesting question of whether or not 'opportunity' plays a direct or indirect role in the 'decision to act'. In other words, does being aware of an existing opportunities or vulnerabilities within the organization make it more attractive for the individual to act? 
Finally, in the area of an organization's guardianship, it is clear that more care and attention should be paid to internal security. For example, an employee needs a certain level of trust and access from the organization in order to perform his or her duties effectively. On the other hand, how much trust and access is 'too much', 'just right' or even - misplaced? How well is management evaluating an employee before granting him or her access to their key systems and infrastructure?

Traditionally, employee screening and safety has been part of the HR domain. However, as this research has found, individual engagement and job satisfaction are areas for which all leaders and employees need to take responsibility. In partnership, the three parties can strive for a better and safer environment throughout the organization. 


\section{LIST OF REFERENCES}

Adams, J. S. 1964. Inequity in Social Exchange. In L. Berkowitz (Ed.), Advances in Experimental Social Psychology, Vol. 1. New York: Academic Press

Aguinis, H., \& Henle, C. A. 2003. The search for universals in cross-cultural organizational behavior. In J. Greenberg (Ed.), Organizational behavior: The state of the science: $373-411$.

Ajzen, I. 1991. The Theory of Planned Behavior. Organizational Behavior and Human Decision Processes, 50(2): 179.

Ajzen, I., \& Fishbein, M. 1980. Understanding attitudes and predicting social behavior. Englewood Cliffs, NJ: Prentice-Hall.

Akers, R. L. 1996. Is differential association/social learning cultural deviance theory? Criminology, 34(2): 229.

Akkirman, A. D., \& Harris, D. L. 2005. Organizational communication satisfaction in the virtual workplace. The Journal of Management Development, 24(5/6): 397.

Alsop, R. 2008. The trophy kids grow up: How the millennial generation is shaking up the workplace: San Francisco, Calif: Jossey-Bass.

Ambrose, M. L., Seabright, M. A., \& Schminke, M. 2002. Sabotage in the workplace: The role of organizational injustice. Organizational Behavior and Human Decision Processes, 89(1): 947.

Anawati, D., \& Craig, A. 2006. Behavioral Adaptation Within Cross-Cultural Virtual Teams. IEEE Transactions on Professional Communication, 49(1): 44.

Ansari, M. A., Hung, D. K. M., \& Aafaqi, R. 2007. Leader-member exchange and attitudinal outcomes: role of procedural justice climate. Leadership \& Organization Development Journal, 28(8): 690.

Appelbaum, S. H., \& Roy-Girard, D. 2007. Toxins in the workplace: affect on organizations and employees. Corporate Governance, 7(1): 17.

Aquino, K., \& Douglas, S. 2003. Identity threat and antisocial behavior in organizations: The moderating effects of individual differences, aggressive modeling, and hierarchical status. Organizational Behavior and Human Decision Processes, 90(1): 195.

Aquino, K., Lewis, M. U., \& Bradfield, M. 1999. Justice constructs, negative affectivity, and employee deviance: A proposed model and empirical test. Journal of Organizational Behavior, 20(7): 1073. 
Ashkanasy, N. M., Windsor, C. A., \& Trevino, L. K. 2006. Bad Apples in Bad Barrels Revisited: Cognitive Moral Development, Just World Beliefs, Rewards, and Ethical Decision-Making. Business Ethics Quarterly, 16(4): 449.

Banerji, P., \& Krishnan, V. R. 2000. Ethical Preferences of Transformational Leaders: an Empirical Investigation. Leadership \& Organization Development Journal, 21(8): 405.

Bass, B. M., \& Avolio, B. J. 1995. MLQ: Multifactor Leadership Questionnaire . Redwood City. CA: Mind Garden.

Bass, B. M., \& Steidlmeier, P. 1999. Ethics, character, and authentic transformational leadership behavior. Leadership Quarterly, 10(2): 181-217.

Becker, T. E., Billings, R. S., Eveleth, D. M., \& Gilbert, N. L. 1996. Foci and bases of employee commitment: Implications for job performance. Academy of Management Journal, 39(2): 464.

Bennett, R. J., \& Robinson, S. L. 2000. Development of a measure of workplace deviance. Journal of Applied Psychology, 85(3): 349.

Bernstein, S. 1993. Former Sears Mechanic Files Suit Courts: The man contends he was forced to quit because he refused to sell customers unneeded parts and services, Los Angeles Times (pre-1997 Fulltext): 4.

Bhal, K. T., \& Ansari, M. A. 2007. Leader-member exchange-subordinate outcomes relationship: role of voice and justice. Leadership \& Organization Development Journal, 28(1): 20.

Bolin, A., \& Heatherly, L. 2001. Predictors of Employee Deviance: The Relationship Between Bad Attitudes and Bad Behavior. Journal of Business and Psychology, 15(3): 405.

Bordia, P., STang, R,. 2008. When employees strike back: Investigating mediating mechanisms between psychological contract breach and workplace deviance. Journal of Applied Psychology, 93(5): 1104.

Branigan, S. 2005. High-Tech Crimes Revealed. Boston: Addison-Wesley.

Brockner, J., Chen, Y.-R., Mannix, E. A., Leung, K., \& Skarlicki, D. P. 2000. Culture and procedural fairness: When the effects of what you do depend on how you do it. Administrative Science Quarterly, 45(1): 138.

Brockner, J., Wisenfeld, B. M., \& Martin, C. L. 1995. Decision frame, procedural justice, and survivors' reactions to job layoffs. Organizational Behavior and Human Decision Processes, 63(1): 59. 
Brown, M. E., Trevino, L. K., \& Harrison, D. A. 2005. Ethical leadership: A social learning perspective for construct development and testing. Organizational behavior and human decision processes, 97: 117-134.

Caballer, A., Gracia, F., Jos, eacute, Mar, iacute, Peir, a., \& oacute. 2005. Affective responses to work process and outcomes in virtual teams: Effects of communication media and time pressure. Journal of Managerial Psychology, 20(3/4): 245 .

Cable, D. M., \& Judge, T. A. 1996. Person-organization fit, job choice decisions, and organizational entry. Organizational Behavior and Human Decision Processes, 67(3): 294-311.

Cadbury, A. 1987. Ethical Managers Make Their Own Rules. Harvard Business Review, 65(5): 69.

Calton, J. M., \& Payne, S. L. 2003. Coping with paradox. Business and Society, 42(1): 7.

Chatman, J. A. 1989. Improving Interactional Organizational Research: A Model of Person-Organization Fit. Academy of Management Review, 14(3): 333-349.

Chudoba, K. M., Wynn, E., Lu, M., \& Watson-Manheim, M. B. 2005. How virtual are we? Measuring virtuality and understanding its impact in a global organization. Information Systems Journal, 15(4): 279.

Cohen, L. E., \& Felson, M. 1979. Social Change and Crime Rate Trends: A Routine Activity Approach. American Sociological Review, 44(4): 588-608.

Cohen, W. M., \& Levinthal, D. A. 1994. Fortune favors the prepared firm. Management Science, 40(2): 227.

Colbert, A. E., Mount, M. K., Harter, J. K., Witt, L. A., \& Barrick, M. R. 2004. Interactive Effects of Personality and Perceptions of the Work Situation on Workplace Deviance. Journal of Applied Psychology, 89(4): 599.

Cole, E., \& Ring, S. 2006. Insider Threat: Protecting the Enterprise from Sabotage, Spying and Theft. Rockland: Syngress Publishing, Inc.

Conway, L. G., III, \& Schaller, M. 2005. When Authorities' Commands Backfire: Attributions About Consensus and Effects on Deviant Decision Making. Journal of Personality and Social Psychology, 89(3): 311.

Cousins, K. C., Robey, D., \& Zigurs, I. 2007. Managing strategic contradictions in hybrid teams. European Journal of Information Systems, 16(4): 460. 
Cropanzano, R., Prehar, C. A., \& Chen, P. Y. 2002. Using social exchange theory to distinguish procedural from interactional justice. Group \& Organization Management, 27(3): 324.

DeCelles, K. A., \& Pfarrer, M. D. 2004. Heroes or Villains? Corruption and the Charismatic Leader. Journal of Leadership \& Organizational Studies, 11(1): 67.

Denton, J. 1998. Organisational Learning and Effectiveness. London: Routledge.

DeVellis, R. F. 1991. Scale Development: theory and applications. Newbury Park: Sage Publications.

Dunlop, P. D., \& Lee, K. 2004. Workplace deviance, organizational citizenship behavior, and business unit performance: the bad apples do spoil the whole barrel. Journal of Organizational Behavior, 25(1): 67.

Eisenhardt, K. M. 1989. Agency Theory: An Assessment and Review. Academy of Management Review, 14(1): 57-74.

Elron, E., \& Vigoda-Gadot, E. 2006. Influence and Political Processes in Cyberspace: The Case of Global Virtual Teams. International Journal of Cross Cultural Management : CCM, 6(3): 295.

Emery, C. R., \& Barker, K. J. 2007. The Effect of Transactional and Transformational Leadership Styles on the Organizational Commitment and Job Satisfaction of Customer Contact Personnel. Journal of Organizational Culture, Communication and Conflict, 11(1): 77.

Erdogan, B., \& Enders, J. 2007. Support From the Top: Supervisors' Perceived Organizational Support as a Moderator of Leader-Member Exchange to Satisfaction and Performance Relationships. Journal of Applied Psychology, 92(2): 321.

Fang, M.-L. 2006. Evaluating Ethical Decision-Making of Individual Employees in Organizations-An Integration Framework. Journal of American Academy of Business, Cambridge, 8(2): 105.

Felson, M., \& Clarke, R. V. 1998. Opportunity Makes a Thief: practical theory for crime prevention. In B. Webb (Ed.), Police Research Series. London: British Home Office.

Ferris, D., Brown, D., \& Heller, D. 2009. Organizational supports and organizational deviance: The mediating role of organization-based self-esteem. Organizational Behavior and Human Decision Processes, 108(2): 279.

Fishbein, M., \& Ajzen, I. 1975. Belief, attitude, intention, and behavior: An introduction to theory and research. Reading, MA: Addison-Wesley. 
Folger, R., \& Skarlicki, D. P. 1998. When tough times make tough bosses: Managerial distancing as a function of layoff blame. Academy of Management Journal, 41(1): 79.

Fox, S., Spector, P. E., \& Miles, D. 2001. Counterproductive Work Behavior (CWB) in Response to Job Stressors and Organizational Justice: Some mediator and moderator test for autonomy and emotions. Journal of Vocational Behavior, 59(3): 291-309.

Furnham, A., \& Taylor, J. 2004. The Dark Side of Behaviour at Work: Understanding and avoiding employees leaving, theiving and deceiving. New York: Pagrave Macmillan.

Furuya, K. 2002. A socio-economic model of stigma and related social problems. Journal of Economic Behavior \& Organization, 48(3): 281.

Gaudin, S. 2007, September 21. Fewer Companies Suffer Security Breaches, But They're Much More Severe, InformationWeek.

Giacalone, R. A., \& Payne, S. L. 1987. Are Business Leaders Staging a Morality Play? Business and Society Review(62): 22.

Gilliam, C., \& Oppenheim, C. 2006. Reviewing the impact of virtual teams in the information age. Journal of Information Science, 32(2): 160.

Golden, T. 2007. Co-workers who telework and the impact on those in the office: Understanding the implications of virtual work for co-worker satisfaction and turnover intentions. Human Relations, 60(11): 1641.

Golden, T., \& Veiga, J. 2008. The impact of superior-subordinate relationships on the commitment, job satisfaction, and performance of virtual workers. Leadership Quarterly, 19(1): 77.

Gordon, L. A., Loeb, M. P., Lucyshyn, W., \& Richardson, R. 2006. 2006 CSI / FBI Computer Crime and Security Survey. San Francisco: Federal Bureau of Investigations and Computer Security Institute.

Gorman, P., Nelson, T., \& Glassman, A. 2004. The millennial generation: A strategic opportunity. Organizational Analysis, 12(3): 255-270.

Graen, G. B., \& Uhl-Bien, M. 1995. Relationship-based approach to leadership: Development of leader-member exchange (LMX) theory of leadership over 25 years: Applying a multi-level multi-domain perspective. The Leadership Quarterly, 6(2): 219-247.

Greenberg, J. 2004. Stress Fairness to Fare No Stress: Managing Workplace Stress by Promoting Organizational Justice. Organizational Dynamics, 33(4): 352. 
Greenberg, J. 2006. Losing Sleep Over Organizational Injustice: Attenuating Insomniac Reactions to Underpayment Inequity With Supervisory Training in Interactional Justice. Journal of Applied Psychology, 91(1): 6.

Greenberg, J., Ashton-James, C. E., \& Ashkanasy, N. M. 2007. Social comparison processes in organizations. Organizational Behavior and Human Decision Processes, 102(1): 22.

Greenemeier, L. 2006. Insider Threats. InformationWeek(1118): 25.

Griffin, R., O'Leary-Kelly, A., \& Collins, J. 1998. Dysfunctional Work Behaviors in Organizations. Journal of Organizational Behavior: 65.

Griffin, R. W., \& Moorhead, G. 2004. Organizational Behavior: Managing People and Organizations: Houghton Mifflin Co.

Hambley, L. A., O'Neill, T. A., \& Kline, T. J. B. 2007. Virtual team leadership: The effects of leadership style and communication medium on team interaction styles and outcomes. Organizational Behavior and Human Decision Processes, 103(1): 1.

Hannah, D. R. 2006. Keeping Trade Secrets Secret. MIT Sloan Management Review, 47(3): 17.

Hanson, J. 2007. 24/7 how Cell Phones and the Internet Change the Way We Live, Work, and Play: Praeger.

Heck, M. 2007. Surveying the Insider Threat Detection Landscape. InfoWorld, 29(8): 39.

Henle, C. A. 2005. Predicting Workplace Deviance from the Interaction between Organizational Justice and Personality. Journal of Managerial Issues, 17(2): 247.

Henle, C. A., Giacalone, R. A., \& Jurkiewicz, C. L. 2005. The Role of Ethical Ideology in Workplace Deviance. Journal of Business Ethics, 56(3): 219.

Henttonen, K., \& Blomqvist, K. 2005. Managing distance in a global virtual team: the evolution of trust through technology-mediated relational communication. Strategic Change, 14(2): 107.

Huang, M.-P., Cheng, B.-S., \& Chou, L.-F. 2005. Fitting in organizational values: The mediating role of person-organization fit between CEO charismatic leadership and employee outcomes. International Journal of Manpower, 26(1): 35.

Huntley, R. 2006. The world according to Y: inside the new adult generation: Allen \& Unwin Academic.

Hurley, R. F. 2006. The Decision to Trust. Harvard Business Review, 84(9): 55. 
Hutchison, S., Sowa, D., Eisenberger, R., \& Huntington, R. 1986. Perceived organizational support. Journal of Applied Psychology, 71(3): 500-507.

Jessup, L. M., \& Robey, D. 2002. The relevance of social issues in ubiquitous computing environments. Association for Computing Machinery. Communications of the $A C M, 45(12): 88$.

Judge, T. A., Scott, B. A., \& Illies, R. 2006. Hostility, Job Attitudes, and Workplace Deviance: Test of a Multilevel Model. Journal of Applied Psychology, 91(1): 10.

Kanungo, R. N. 2001. Ethical values of transactional and transformational leaders. Administrative Sciences Association of Canada, 18(4): 257-265.

Keeney, M. M., Kowalski, E. F., Cappelli, D. M., Moore, A., Shimeall, T., \& Rogers, S. 2005. Insider Threat Study: Computer System Sabotage in Critical Infrastructure Sectors: U.S. Secret Service and CERT® Coordination Center.

Kidwell, R. E., Jr., \& Kochanowski, S. M. 2005. The Morality of Employee Theft: Teaching About Ethics and Deviant Behavior in the Workplace. Journal of Management Education, 29(1): 135.

Kirkman, B. L., Rosen, B., Tesluk, P. E., \& Gibson, C. B. 2004. The Impact of Team Empowerment on Virtual Team Performance: the Moderating Role of Face-toFace Interaction. Academy of Management Journal, 47(2): 175.

Koh, J., Kim, Y.-G., Butler, B., \& Bock, G.-W. 2007. Encouraging participation in virtual communities. Association for Computing Machinery. Communications of the $A C M, 50(2): 68$.

Kumar, K., Van Fenema, P., \& Von Glinow, M. 2009. Offshoring and the global distribution of work: Implications for task interdependence theory and practice. Journal of International Business Studies, 40(4).

Lara, P. Z. M. d. 2006. Fear in organizations. Journal of Managerial Psychology, 21(6): 580.

Latapie, H. M., \& Tran, V. N. 2007. Subculture Formation, Evolution, and Conflict between Regional Teams in Virtual Organizations - Lessons Learned and Recommendations. The Business Review, Cambridge, 7(2): 189.

Lawler, E. E., \& Worley, C. G. 2006. Designing Organizations That Are Built to Change. MIT Sloan Management Review, 48(1): 19.

Lee-Kelley, L., Crossman, A., \& Cannings, A. 2004. A social interaction approach to managing the "invisibles" of virtual teams. Industrial Management + Data Systems, 104(8/9): 650. 
Leitsch, D. L. 2004. Differences in the Perceptions of Moral Intensity in the Moral Decision Process: An Empirical Examination of Accounting Students. Journal of Business Ethics, 53(3): 313.

Levine, D. P. 2005. The corrupt organization. Human Relations, 58(6): 723.

Liao, H., Joshi, A., \& Chuang, A. 2004. Sticking out Like a Sore Thumb: Employee Dissimilarity and Deviance at Work. Personnel Psychology, 57(4): 969.

Lim, V. K. G. 2002. The IT way of loafing on the job: Cyberloafing, neutralizing and organizational justice. Journal of Organizational Behavior, 23(5): 675.

Lindenmayer, I. 2005. FBI Report Underscores Insider Data-Theft Threat, American Banker: 10.

Lu, M., Watson-Manheim, M. B., Chudoba, K. M., \& Wynn, E. 2006. Virtuality and Team Performance: Understanding the Impact of Variety of Practices. Journal of Global Information Technology Management, 9(1): 4.

Lublin, J. S. 2005. Korn/Ferry Accuses 5 in Suit Of Stealing Secret Client Lists, Wall Street Journal: B.2.

Lucas, G. M., \& Friedrich, J. 2005. Individual Differences in Workplace Deviance and Integrity as Predictors of Academic Dishonesty. Ethics \& Behavior, 15(1): 15.

Lurey, J. S., \& Raisinghani, M. S. 2001. An empirical study of best practices in virtual teams. Information \& Management, 38(8): 523.

Magklaras, G. B., \& Furnell, S. M. 2002. Insider threat prediction tool: Evaluating the probability of IT misuse. Computers \& Security, 21(1): 62.

Majchrzak, A., Malhotra, A., Stamps, J., \& Lipnack, J. 2004. Can Absence Make a Team Grow Stronger? Harvard Business Review, 82(5): 131.

Martinko, M. J., Harvey, P., \& Gundlach, M. J. 2007. A Causal Reasoning Perspective. Managing social and ethical issues in organizations: 253.

McKay, B. 2006. Coke Employee Faces Charges in Plot to Sell Secrets, Wall Street Journal: B.6.

Merriman, K. K., Schmidt, S. M., \& Dunlap-Hinkler, D. 2007. Profiling Virtual Employees: The Impact of Managing Virtually. Journal of Leadership \& Organizational Studies, 14(1): 6.

Miller, J. M., Schreck, C. J., \& Tewksbury, R. 2006. Criminological Theory: a brief introduction. Boston: Pearson Education. 
Minkes, A. L., Small, M. W., \& Chatterjee, S. R. 1999. Leadership and business ethics: Does it matter? Implications for management. Journal of Business Ethics, 20(4): 327.

Mitchell, M. S., \& Ambrose, M. L. 2007. Abusive supervision and workplace deviance and the moderating effects of negative reciprocity beliefs. Journal of Applied Psychology, 92(4): 1159.

Morley, M. J. 2007. Person-organization fit. Journal of Managerial Psychology, 22(2): 109.

Morris, S. A., \& McDonald, R. A. 1995. The role of moral intensity in moral judgments: An empirical investigation. Journal of Business Ethics, 14(9): 715.

Namlu, A. G., \& Odabasi, H. F. 2007. Unethical Computer Using Behavior Scale: a study of reliability and validity on Turkish university students. Computers and Education, 48: 205 - 215.

Nonaka, I. 1991. The Knowledge-Creating Company. Harvard Business Review, 69(6): 96-104.

Osborn, R. N., Hunt, J. G., \& Jauch, L. R. 2002. Toward a contextual theory of leadership. Leadership Quarterly, 13(6): 797-837.

Pauleen, D. J., \& Yoong, P. 2001. Relationship building and the use of ICT in boundarycrossing virtual teams: a facilitator's perspective. Journal of Information Technology, 16(4): 205.

Pillis, E. d., \& Furumo, K. 2007. Counting the Cost of Virtual Teams. Association for Computing Machinery. Communications of the ACM, 50(12): 93.

Pirola-Merlo, A., Hartel, C., Mann, L., \& Hirst, G. 2002. How leaders influence the impact of affective events on team climate and performance in R\&D teams. Leadership Quarterly, 13(5): 561.

Price, J. L., \& Mueller, C. W. 1986. Absenteeism and turnover of hospital employees: JAI Press Greenwich, CT.

Rael, R. 2006. Pickles Will Make Employees Take the Unethical Low Road! How Employers Can Foster Ethical Decision-Making. The Business Review, Cambridge, 5(1): 89.

Randazzo, M. R., Cappelli, D. M., Keeney, M. M., Moore, A. P., \& Kowalski, E. F. 2004. Insider Threat Study: Illicit Cyber Activity in the Banking and Finance Sector: U.S. Secret Service and CERT® Coordination Center. 
Rao, M. T. 2004. Key Issues for Global it Sourcing: Country and Individual Factors. EDPACS, 32(4): 1-11.

Ravasi, D., \& Schultz, M. 2006. Responding to Organizational Identity Threats: Exploring the Role of Organizational Culture. Academy of Management Journal, 49(3): 433-458.

Resick, C. J., Baltes, B. B., \& Shantz, C. W. 2007. Person-organization fit and workrelated attitudes and decisions: Examining interactive effects with job fit and conscientiousness. Journal of Applied Psychology, 92(5): 1446.

Robertson, D. C., \& Ross, W. T., Jr. 1995. Decision-making processes on ethical issues: The impact of a social contract perspective. Business Ethics Quarterly, 5(2): 213.

Robinson, S. L., \& Bennett, R. J. 1995. A Typology of Deviant Workplace Behaviors: A Multidimensional Scaling Study. Academy of Management Journal, 38(2): 555.

Robinson, S. L., \& O'Leary-Kelly, A. M. 1998. Monkey See, Monkey Do: The Influence of Work Groups on the Antisocial Behavior of Employees. The Academy of Management Journal, 41(6): 658-672.

Rosen, B., Furst, S., \& Blackburn, R. 2007. Overcoming Barriers to Knowledge Sharing in Virtual Teams. Organizational Dynamics, 36(3): 259.

Salas, S., \& Von Glinow, M. A. 2008. Fostering organizational learning: Creating and maintaining a learning culture. In R. J. Burke, \& C. L. Cooper (Eds.), Building More Effective Organizations: HR Management and Performance in Practice: Cambridge University Press.

Sarros, J. C., Tanewski, G. A., Winter, R. P., Santora, J. C., \& Densten, I. L. 2002. Work alienation and organizational leadership. British Journal of Management, 13(4): 285.

Scandura, T. A. 1999. Rethinking leader-member exchange: An organizational justice perspective. Leadership Quarterly, 10(1): 25.

Scandura, T. A., \& Graen, G. B. 1984. Moderating effects of initial leader-member exchange status on the effects of a leadership intervention. Journal of Applied Psychology, 69(3): 428-436.

Schneider, I. 2005. Security Pros Respond to New Jersey Bank Breach. Bank Systems \& Technology, 42(6): 12.

Schriesheim, C., \& Tsui, A. S. 1980. Development and validation of a short satisfaction instrument for use in survey feedback interventions. Western Academy of Management Meeting. 
Seabright, M. A., \& Schminke, M. 2002. Immoral imagination and revenge in organizations. Journal of Business Ethics, 38(1/2): 19.

Shekhar, S. 2006. Understanding the virtuality of virtual organizations. Leadership \& Organization Development Journal, 27(6): 465-483.

Skarlicki, D. P., \& Folger, R. 1997. Retaliation in the workplace: The roles of distributive, procedural, and interactional justice. Journal of Applied Psychology, 82(3): 434.

Smola, K. W., \& Sutton, C. D. 2002. Generational differences: revisiting generational work values for the new millennium. Journal of Organizational Behavior: 363382.

Stamper, C. L., \& Masterson, S. S. 2002. Insider or outsider? How employee perceptions of insider status affect their work behavior. Journal of Organizational Behavior, 23(8): 875.

Stiennon, R. 2006. Ignoring the insider threat. Network World, 23(33): 58.

Streitfeld, D. 1992. Consummate Consumer; Avoiding The Shaft; Sears Auto Repair Scandal Fallout, The Washington Post: b.05.

Swartz, N. 2007. Protecting Information from Insiders. Information Management Journal, 41(3): 20.

Sweeney, P. D., \& McFarlin, D. B. 1993. Workers'evaluations of the "ends" and the "means": An examination of four models of distributive and procedural justice. Organizational Behavior and Human Decision Processes, 55: 23-23.

Tepper, B. J., Henle, C. A., Lambert, L. S., Giacalone, R. A., \& Duffy, M. K. 2008. Abusive supervision and subordinates' organization deviance. Journal of Applied Psychology, 93(4): 721.

Trevino, L. K. 1986. Ethical Decision Making in Organizations: A Person-Situation Interactionist Model. Academy of Management Review, 11(3): 601.

Trevino, L. K., \& Brown, M. E. 2005. The Role of Leaders in Influencing Unethical Behavior in the Workplace. In J. Roland E. Kidwell, \& C. L. Martin (Eds.), Managing Organizational Deviance. Thousand Oaks: Sage Publications.

Trevino, L. K., Hartman, L. P., \& Brown, M. 2000. Moral Person and Moral Manager: How executives develop a reputation for ethical leadership. California Management Review, 42(4): 128-142.

Trevino, L. K., \& Nelson, K. A. 2004. Managing Business Ethics: Straight Talk About How to Do It Right. Hoboken, NJ: John Wiley \& Sons. 
Trevino, L. K., Weaver, G. R., Gibson, D. G., \& Toffler, B. L. 1999. Managing ethics and legal compliance: What works and what hurts. California Management Review, 41(2): 131.

Trevino, L. K., \& Youngblood, S. A. 1990. Bad Apples in Bad Barrels: A Causal Analysis of Ethical Decision-Making Behavior. Journal of Applied Psychology, 75(4): 378-385.

Tsui, A. S., Egan, T. D., \& O'Reilly Iii, C. A. 1992. Being Different: Relational Demography and Organizational Attachment. Administrative Science Quarterly, 37(4).

Tucker, B. A., \& Russell, R. F. 2004. The Influence of the Transformational Leader. Journal of Leadership \& Organizational Studies, 10(4): 103.

Valentine, S., Godkin, L., \& Lucero, M. 2002. Ethical Context, Organizational Commitment, and Person-Organization Fit. Journal of Business Ethics, 41(4): 349-360.

Vandenberghe, C., Bentein, K., Michon, R., Chebat, J.-C., \& et al. 2007. An examination of the role of perceived support and employee commitment in employee-customer encounters. Journal of Applied Psychology, 92(4): 1177.

Vardi, Y., \& Weitz, E. 2004. Misbehavior in Organizations: Theory, Research and Management. London: Lawrence Erlbaum Associates.

Vijayan, J. 2005, May 30. Insider Threats Mount: Security experts cite need for strong internal controls to prevent data thefts, Computerworld.

Vinten, G. 1990. Business Ethics: Busybody or Corporate Conscience? Leadership \& Organization Development Journal, 11(3): 4.

Virick, M. 2002. Managing a virtual workplace: An investigation of processes in virtual work. Unpublished Ph.D., The University of Texas at Arlington, Texas.

Watt, A. H. 2007. The impact of managerial virtuality on employee performance. Unpublished Ph.D., Rensselaer Polytechnic Institute, New York.

Wayne, S. J., Shore, L. M., Bommer, W. H., \& Tetrick, L. E. 2002. The role of fair treatment and rewards in perceptions of organizational support and leadermember exchange. Journal of Applied Psychology, 87(3): 590.

Weiss, T. October 17, 2006. In separate incidents, three laptops stolen; data at risk, Computerworld.

Wells, J. T. 2002. Billing schemes, Part 3: Pay-and-return invoicing. Journal of Accountancy, 194(3): 96. 
Whitman, M. E., \& Mattord, H. J. 2006. Readings and Cases in the Managment of Information Security. Boston: Thomson Course Technology.

Willison, R. 2006. Understanding the perpetration of employee computer crime in the organisational context. Information and Organization, 16(4): 304.

Yammarino, F. J. 1994. Indirect Leadership: Transformational Leadership at a Distance. In B. M. Bass, \& B. J. Avolio (Eds.), Improving Organizational Effectiveness Through Transformational Leadership. Thousand Oaks, CA: Sage Publications.

Zimbardo, P. G. 2007. The Lucifer Effect: Understanding How Good People Turn Evil. New York: Random House. 
VITA

\section{SILVIA SALAS}

2002

2003

$2004-2009$

$1993-2009$
BBA, Business Administration

University of Miami

Miami, Florida

M.S., Management Information Systems

Florida International University

Miami, Florida

Doctoral Candidate, Business Administration

Florida International University

Miami, Florida

Consultant

Burger King Corporations

American Bankers Insurance Group

Royal Caribbean Cruises

Sun Microsystems

Spherion Corporation

Blue Cross Blue Shield of South Carolina

\section{PUBLICATIONS}

Niederman, F., S. Kundu, and S. Salas. (2006). IT Software Development Offshoring: A multi-level theoretical framework and research agenda. Journal of Global Information Management, 14(2), 54-76.

Salas, S., and Von Glinow, M. A. (2007). Fostering Organizational Learning: creating and maintaining a learning culture. In R. Burke and C. Cooper (Eds.), Building more effective organizations: Cambridge University Press.

Rama, D., B. Milano, S. Salas, and C. Liu. (2008). CSR Implementation: Developing the Capacity for Collective Action, Journal of Business Ethics.

\section{PRESENTATIONS}

Salas, S. (2008). Influence of Direct and Indirect Leadership on Technology-enabled Deviance. Paper to be presented at the Academy of Management, Anaheim, CA. 
Salas, S. (2008). The Role of Knowledge, Opportunity and Strategic Alliances in the Private Military Industry. Paper to be presented at the Fifth Annual JIBS Paper Development Workshop at the Academy of International Business, Milan, Italy.

Salas, S. (2008). Leadership Influence on Ethical Workplace Behavior. Paper to be presented at the International Association of Business and Society (IABS) Annual Conference, Tampere, Finland.

Salas, S. (2008). The Business of War: How private companies are taking the place of state functions. Paper to be presented at the International Association of Business and Society (IABS) Annual Conference, Tampere, Finland.

Salas, S. (2007). Explaining the Growth and Expansion of Private Military Companies in the Global Arena. Paper presented at the Fifth Annual Academy of International Business (AIB)/Journal of International Business Studies (JIBS) Conference on Emerging Research Frontiers in International Business, Miami, FL.

Salas, S. (2007). The Role of Technology in Organizational Deviance: a routine activity approach. Paper presented at the Academy of Management, Philadelphia, PA.

Niederman, F., Kundu, S., Salas, S. (2005). IT Software Development Offshoring: A multi-level theoretical framework and research agenda. Paper presented at the Second Annual JIBS Paper Development Workshop at the Academy of International Business, Quebec City, Canada. 